October 2001 • NREL/TP-620-30101 • LBNL-48611

\title{
Forecasting the Growth of Green Power Markets in the United States
}

Ryan Wiser and Mark Bolinger

Lawrence Berkeley National Laboratory

Edward Holt

Ed Holt \& Associates, Inc.

Blair Swezey

National Renewable Energy Laboratory
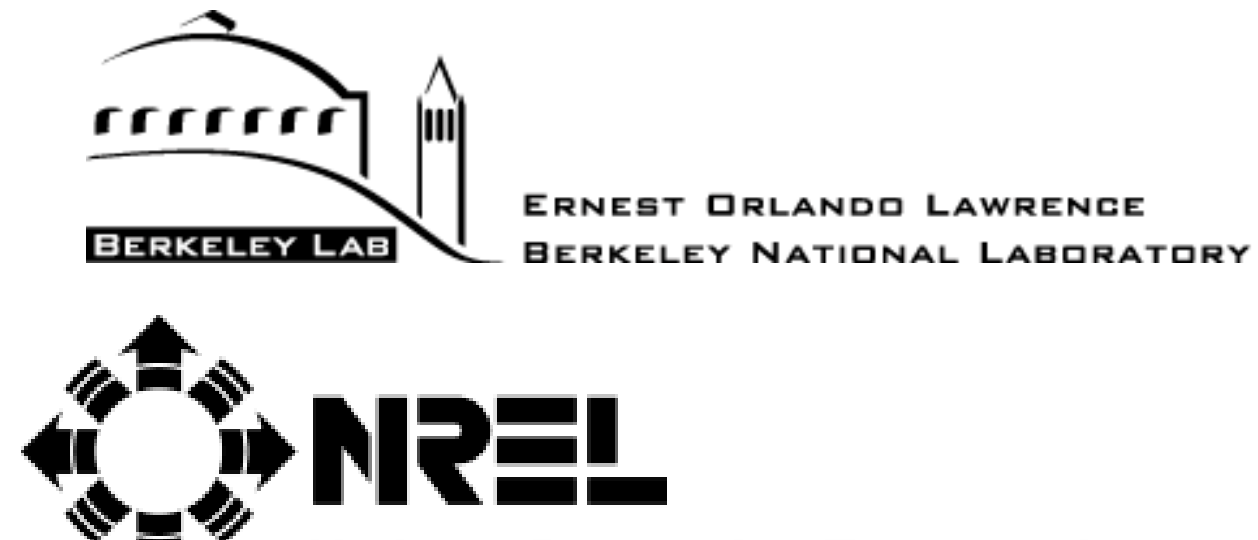

National Renewable Energy Laboratory

1617 Cole Boulevard

Golden, Colorado 80401-3393

NREL is a U.S. Department of Energy Laboratory

Operated by Midwest Research Institute $\bullet$ Battelle $\bullet$ Bechtel

Contract No. DE-AC36-99-G010337 


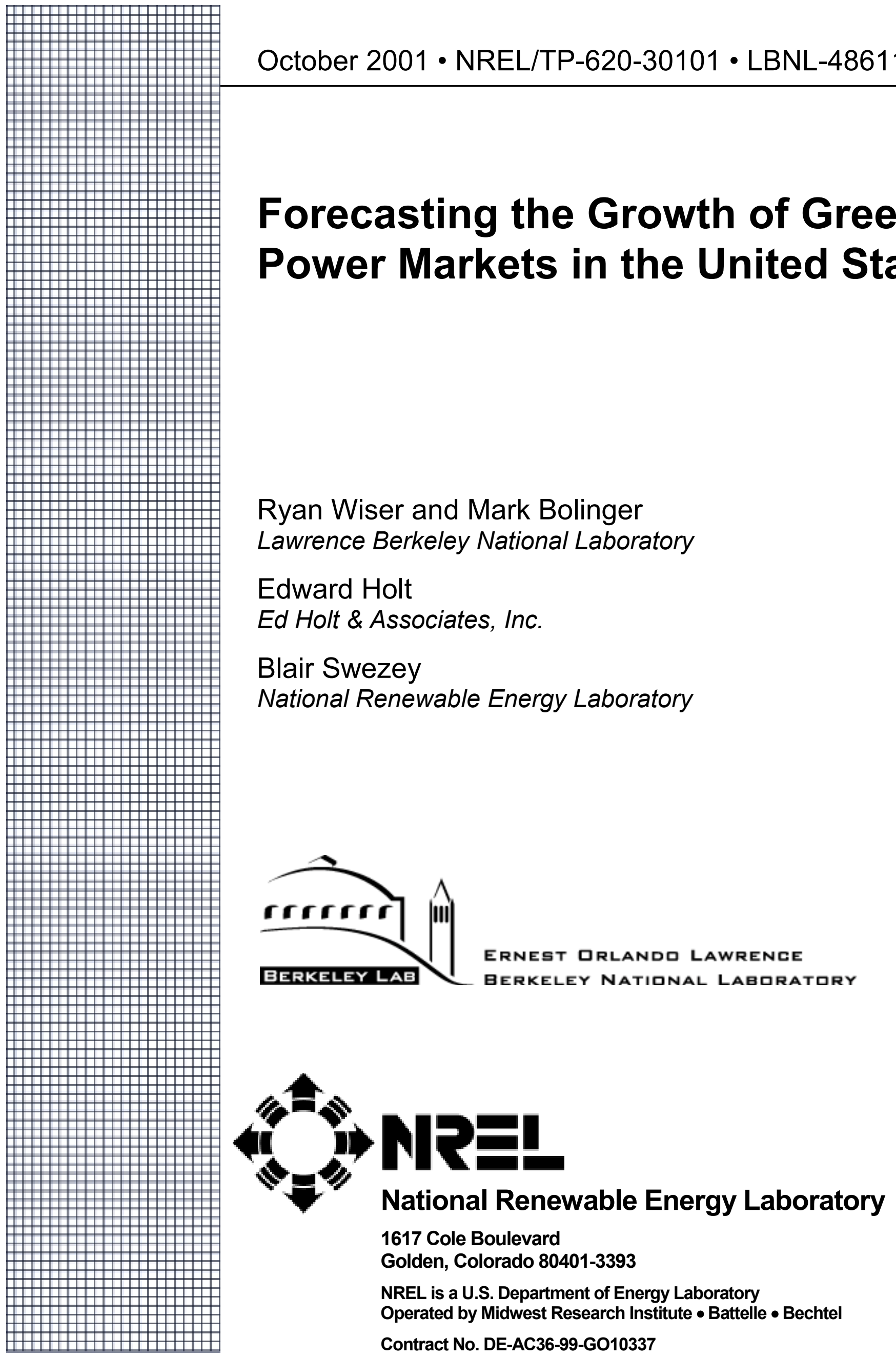




\section{NOTICE}

This report was prepared as an account of work sponsored by an agency of the United States government. Neither the United States government nor any agency thereof, nor any of their employees, makes any warranty, express or implied, or assumes any legal liability or responsibility for the accuracy, completeness, or usefulness of any information, apparatus, product, or process disclosed, or represents that its use would not infringe privately owned rights. Reference herein to any specific commercial product, process, or service by trade name, trademark, manufacturer, or otherwise does not necessarily constitute or imply its endorsement, recommendation, or favoring by the United States government or any agency thereof. The views and opinions of authors expressed herein do not necessarily state or reflect those of the United States government or any agency thereof.

Available electronically at http://www.doe.gov/bridge

Available for a processing fee to U.S. Department of Energy and its contractors, in paper, from:

U.S. Department of Energy

Office of Scientific and Technical Information

P.O. Box 62

Oak Ridge, TN 37831-0062

phone: 865.576 .8401

fax: 865.576.5728

email: reports@adonis.osti.gov

Available for sale to the public, in paper, from:

U.S. Department of Commerce

National Technical Information Service

5285 Port Royal Road

Springfield, VA 22161

phone: 800.553 .6847

fax: 703.605.6900

email: orders@ntis.fedworld.gov

online ordering: http://www.ntis.gov/ordering.htm

Printed on paper containing at least $50 \%$ wastepaper, including $20 \%$ postconsumer waste 


\section{Contents}

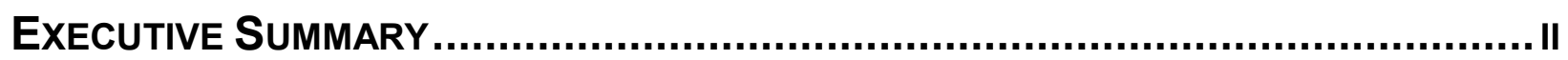

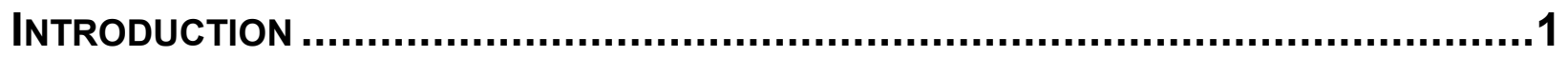

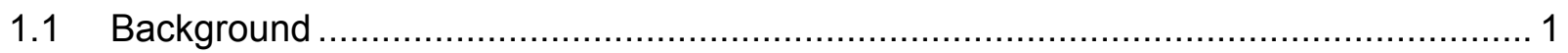

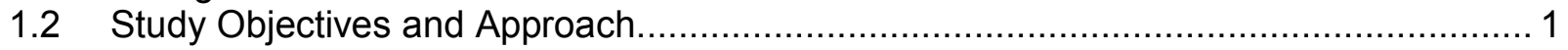

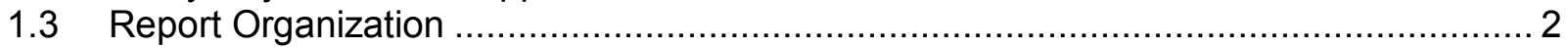

Review of Green Power Market Research and Marketing Experience ..4

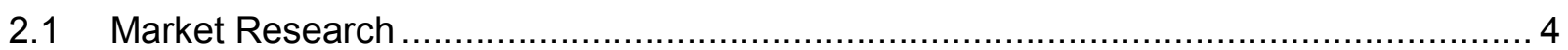

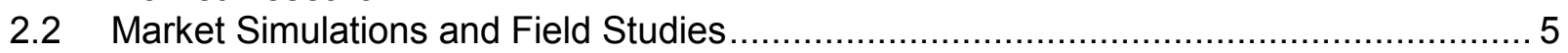

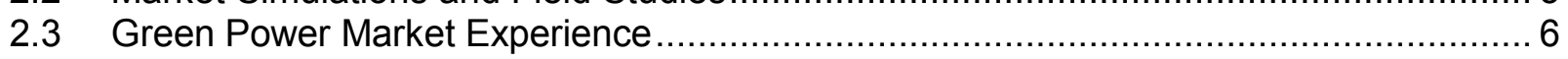

Regulated Utility Markets ............................................................................................................................. 6

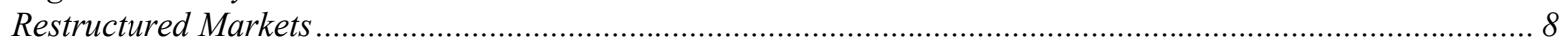

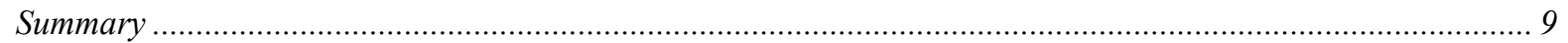

\section{MARKET DIFFUSION: EXPERIENCE FROM OTHER INDUSTRIES ........................10}

3.1 Newly Restructured Markets.............................................................................. 11

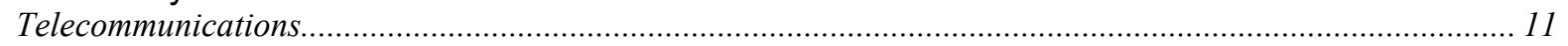

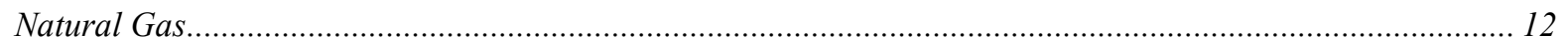

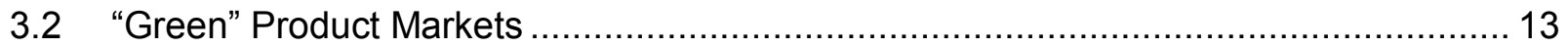

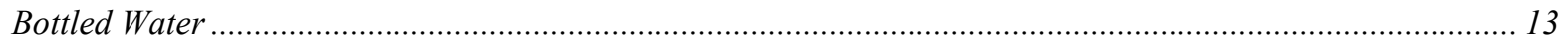

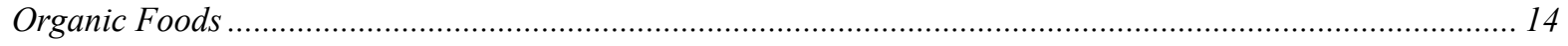

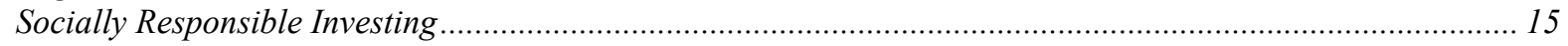

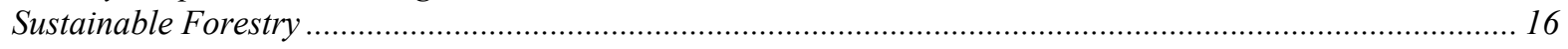

Charitable Contributions to Environmental Organizations..................................................................... 18

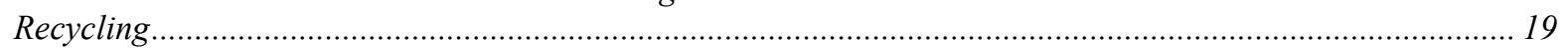

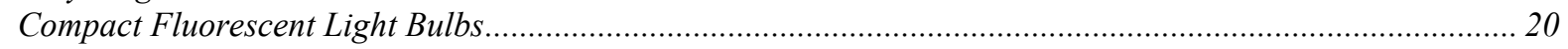

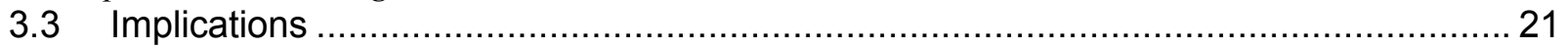

Model OVerview And Key AssumptionS ............................................23

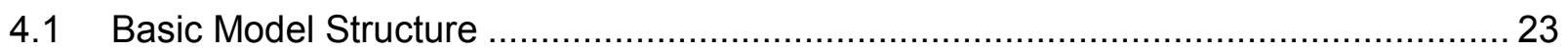

4.2 Scenario Analysis Approach ............................................................................. 26

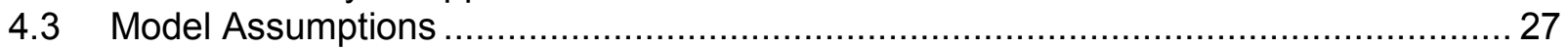

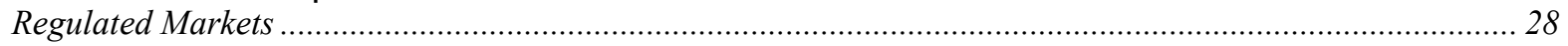

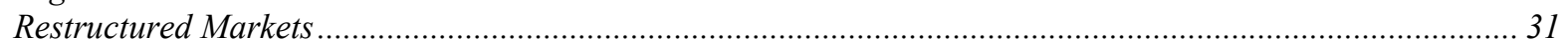

Forecasting the Growth of Green Power Demand: Model Results ....34

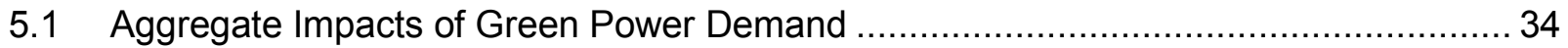

5.2 Environmental Improvement ............................................................................. 36

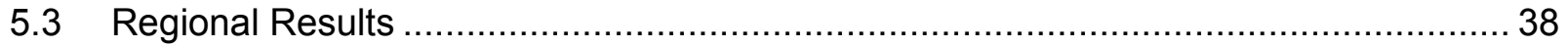

5.4 Impacts of Restructured and Regulated Markets ……….............................................. 39

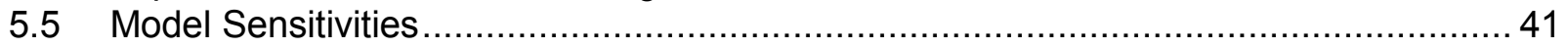

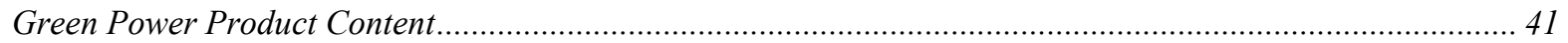

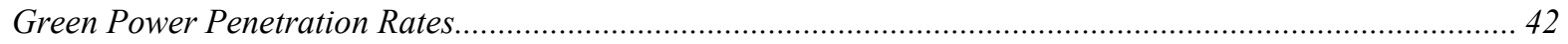

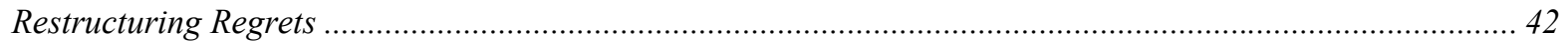

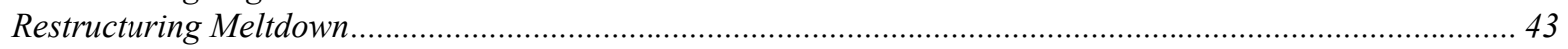

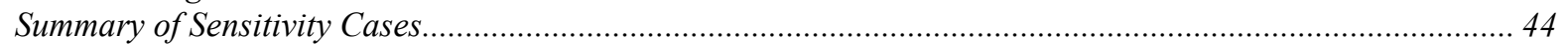




\section{Market DeVelopment Issues: A Qualitative Discussion of the Drivers FOR GREEN POWER GROWTH.................................................................46}

6.1 Access to Aggressive Green Marketing Programs .............................................. 46

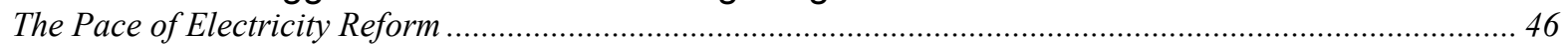

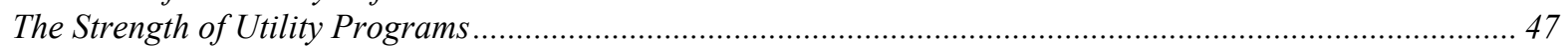

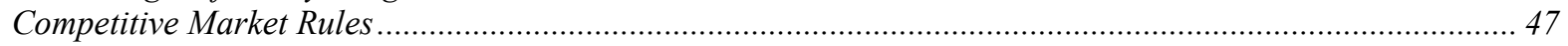

6.2 Consumer Education and Assurance Mechanisms ........................................... 48

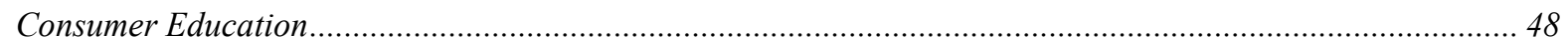

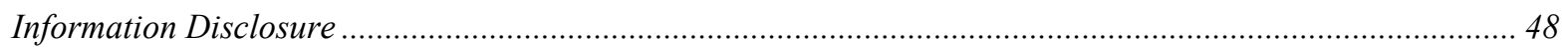

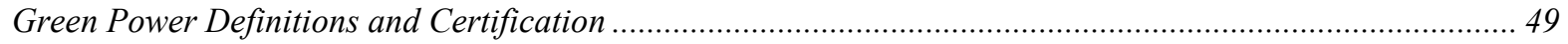

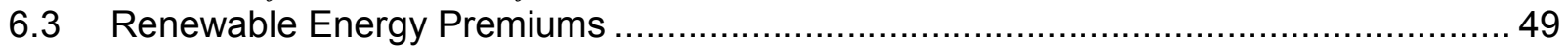

6.4 Emerging Opportunities to Increase Green Power Sales ........................................ 49

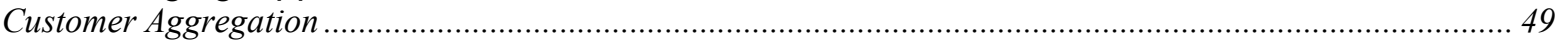

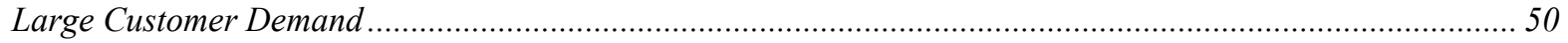

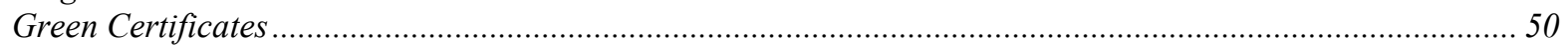

6.5 Relationship Between Green Power Markets and Public Policy............................ 51

CONCLUSIONS ...............................................................................52

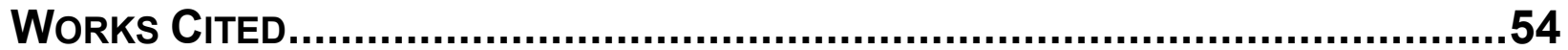




\section{Figures}

Figure ES-1. The Production Diffusion Curve ................................................................................. vi

Figure ES-2. Total Renewables Capacity, High- and Low-Growth Scenarios ....................................... vi

Figure ES-3. Total Renewables Capacity Resulting from Sensitivity Cases in 2010 ............................ viii

Figure 1. Aggregated Willingness to Pay Curve, Residential Customers .............................................

Figure 2. Residential Market Penetration for Utility Energy Tariff Programs ......................................

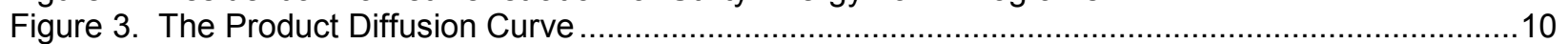

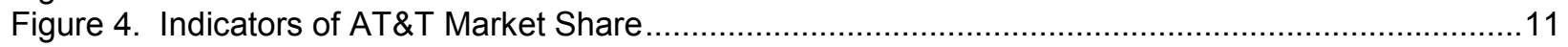

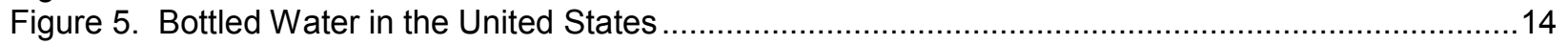

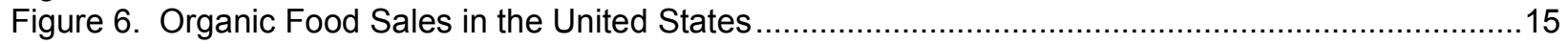

Figure 7. Assets Managed in A Socially Responsible Manner.........................................................16

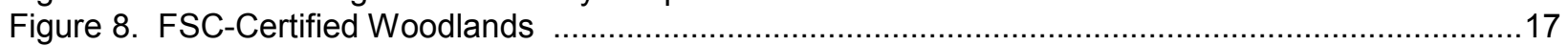

Figure 9. Contributions Received and Market Penetration by Type of Recipient Organization.................19

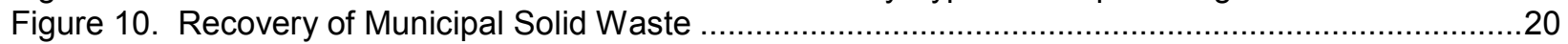

Figure 11. Flow Chart of Green Power Growth Model ................................................................24

Figure 12. Total Renewables Capacity, High- and Low-Growth Scenarios ….....................................35

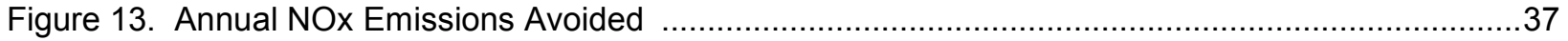

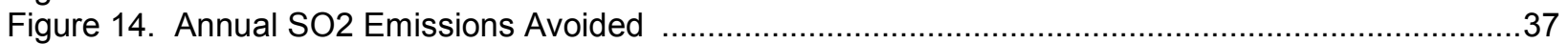

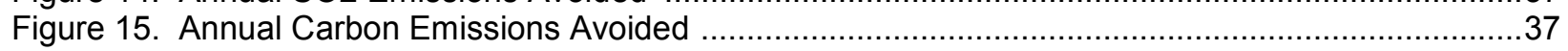

Figure 16. Regional Contribution to Total Renewable Capacity, High-Growth Scenario, 2010...............38

Figure 17. Renewables Capacity by Market Type, High-Growth Scenario .........................................40

Figure 18. Renewables Capacity by Market Type, Low-Growth Scenario ..........................................40

Figure 19. Sensitivity Case: Green Power Product Content ...........................................................41

Figure 20. Sensitivity Case: Green Power Penetration Rates ......................................................42

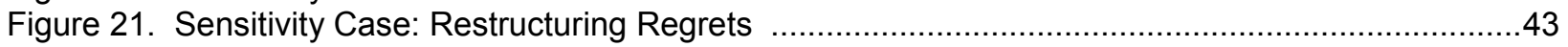

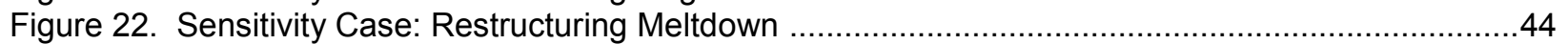

Figure 23. Total Renewables Capacity Resulting from Sensitivity Cases in 2010 ..............................44

Figure 24. New Renewables Capacity Resulting from Sensitivity Cases in 2010 ...............................45

\section{Tables}

Table ES-1. Summary of Actual Market Experience To Date ….........................................................

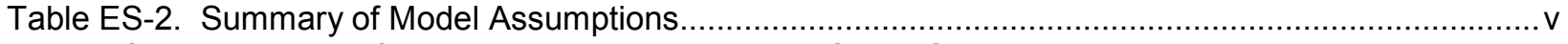

Table ES-3. Estimates of Renewables Development to Serve Green Power Markets ............................ vi

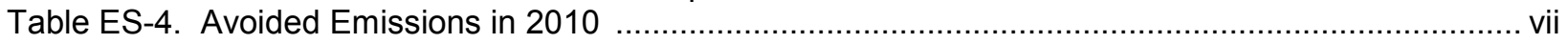

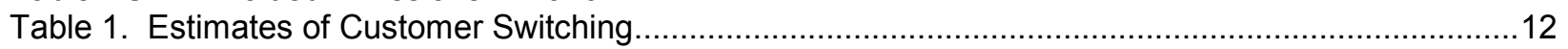

Table 2. Summary of Actual Market Experience To Date ...............................................................27

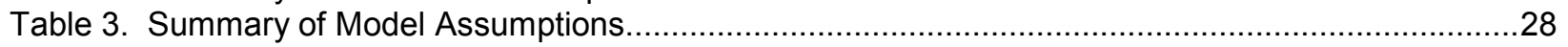

Table 4. Estimates of Renewables Development to Serve Green Power Markets ...............................35

Table 5. Estimates of Renewables Development to Serve Green Power Markets by Market Type...........39

\section{Text Boxes}

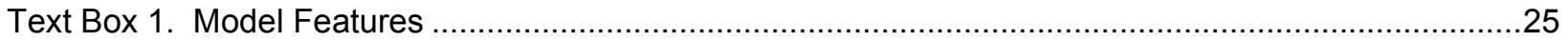

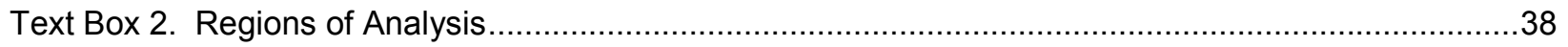




\section{Acknowledgements}

Funding support for this study came from the Office of Power Technologies of the U.S. Department of Energy (DOE) under Contract No. DE-AC36-98-GO10337 for the National Renewable Energy Laboratory (NREL) and Contract No. DE-AC03-76SF00098 for Lawrence Berkeley National Laboratory. The authors would particularly like to thank Tina Kaarsberg and Joseph Galdo of DOE for their support and review of this work. We also benefited from helpful review comments provided by Lori Bird (NREL), Tom Kerr (U.S. Environmental Protection Agency), Tom Rawls (Green Mountain Energy Company), John Saintcross (New York State Energy Research and Development Authority), and Virinder Singh (Renewable Energy Policy Project). Kyra Epstein of NREL provided editorial assistance. Any remaining errors or omissions are the responsibility of the authors. 


\section{Executive Summary}

Greater use of renewable energy offers the potential to reduce the environmental footprint of the electricity generation sector. Though many believe that state and federal renewable energy policy incentives and mandates will continue to play a crucial role in the deployment of renewable energy technologies, the recent introduction of customer choice in domestic electricity markets offers a complementary approach to encourage renewable electricity supply. In particular, green power marketing - defined here as the marketing and sale of renewable electricity to end-use customers - empowers consumers to choose electricity generated from sources that are less damaging to the environment and that may offer price stability in a time of increased electricity price volatility.

In this report, we quantify the potential size and impact of the green power market in the United States, and identify features of the market that will most affect its ultimate growth trajectory. ${ }^{1}$ We do this through a 10-year forecast of market development under both low- and high-growth scenarios. In addition, we present four scenarios structured to gauge the sensitivity of our low- and high-growth forecasts to assumptions about green power product content, market penetration, and the fallout from the recent California power crisis. We base all forecasts on a detailed model of national green power demand that we developed specifically for this purpose. Our analysis emphasizes the impacts of green power demand on renewable energy development and air pollutant emissions.

To develop our modeling assumptions, we review green power market research and experience to date and identify and discuss variables that will help determine market size and the rate of market development. We also examine the experiences of a select group of other industries that have undergone "deregulation" or that sell products with a high degree of environmental or health-related content. Data from these industries provides additional insights into the possible growth of, as well as the barriers to, green power demand.

\section{Green Power Market Development}

As reported in Chapter 2, opinion surveys consistently find that $50 \%$ to $95 \%$ of Americans say they are willing to pay more for power derived from renewable sources. Market simulations or field studies, in which consumers have an actual opportunity to purchase green power in a research setting, demonstrate that a far smaller percentage - $10 \%$ to $20 \%$ - do so. Actual marketing efforts to date have achieved even lower penetration levels: among the 40 million American households with access to green power through either regulated or restructured markets today, roughly 350,000 households, or approximately $1 \%$, have chosen to buy green power. Non-residential demand for green power, meanwhile, has averaged approximately $20 \%$ of residential demand in many markets.

Thus, despite the high expectations raised by market research and even market simulations, actual green power market penetration in both regulated and restructured markets is still low. Many factors may influence this result, including lack of customer awareness, unfavorable market conditions, customer inertia, and lackluster promotional efforts. Three of the more important barriers going forward are believed to be low default service pricing (i.e., the "shopping credit") relative to wholesale power costs

${ }^{1}$ Our analysis does not cover the market for customer-sited distributed generation technologies, though it is arguably part of the green power market and there is a considerable amount of excitement surrounding its prospects. A discussion of some of the barriers to the growth of distributed power markets can be found in Alderfer, et al. (2000). 
the pervasive lack of customer understanding about green power choice, and the negative influence of the California electricity crisis on the emergence of restructured retail markets in other states.

This early market experience may not, however, be representative of the long-run potential of green power, and forecasting future demand for green power based exclusively on the first years of market development is probably unwise. Market penetration by new products typically follows an "S" curve of product diffusion. This diffusion curve is characterized by slow, initial market entry followed by rapid growth before tapering off at higher market penetration levels, as shown in Figure ES-1. Product diffusion is a process in which a product passes through life cycle stages (product development, growth, maturity, and decline) as the nature of the product or service use changes. The rate of product diffusion depends on many factors, including anticipated product cost reductions, consumer awareness and understanding, and removal of market barriers.

Because experience from other more mature markets can provide useful insights in developing our modeling assumptions, in Chapter 3 of this report we investigate the effect of consumer choice on product penetration in several other industries. First we look at customer switching in newly restructured markets, focusing on the long distance telecommunications and natural gas markets. By examining the rate and drivers of customer switching in these two formerly regulated markets, we gain insights into the potential nature and pace of customer switching in

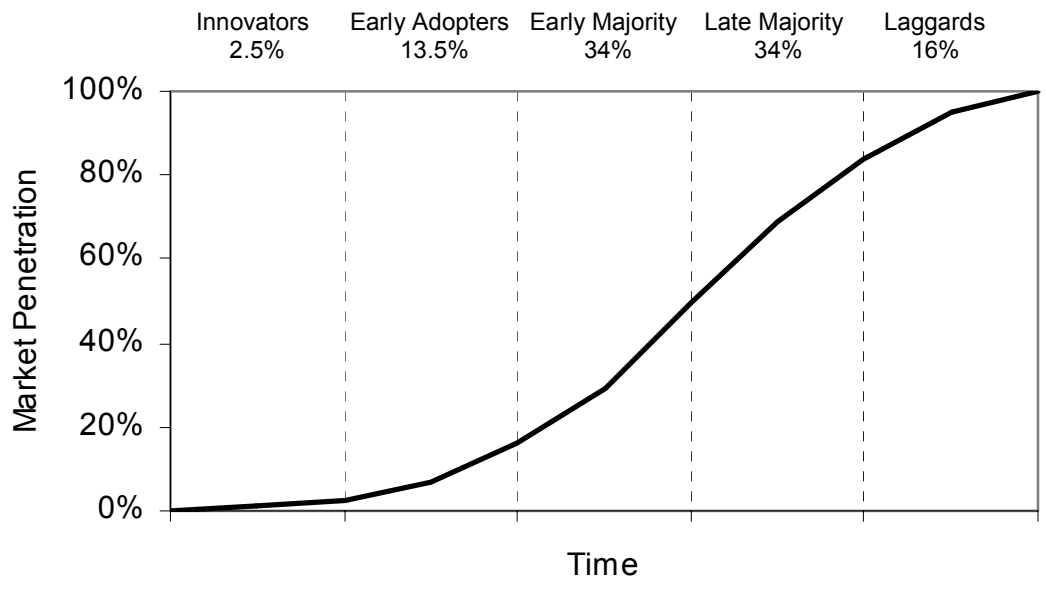
Source: Rogers, E. (1992) restructured electricity markets.

We then highlight experience with the marketing of other "green" consumer products, services, and behaviors, including bottled water, organic foods, socially responsible investing, sustainable forestry products, charitable contributions to environmental organizations, recycling, and compact fluorescent light bulbs. The general pattern of market development among these green products and activities has almost without exception been one of steady but restrained growth in early years followed by acceleration. Though it is perhaps too early to conclude that these markets are beginning to move out of the product development phase and into the growth phase of the product diffusion "S" curve, recent market action at least hints at the beginnings of such a transition.

While none of these industry case studies offers a perfect analogy to green power, they do provide a sense of what is possible over a longer period of time than the few years that green power has been offered to consumers. Perhaps the most relevant implication for our 10-year forecast of green power penetration is that it often takes a long time for markets to develop. When long distance telephone service was deregulated, AT\&T did not lose half of its market share in just a few years; it happened gradually at a pace of a few percent each year over 15 years. Similarly, bottled water reached $8 \%$ market penetration, socially responsible investing $13 \%$, and recycling $25 \%$, each over an extended time period. This pattern implies that any forecast of green power penetration should start out low and grow steadily over a period of time, one that will most likely exceed our 10-year forecast horizon. 


\section{Model Overview and Assumptions}

\section{Background}

The primary aim of this study is to quantify the potential size and impact of the green power market in the United States over the next 10 years. To perform this analysis, we developed a model of national green power demand. Incorporating separate assumptions for restructured and regulated green power markets, the model allows us to simulate the potential impacts of green power demand on renewable energy supply and electricity-sector air pollutant emissions under various input assumptions.

\section{Basic Model Structure}

At the core of the model is a state-level forecast of residential electricity load through 2010, split into investor and publicly owned utilities ("IOU" and "Public," respectively). To this load base, the model sequentially applies 10-year assumptions for the following variables:

- The Pace of Restructuring sets the date that a state opens its electricity market to competition.

- Access to Green Power is: (1) the percentage of regulated load that has access to a green pricing tariff, or (2) the percentage of load in restructured markets that has access to a competitive green power product.

- Residential Green Power Market Penetration is the percentage of load with access to green power that actually chooses to purchase green power. Non-residential green power demand is modeled as a percentage adder to the residential green power load. ${ }^{2}$

- Green Power Product Content is the percentage of existing renewables (renewable capacity built prior to the availability of green power choice), new renewables (renewable capacity built after the beginning of green power choice), and total renewables in a green power product.

Our assumptions, described in more detail later, differ by regulated and restructured markets, and in some cases also by type of utility.

\section{Scenario Analysis Approach}

We develop two scenarios - high- and low-growth - to bound what we consider to be a range of plausible growth paths for the green power market. There is no probability attached to either scenario or the range of possibilities that lie between. More extreme cases could be imagined. ${ }^{3}$

As illustrated by the specific assumptions described in the next section, the high-growth scenario is intended to be aggressive, with sizable green power demand growth and steadily improving green power product content (e.g., the percentage of renewable energy contained in green power products increases). For such a growth pattern to develop, several general market characteristics might be required:

- restructuring proceeds with little delay,

- market rules in restructured markets are conducive to competition and customer switching is high,

\footnotetext{
${ }^{2}$ This overly simplistic methodology was adopted as a modeling tool to circumvent limitations in the data at hand, and is not intended to imply a causal relationship between residential and non-residential demand for green power. That said, as the residential sector becomes increasingly educated about and begins to demand green power, it is plausible that there could be a spillover in demand to the non-residential sector, as businesses themselves become educated and respond to their customers' values (a persuasive case could also be made for a demand spillover in the opposite direction, from the non-residential to the residential sector).

${ }^{3}$ For example, on the low end, one could imagine a scenario where the fallout from California's electricity crisis completely halts the move toward restructuring in other states and greatly reduces access to green power (see our "restructuring meltdown" sensitivity scenario). On the high end, increasing recognition of the "non-green" value of renewable energy - e.g., its ability to function as a fuel price hedge - could become a strong driver of green power demand, above and beyond what we have modeled.
} 
- consumer understanding and acceptance of green power shows significant growth, and

- the premium spread between the cost of renewable and competing generation technologies continues to narrow, because of ongoing reductions in the cost of renewable energy technologies, the continued or enhanced availability of renewable energy tax credits or financial incentives, or increases in fuel (i.e., natural gas) costs for conventional generators.

The low-growth scenario, on the other hand, is intended to represent a far less aggressive case, with more limited growth in customer switching and lower-quality product content (e.g., green power products contain less renewable energy). This case may be qualitatively characterized by a scenario in which:

- the introduction of restructured markets and utility green pricing programs is delayed,

- market rules in restructured markets are far less conducive to competitive suppliers and customer switching than under the high-growth scenario,

- consumer understanding and acceptance of green power grows, but slowly, and

- the premium spread between the cost of renewable and competing generation technologies does not narrow appreciably.

In addition to the high- and low-growth scenarios, we constructed four other scenarios designed to test the sensitivity of our model to assumptions about product content, green power market penetration, and the fallout from California's electricity crisis (which could slow or even halt the pace of restructuring and limit consumer access to green power products). The specific assumptions behind all of our scenarios are described in more detail in the next section.

\section{Model Assumptions}

The model requires assumptions for each of the variables defined above under both the low- and highgrowth scenarios, as well as the sensitivity scenarios. In developing these input assumptions we began with current data on green power availability, customer response, and product content and knowledge of how these variables have changed in the past. Table ES-1 summarizes the current state of these variables in both regulated and restructured green power markets.

Results from market simulations and field studies (showing 10\% to $20 \%$ residential market penetration) and our review of the case studies from other industries influenced our longer-term assumptions. Nonetheless, we acknowledge that ultimately our assumptions are derived largely from our own professional judgments. Table ES-2 summarizes the assumptions made in the low- and high-growth scenarios. For more detail on the nature of these assumptions, as well as the structure of the model itself, see Chapter 4 of the full report.

To examine the model's sensitivity to assumptions about product content, we simply substituted our lowgrowth product content assumptions into the high-growth model run, and vice versa. We tested sensitivity to green power penetration rates in an identical fashion. ${ }^{4}$ To examine the potential impact of California's electricity crisis on green power demand nationwide, we constructed two scenarios - dubbed "restructuring regrets" and "restructuring meltdown" - intended to represent a dramatic rethinking of the move towards retail competition. In both of these scenarios, we assume (1) that any state that has not already opened for retail access will not do so during our 10-year forecast period, with the exception of Texas, which is assumed to open on schedule; and (2) that no publicly owned utility in a state that has already restructured will offer its customers retail access. The "restructuring meltdown" scenario goes one step further, and assumes that retail customer access to green power products in states that have already restructured is cut in half (e.g., due to those markets being unattractive, or even reverting to a quasi- or

\footnotetext{
${ }^{4}$ Although we test the sensitivity of the model to each of these variables independently, we note that the variables are not necessarily independent. For example, it is plausible that improved product content could lead to higher market penetration rates.
} 
un-restructured state like California), as is the growth in customer access to green pricing programs in regulated markets (e.g., as the threat of electricity restructuring recedes incentives to develop regulated green pricing program may also fade).

Table ES-1. Summary of Actual Market Experience To Date

\begin{tabular}{|c|c|c|}
\hline Variable & Market & Actual Market Experience To Date \\
\hline \multirow{3}{*}{$\begin{array}{c}\text { Pace of } \\
\text { Restructuring } \\
\text { (IOUs) }\end{array}$} & $\begin{array}{c}\text { States that } \\
\text { are already } \\
\text { open }\end{array}$ & $\sim 25 \%$ of nationwide residential load (13 states) \\
\hline & $\begin{array}{l}\text { States with } \\
\text { "firm" dates }\end{array}$ & $\sim 25 \%$ of nationwide residential load (8 states) \\
\hline & $\begin{array}{l}\text { States without } \\
\text { dates }\end{array}$ & $\sim 50 \%$ of nationwide residential load (29 states) \\
\hline $\begin{array}{c}\text { Pace of } \\
\text { Restructuring } \\
\text { (Public) }\end{array}$ & All states & $\begin{array}{l}\sim 0 \% \text { of nationwide residential load (to date, few publicly owned utilities have } \\
\text { opted to open their markets to competition) }\end{array}$ \\
\hline \multirow{2}{*}{$\begin{array}{l}\text { Access to } \\
\text { Green Power }\end{array}$} & Regulated & $\begin{array}{l}\text { IOU: } \sim 22 \% \text { of residential load } \\
\text { Public: } \sim 19 \% \text { of residential load }\end{array}$ \\
\hline & Restructured & $\begin{array}{l}\text { IOU: }>90 \% \text { of IOU load has access to green power } \\
\text { Public: few public utilities are open to competition }\end{array}$ \\
\hline \multirow{2}{*}{$\begin{array}{c}\text { Green Power } \\
\text { Market } \\
\text { Penetration }\end{array}$} & Regulated & $\begin{array}{l}\text { Residential: }<1 \% \text { to } 7.4 \% \text { ( } 0.8 \% \text { median) of load with access to green power } \\
\text { Non-Residential: } 20 \% \text { of residential demand in many, but not all, markets }\end{array}$ \\
\hline & Restructured & $\begin{array}{l}\text { Residential: } 1.6 \% \text { (PA) to } 1.9 \% \text { (CA at height of market); CA is } \sim 1 \% \text { now } \\
\text { Non-Residential: } 20 \% \text { (PA) to } 100 \% \text { (CA at height of market) }\end{array}$ \\
\hline \multirow{2}{*}{$\begin{array}{c}\text { Green Power } \\
\text { Product } \\
\text { Content }\end{array}$} & Regulated & $\begin{array}{l}\text { \% existing renewables: } \sim 0 \% \text { of energy-based products on average } \\
\% \text { new renewables: } \sim 30 \% \text { of energy-based products on average }\end{array}$ \\
\hline & Restructured & $\begin{array}{l}\text { \% existing renewables: } 17.5 \%(\mathrm{PA}) \text { to } 95 \%(\mathrm{CA}) \text { of product } \\
\% \text { new renewables: } 2 \%(\mathrm{PA}) \text { to } 5 \%(\mathrm{CA}) \text { of product }\end{array}$ \\
\hline
\end{tabular}

Table ES-2. Summary of Model Assumptions (ranges are over 10 years, unless otherwise noted)*

\begin{tabular}{|c|c|c|c|}
\hline Variable & Market & Low-Growth Scenario & High-Growth Scenario \\
\hline \multirow{3}{*}{$\begin{array}{l}\text { Pace of } \\
\text { Restructuring } \\
\text { (IOUs) }\end{array}$} & $\begin{array}{l}\text { States that } \\
\text { are already } \\
\text { open }\end{array}$ & Remain open to competition & Remain open to competition \\
\hline & $\begin{array}{l}\text { States with } \\
\text { "firm" dates }\end{array}$ & Retail choice delayed for 2 years & Retail choice occurs on schedule \\
\hline & $\begin{array}{c}\text { States without } \\
\text { dates }\end{array}$ & $\begin{array}{l}\text { Fast states: } 25 \%(2004) \text { to } 100 \%(2008) \\
\text { Slow states: } 5 \%(2004) \text { to } 20 \%(2010)\end{array}$ & $\begin{array}{l}\text { Fast states: } 50 \%(2004) \text { to } 100 \%(2005) \\
\text { Slow states: } 20 \%(2004) \text { to } 100 \%(2008)\end{array}$ \\
\hline $\begin{array}{c}\text { Pace of } \\
\text { Restructuring } \\
\text { (Public) }\end{array}$ & All states & $\begin{array}{l}0.5 \% \text { (starting in } 3^{\text {rd }} \text { year after IOUs } \\
\text { open) to } 4 \% \text { in } 10^{\text {th }} \text { year }\end{array}$ & $\begin{array}{l}2.5 \% \text { (starting in } 3^{\text {rd }} \text { year after IOUs } \\
\text { open) to } 20 \% \text { in } 10^{\text {th }} \text { year }\end{array}$ \\
\hline \multirow{2}{*}{$\begin{array}{l}\text { Access to } \\
\text { Green Power }\end{array}$} & Regulated & $\begin{array}{l}\text { IOU: } 5 \% \text { to } 27.5 \% \text {, incremental } \\
\text { Public: } 5 \% \text { to } 27.5 \% \text {, incremental }\end{array}$ & $\begin{array}{l}\text { IOU: } 10 \% \text { to } 55 \% \text {, incremental } \\
\text { Public: } 10 \% \text { to } 55 \% \text {, incremental }\end{array}$ \\
\hline & Restructured & $\begin{array}{l}\text { IOU: constant } 100 \% \text { of open markets } \\
\text { Public: constant } 100 \% \text { of open markets }\end{array}$ & $\begin{array}{l}\text { IOU: constant } 100 \% \text { of open markets } \\
\text { Public: constant } 100 \% \text { of open markets }\end{array}$ \\
\hline \multirow{2}{*}{$\begin{array}{c}\text { Green Power } \\
\text { Market } \\
\text { Penetration }\end{array}$} & Regulated & $\begin{array}{l}\text { Residential: } 0.25 \% \text { to } 2.5 \% \\
\text { Non-Residential: constant } 10 \% \text { of Res }\end{array}$ & $\begin{array}{l}\text { Residential: } 0.75 \% \text { to } 7.50 \% \\
\text { Non-Residential: constant } 25 \% \text { of Res }\end{array}$ \\
\hline & Restructured & $\begin{array}{l}\text { Residential: } 0.25 \% \text { to } 2.5 \% \\
\text { Non-Residential: constant } 10 \% \text { of Res }\end{array}$ & $\begin{array}{l}\text { Residential: } 1 \% \text { to } 10 \% \\
\text { Non-Residential: constant } 25 \% \text { of Res }\end{array}$ \\
\hline \multirow{2}{*}{$\begin{array}{c}\text { Green Power } \\
\text { Product } \\
\text { Content }\end{array}$} & Regulated & $\begin{array}{l}\% \text { existing renewables: constant } 0 \% \\
\% \text { new renewables: constant } 20 \%\end{array}$ & $\begin{array}{l}\% \text { existing renewables: constant } 0 \% \\
\% \text { new: } 30 \% \text { to } 40 \% \text { over } 5 \text { years }\end{array}$ \\
\hline & Restructured & $\begin{array}{l}\% \text { existing renewables: constant } 20 \% \\
\% \text { new renewables: } 1 \% \text { to } 15 \%\end{array}$ & $\begin{array}{l}\% \text { existing renewables: constant } 30 \% \\
\% \text { new renewables: } 2 \% \text { to } 27.5 \%\end{array}$ \\
\hline
\end{tabular}

*For notes to this table, see Table 2 of the full report. 


\section{Model Results}

\section{Low- and High-Growth Scenarios}

Chapter 5 of the report describes the modeling results. Given the assumptions presented in Table ES-2, our model projects that the total amount of renewable energy capacity supported by green power demand could range from 905 average megawatts (aMW) in our low-growth scenario to as much as 6,971 aMW in our high-growth scenario by 2010 (see Figure ES-2). ${ }^{5}$ This seven-fold difference reflects the high degree of uncertainty around the future development of green power markets.

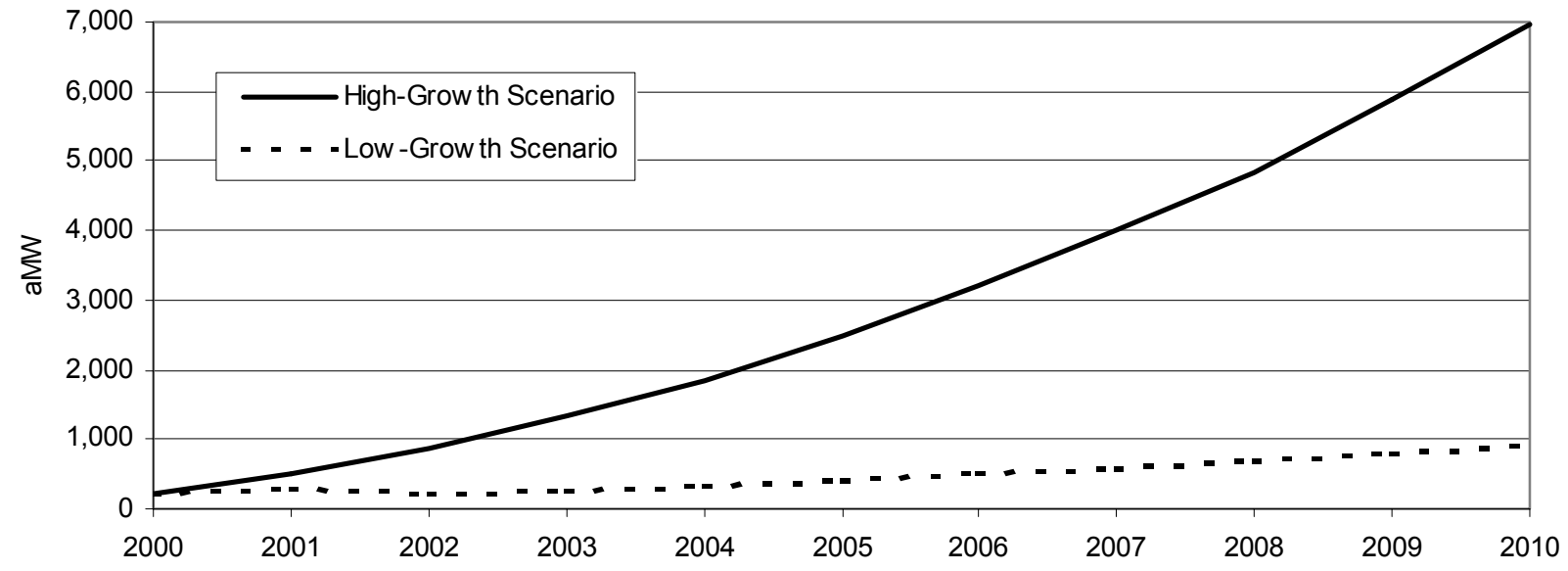

Figure ES-2. Total Renewables Capacity, High- and Low-Growth Scenarios (aMW)

In Table ES-3, we divide the total amount of renewable capacity supported by green power demand in 2010 into "existing" and "new" capacity in both regulated and restructured markets. Broadly speaking, "existing" capacity is defined as renewable capacity that was operating prior to the inception of green power markets, but that is subsequently sold within a green power product. "New" renewable capacity is that which has come on line since the inception of these markets and that is sold as green power to enduse customers. Because new renewable generation provides clearer incremental environmental benefits, the distinction between new and existing renewable capacity is important.

Table ES-3. Estimates of Renewables Development to Serve Green Power Markets (2010)

\begin{tabular}{|l|c|c|c|c|c|c|}
\hline Capacity Type & \multicolumn{3}{|c|}{ Low-Growth Scenario (aMW) } & \multicolumn{3}{c|}{ High-Growth Scenario (aMW) } \\
\hline & Regulated & Restructured & Total & Regulated & Restructured & Total \\
\hline Existing & 0 & 309 & 309 & 0 & 3,082 & 3,082 \\
\hline New & 362 & 234 & 596 & 1,026 & 2,863 & 3,890 \\
\hline Total & 362 & 543 & 905 & 1,026 & 5,945 & 6,971 \\
\hline
\end{tabular}

To put these numbers into perspective, there are approximately 9,100 aMW of existing non-hydro renewables capacity in the United States today. Under the low-growth scenario, only 3\% of this existing capacity is used to supply competitive green power products by 2010 (309 aMW), while under our highgrowth scenario this utilization rate jumps to $34 \%$ (3,082 aMW). Meanwhile, the amount of new renewable generating capacity added to serve green power markets increases the total amount of non-

${ }^{5}$ An average megawatt is defined as a megawatt of capacity that operates continuously, or has a capacity factor of $100 \%$. Because all electric generators tend to have different operating characteristics and thus capacity factors, the use of average megawatts allows us to represent the contribution from renewables in a generic fashion. As an example, 1,000 aMW is equivalent to 3,333 megawatts of nameplate wind power capacity operating at a $30 \%$ capacity factor or 1,250 megawatts of nameplate geothermal capacity operating at an $80 \%$ capacity factor. 
hydro renewables capacity in the United States (i.e., 9,100 aMW) by about 7\% under our low-growth scenario (596 aMW), and by about $43 \%$ under our high-growth scenario $(3,890 \mathrm{aMW})$ by 2010 . In both the low- and high-growth scenarios, by 2010 green power demand supports more new renewable generating capacity than it does existing renewable capacity.

While regulated markets play a smaller role than restructured markets in total support for renewable generation under our low- and high-growth scenarios, they play a proportionately greater role in supporting new renewable generation. This outcome is a result of our assumption that regulated green pricing programs support only new renewable generation. In the low-growth scenario, regulated markets account for $61 \%$ of all new renewable capacity. Regulated markets play an even larger role in some of our sensitivity scenarios that evaluate the possible impacts of a slowdown in electricity restructuring efforts.

Because green power demand should reduce the environmental footprint of the electric power industry through the displacement of fossil-fueled generation, we also forecast avoided air pollutant emissions under our low- and high-growth scenarios. We calculate the annual emissions reductions of $\mathrm{NOx}, \mathrm{SO}_{2}$, and carbon ${ }^{6}$ for each state using average fossil fuel emissions rates contained in the U.S. Environmental Protection Agency's E-GRID database for $1998 .^{7}$ Assuming that only new renewable generation will create incremental environmental improvement through emissions avoidance, ${ }^{8}$ and that new renewable energy technologies emit no pollutants themselves, ${ }^{9}$ Table ES-4 shows avoided emissions in 2010.

Table ES-4. Avoided Emissions in 2010 (metric tons of pollutant)

\begin{tabular}{|c|c|c|}
\hline Pollutant & Low-Growth Scenario & High-Growth Scenario \\
\hline $\mathbf{N O}_{\mathbf{x}}$ & 10,000 & 70,000 \\
\hline $\mathbf{S O}_{\mathbf{2}}$ & 20,000 & 160,000 \\
\hline Carbon & $1,200,000$ & $8,200,000$ \\
\hline
\end{tabular}

To put the carbon reduction estimates into perspective, by 2010 the United States would need to cut roughly 300 million metric tons of carbon from current (year 2000) emissions levels in order to reach its original commitment under the Kyoto Protocol; the carbon emissions reductions attained in our low- and high-growth scenarios represent $0.4 \%$ to $2.7 \%$ of this amount, respectively.

\section{Sensitivity Scenarios}

Figure ES-3 summarizes the results of all four sensitivity scenarios, described earlier, in terms of total renewables capacity supported by green power demand in 2010. For comparison purposes, the dashed horizontal lines represent the capacity resulting from our low- and high-growth scenarios.

${ }^{6}$ While we report emissions avoidance results for $\mathrm{SO}_{2}, \mathrm{NO}_{\mathrm{X}}$, and carbon, because of national "cap and trade" policies for $\mathrm{SO}_{2}$ and regional policies for $\mathrm{NO}_{\mathrm{X}}$, new renewable energy development may not directly reduce these emissions unless the resulting emissions allowances are retired.

${ }^{7}$ See www.epa.gov/airmarkets/egrid.

${ }^{8}$ Most (but not all) existing renewable generation would likely continue to operate whether or not it was being supported by green power demand. Thus, green power support for existing facilities often results in little $n e w$ or incremental environmental benefits.

${ }^{9}$ This assumption is contestable. Generation from landfill gas may in fact be doubly beneficial (i.e., have a negative emissions profile) as it not only offsets emissions from fossil-fuel generation, but it may also reduce damaging methane emissions. The combustion of biomass, on the other hand, may result in net carbon emissions if the feedstock is not obtained in a sustainable manner, and net emissions of other pollutants are also possible, regardless of how the feedstock is obtained. 
Restructuring Regrets $\square$ Restructuring Meltdown $\square$ Product Content $\square$ Market Penetration

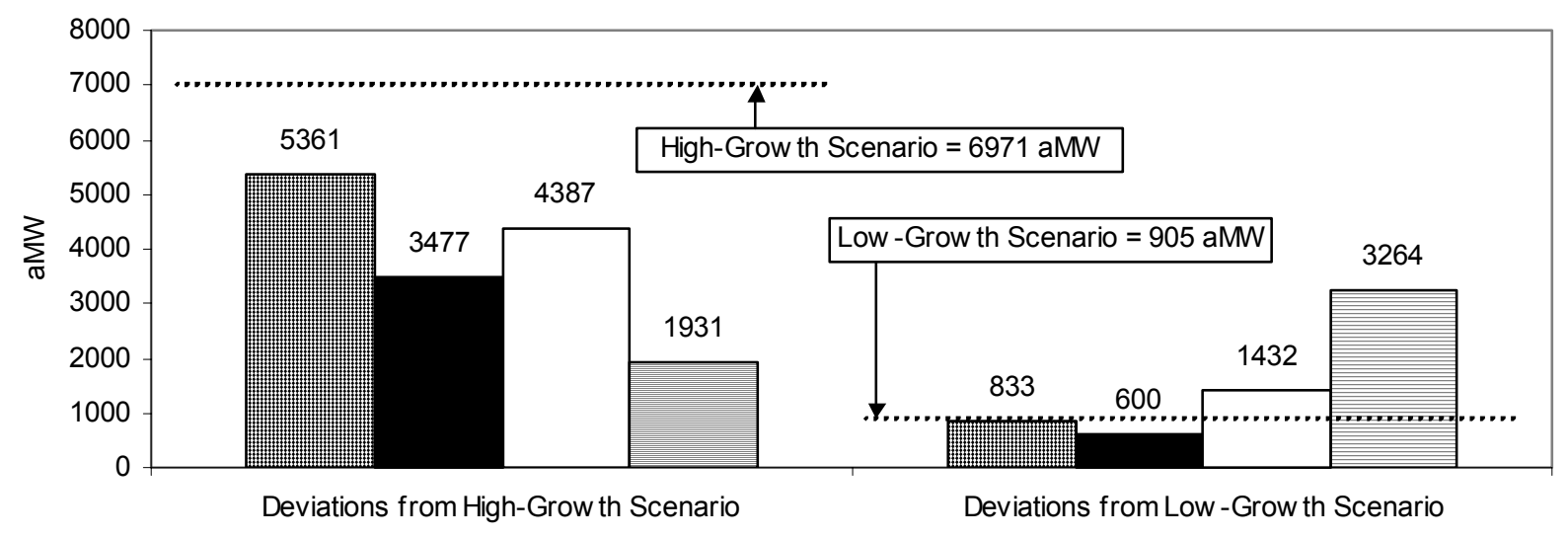

Figure ES-3. Total Renewables Capacity Resulting from Sensitivity Cases in 2010 (aMW)

Changes in our green power market penetration assumptions clearly have the largest impact on our modeling results for total renewable capacity. Green power demand as forecast in our model is also quite sensitive to changes in product content assumptions. Interestingly, the model is least sensitive to changes in our assumptions about the pace of electricity reform, as demonstrated by the "restructuring regrets" scenario. This outcome reflects a modeling assumption that regulated green pricing programs will become increasingly available to customers in regions that do not open to retail competition. Consequently, the model forecasts increased renewable demand from regulated markets as restructuring grinds to a halt, offsetting some of the lost renewable energy demand derived from restructured markets. Because the veracity of this assumption is debatable, the "restructuring meltdown" scenario, which in addition to halting the trend towards further restructuring also cuts access to green power in half, presents another plausible scenario - one that reduces our high-growth outcome by half.

\section{Market Development Issues}

Given the pervasive uncertainties that face the future development of the green power market and the significant possibility that a low-growth scenario will prevail (especially given recent events in the electricity sector), Chapter 6 describes qualitatively a number of the factors that may determine the future growth of green power markets. We describe some of these factors here, not ranked in any particular order:

Access to Aggressive Green Power Marketing Programs: Widespread access to aggressively marketed green power programs, whether in restructured or regulated markets, is an essential ingredient to achieving the targets suggested by our high-growth green power development scenario. The single-largest barrier to achieving such widespread access may be the present uncertainty surrounding the pace and form of electricity restructuring. Though our "restructuring regrets" scenario suggests that regulated green pricing programs could compensate should the pace of restructuring slow, the premise behind these results is questionable. Given that part of the impetus for regulated utilities to offer green pricing programs has been the threat of competition, the higher risk "restructuring meltdown" scenario provides an alternative view of this uncertain future, where growth in regulated green pricing markets also shrinks as restructuring fades. Even where retail competition proceeds, the attractiveness of those markets to both competitive switching generally and to green power choice specifically will depend on a host of regulatory rules and policies established by state legislatures and regulatory commissions, one of the most important being the level of default service pricing (also known as the "shopping credit"). 
Consumer Education and Assurance Mechanisms: The industry case studies examined in Chapter 3 suggest that widespread customer education on the merits of exercising green product choice is needed. Absent such education, and recognition by individual consumers that their actions are both necessary and make a difference, consumer response to green product offers will generally remain limited. Indeed, the pervasive lack of consumer understanding of electricity restructuring generally, and green power specifically, has often been cited as one of the largest barriers to the growth of green power markets. We therefore view consumer education as absolutely essential if the high-growth green power scenario is to be achieved. Mandatory information disclosure of the environmental attributes of green power and other forms of generation, and certification programs that identify products that meet minimum environmental standards are two additional ways to provide consumers with the basic information needed to make educated purchase decisions.

Renewable Energy Premiums: Over the past year, sharp increases in natural gas and wholesale power prices nationwide, accompanied by ongoing cost reductions in renewable technologies, have reduced the cost premium for renewable power to its lowest level ever. In fact, in several recent instances throughout the West, wind power (aided by the $1.7 \phi /$ kilowatt-hour $[\mathrm{kWh}]$ federal production tax credit) has been deemed the cheapest source of new electricity generation. Even where renewables are not the cheapest resource, renewable technologies can play an important role as a price hedge against rising future fuel or wholesale power costs. Regulated utilities and competitive green power marketers can take advantage of this largely untapped value by offering fixed-price electricity service to their retail customers. The realization of such "non-green" values, along with even deeper reductions in renewable energy premiums (realized through some combination of lower renewable energy costs, higher wholesale prices for conventional generation, or the continuation or enhancement of renewable energy tax credits and financial incentives), may be necessary to ensure the availability of highly credible and reasonably priced green power products, and therefore to deliver the sizable customer demand necessary to achieve the highgrowth scenario.

Emerging Opportunities to Increase Green Power Sales: Innovation in the types of green power products offered and the strategies used to reach out and attract customers are also likely to increase the pace of market development. Customer aggregation, large customer purchases, and green certificate trading are all opportunities to boost the level of green power demand.

Relationship Between Green Power Markets and Public Policy: Although green power marketing represents a market-based approach to increasing the deployment of renewable energy sources, the development of this market is often intertwined with policy initiatives or other supporting actions. There are at least two ways in which the relationship between public policy measures and green markets will influence the rate and impact of green market growth. First, financial support for renewables through public policy measures is still important to help lower the cost of green power to consumers, and thereby increase demand. Federal tax incentives and state system benefits charge (SBC) support appear to be particularly critical. Second, consumer demand for green power will only have a measurable impact on renewable energy supply if such demand is in addition to any supply-side obligations such as a renewables portfolio standard (RPS). Such supply policies should incorporate the principle of additionality by requiring that the obligation be met for every customer, not just those who are willing to purchase green power. 


\section{Conclusions}

While it is too early in the development of customer-driven green power markets to make robust conclusions regarding the long-term effectiveness of green power demand, we have attempted to bound the possible impacts of green power demand over the next 10 years through the use of scenarios and sensitivity analysis. Though subject to limitations, our analysis concludes with the following observations:

- The size of the green power market remains small today, hindered in part by unfavorable market rules and market structure and by low consumer understanding, but there is some evidence that sizable growth prospects do exist.

- Experience from other related industries shows that it takes time to build new markets, and that slow and steady growth in the early years is the norm.

- The results from our low-growth scenario are modest by almost any standard, while our high-growth scenario is far more significant. The wide gap between the two scenarios reflects the high degree of uncertainty in the pace and ultimate potential for green power demand.

- Sensitivity analysis reveals that much of the $\sim 6,000$ aMW difference between our low- and highgrowth scenarios in 2010 can be explained by our assumptions about market penetration: substituting low-growth market penetration assumptions into our high-growth model run reduces total renewable capacity in 2010 by $72 \%$ (or 5,040 aMW). The "restructuring meltdown" scenario also has a large impact, resulting in only half as much total renewables capacity in 2010 as in our high-growth scenario. This suggests that the electricity crisis unfolding in the Western United States, and its influence on the pace of electricity restructuring in other states, could dramatically slow green power market growth.

- Aggressive promotion of renewable energy may be needed to achieve the high-growth scenario, including expanded access to high-quality green power products, assuring that markets are truly competitive, effective consumer education programs coupled with information disclosure and product certification, aggregation of small customers and cultivation of large customer demand, continued innovations in low-cost product delivery, and a further narrowing of the renewable energy cost spread over conventional generation.

- Our modeling results further suggest that customer-driven markets for renewable energy are unlikely to adequately replace the need for more fundamental policy measures if accelerated rates of renewable energy development are determined to be in the public interest. Such policies range from financial measures to buy down renewable energy cost premiums (e.g., federal production and investment tax credits, state system benefits charge funds) to mandatory obligations to develop renewable generation (e.g., state renewables portfolio standards) to market rules that encourage green power demand (e.g., default service pricing that allows a retail profit margin and customer education programs). 


\section{Introduction}

\subsection{Background}

Electricity supply, or lack thereof, is a highly visible topic in current national and regional energy debates. In these debates, even where augmenting electricity supply is not an urgent issue, the pervasive environmental impacts of electricity generation force consideration of the tradeoffs between low-cost energy and a cleaner environment. This is because the electric power industry is a leading contributor to the nation's air quality problems. According to the U.S. Environmental Protection Agency, electricity generation is responsible for $67 \%$ of sulfur dioxide emissions, $25 \%$ of nitrogen oxides, $40 \%$ of man-made carbon dioxide emissions, and 34\% of mercury emissions in the United States (Johnson, et al. 2001).

Greater use of renewable electricity has long been promoted as an option for reducing the environmental footprint of the electricity generation sector, and many believe that not enough is being done to develop our nation's vast supply of renewable energy resources. After all, non-hydro renewables account for just $2 \%$ of U.S. electricity generation. Where renewable energy has been developed in the United States it has most typically been buoyed by strong state or federal policy incentives or mandates. It is argued by many that continued near-term support for these technologies - including fundamental R\&D, tax and financial incentives, and renewable energy mandates - is needed for renewable energy to meet its full potential.

The recent introduction of customer choice in domestic electricity markets promises another, complementary approach to encourage renewable electricity supply. While electric utilities have traditionally made decisions about what supply resources to develop, customer choice brings with it the possibility that end-use customers might willingly direct their electricity purchases towards renewable energy. Green power marketing - defined here as the marketing and sale of renewable-energy based electricity products to end-use customers - empowers customers to voluntarily purchase electricity generated from sources that are less damaging to the environment.

With renewable energy purchasing options available in both restructured and regulated markets, green power marketing has the potential to increase demand for renewable generation. The green power market creates new opportunities for businesses to develop renewable energy sources by providing additional outlets for the resulting power generation. A robust green power market may further provide a measure of market stability for renewable energy developers by reducing their vulnerability to government policy swings and transforming renewable energy into a mainstream product. Of course, green power marketing will only deliver these benefits if consumers have choices and if green power options are well marketed. Whether or not large numbers of customers choose to purchase their power from renewable energy sources, the mere existence of green power products in the market may serve to better educate consumers about the environmental impacts of electricity production.

\subsection{Study Objectives and Approach}

This study examines the potential role of green power markets as a stimulus to the deployment of renewable energy technologies in the electricity marketplace. Specifically, we aim to quantify the potential size and impact of the green power market in the United States through a 10-year forecast of market growth under both low- and high-growth scenarios. Although green power markets are only beginning to emerge, experience to date shows that these markets can result in new renewable energy development. Even so, the impacts to date have been modest and the potential role of the green power 
market in renewable energy supply is a contested topic. Market research shows that consumers are misinformed about current sources of electricity generation, how electricity flows from power plants to end users, and, in many cases, the ability to choose alternative electricity suppliers. Thus, while there is promise in the opening up of markets for the sale of green power, there are also reasonable arguments to suggest that the impact may be small. While we cannot know the future, the objective of our analysis is to help bound this discussion through well-documented scenarios and to identify key features of the market that will affect its ultimate growth trajectory. ${ }^{10}$

Central to this effort is the development of a detailed, national green power penetration model, which we use to estimate the potential impacts of the green power market on renewable energy development and electric sector air emissions under high-growth and low-growth scenarios. Using a 10-year forecast period, the model is further used to explore the sensitivity of green power market growth to various model input assumptions. We also identify market and policy factors that may either support or constrain the pace of market development.

To support our modeling assumptions, we review green power market development to date and identify and discuss a number of variables that we believe will be key determinants of market size and the rate of market development. We also examine the experiences of a select group of other industries that have either undergone "deregulation" or that market products with a high degree of environmental or healthrelated content; evidence from these industries provides useful insights into the possible growth of and barriers to green power demand.

The primary audience for this report is electricity-sector policy makers at both the state and federal levels and others interested in understanding the potential role of green power markets in increasing the contribution of renewable energy to meeting future electricity needs. It is our hope that market participants and policy makers alike will work together to remove barriers to green power market development and thus encourage greater use of our domestic renewable resources.

\subsection{Report Organization}

Chapters 2 and 3 of this report provide context for our evaluation of possible green power market growth scenarios, and offer support for the development of our modeling assumptions. In Chapter 2, we review market research findings on stated demand for green power, summarize field studies that aim to evaluate customer demand in a more realistic setting, and describe early experience with green power marketing in the United States in both regulated and restructured markets.

Because the green power market is only beginning to develop and because new products typically diffuse slowly into the economy, the data summarized in Chapter 2 cannot easily be extrapolated over our 10year model forecast period. To examine the evidence for longer-term market penetration and to provide insights into model development, in Chapter 3 we investigate the effect of consumer choice in several other related industries: long-distance telecommunications, natural gas, bottled water, organic foods, socially responsible investing, sustainable forestry products, charitable contributions to environmental organizations, recycling, and compact fluorescent light bulbs. None of these examples is a perfect analogy to green power, but they do provide a sense of what is possible over a longer period of time than the few years that green power has been offered to consumers. Here, we note that Chapter 3, while providing

\footnotetext{
${ }^{10}$ Our analysis does not cover the market for customer-sited distributed generation technologies, though it is arguably part of the green power market and there is a considerable amount of excitement surrounding its prospects. A discussion of some of the barriers to the growth of distributed power markets can be found in Alderfer, et al. (2000).
} 
useful context, is by no means required reading for understanding later chapters of this report that describe our modeling assumptions and results.

In Chapter 4, we turn to a discussion of the structure and assumptions of our green power market penetration model. Built on an Excel platform and incorporating separate assumptions for restructured and regulated green power markets, the model allows us to evaluate the potential impacts of green power demand on renewable energy supply and electricity-sector air emissions under various input scenarios. The input assumptions used for the two scenarios emphasized in this report - high- and low-growth are described in this chapter, as is the basic functioning of the model itself.

In Chapter 5, we provide results from our model runs and bound the possible impacts of green power demand over the 10-year forecast period. We first summarize results from the high- and low-growth scenarios, providing renewable energy capacity estimates (split between "new" and "existing" renewables) and air emissions reduction benefits on an aggregate and regional basis. We then describe and analyze several sensitivity cases. These sensitivity results are useful in understanding the most important factors that will affect the role and impact of green power demand on renewable energy supply. A particular emphasis is placed on analyzing the possible influence of a slowdown in the pace of electricity reform; such a slowdown, at least in the near term, now appears inevitable given events unfolding in California and other states.

Our analysis shows that the potential impacts of green power demand on renewable energy supply are highly uncertain at this time. Using our modeling results and early experience with green power markets as a backdrop, in Chapter 6, we offer a broader discussion of the factors that appear likely to drive the rate of growth in the green market. Factors discussed in this chapter include the pace of electricity reform, the nature of the market rules established at the onset of competition, consumer education, mandatory information disclosure, green power certification, renewable energy premiums, customer aggregation, large customer demand, renewable energy certificate trading, and public policy issues.

In Chapter 7, we conclude the report with brief summary remarks. 


\section{Review of Green Power Market Research and Marketing Experience}

Any forecast of future green power growth must be grounded in what is already known in terms of market research findings and early experience with green power marketing in the United States. Accordingly, here we summarize market research findings, describe market simulations and field studies, and review early results from green power programs in regulated and restructured markets. Our intent is not to provide an exhaustive set of findings, but simply to provide some context for the analysis presented later in this report.

\subsection{Market Research}

Even before renewable electricity was marketed as a differentiated product, years of market research documented that people claim they are willing to pay more for goods and services that protect and improve the environment. With the emergence of green power marketing, research has focused largely on consumer knowledge about renewable energy, awareness of the impacts of electricity generation and use, preferences for various energy resources, motivations for buying renewable energy, and willingness to pay more for green power.

The focus on willingness to pay more for green power is important not only for pricing green power options but also for gauging the potential size of the market, which is our focus in this paper. Based on nearly 20 years of opinion polling (more than 600 surveys), national probability samples show that $56 \%-$ $80 \%$ of American voters say they are willing to pay more for environmental protection and for renewable electricity (Farhar 1993, 1996). More recently, a review and synthesis of 14 surveys conducted in 12 utility service territories (1995-1997) found that majorities of 52\%-95\% of residential customers said they were willing to pay more on their electric bills for power from renewable sources (Farhar 1999).

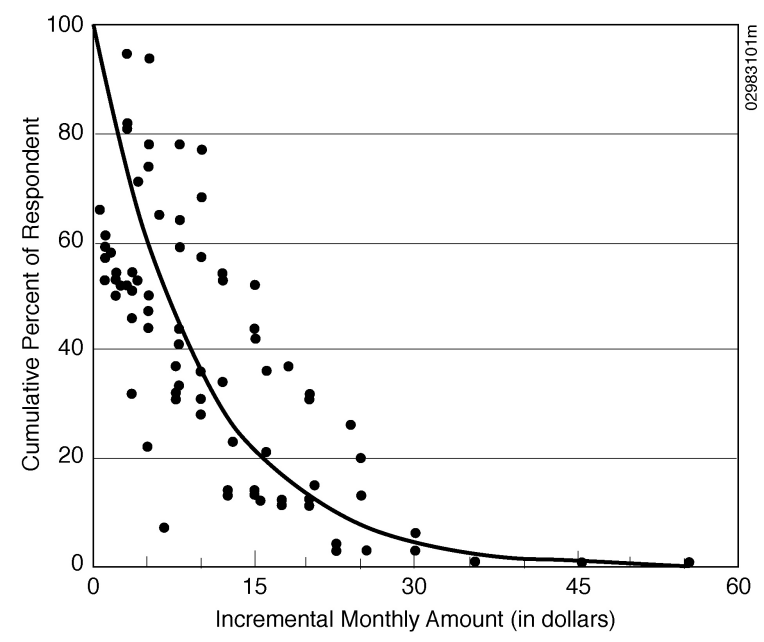

The National Renewable Energy Laboratory has integrated the responses to the 14 utility surveys to create an aggregated "willingness-to-pay curve" showing the percent of residential customers that indicate a willingness to pay for renewable energy at different premium payment levels. As might be expected, the size of the market is inversely related to the incremental monthly cost of renewable energy, as shown in Figure 1.

Similarly, when asked for opinions, $47 \%$ to $62 \%$ of non-residential customers indicate an interest in green power even if it costs more (Holt, et al. 2001).

Source: Farhar, B. (1999)

Figure 1. Aggregated Willingness to Pay Curve, Residential Customers 


\subsection{Market Simulations and Field Studies}

The market research data just summarized suggest a potentially large green power market, but opinion surveys of this type frequently overestimate response to actual product offers. Opinion surveys postulate a hypothetical situation not requiring action or the real commitment of money, for example, and often without specific product descriptions. The responses indicate positive attitudes towards environmental improvement through the use of renewable energy, but should not be viewed as an accurate indicator of potential market size. To better estimate actual response to a product offer, market simulations or field studies are frequently employed.

A few utilities have sponsored residential market simulations for green power. ${ }^{11}$ In these simulations, residential consumers are presented with an actual opportunity to purchase green power in a research setting (i.e., through telephone interviews, mail surveys, or laboratory experiments). Responses to the actual product offer can then be compared to the responses to a similar hypothetical offer to estimate the gap between hypothetical and actual willingness to pay for renewable energy. Because in field studies consumers are typically given thorough product information and their decisions are real, response to the offer may also provide a reasonable estimate of the ultimate penetration rate of green power. We are aware of four green power-related field studies for which results are publicly available, each of which is focused on residential demand. Overall, we believe that these market simulations provide a far better estimate of the ultimate potential of the green power market than do the opinion studies summarized earlier.

- Cornell University researchers conducted a telephone survey of a random sample of Buffalo-area residential customers of Niagara Mohawk Power Company. The utility's actual contribution program was described to these customers, and they were asked if they would like to enroll in the program at a cost of $\$ 6$ per month. Of those that completed the telephone survey, 20\% agreed to sign up. If those who did not complete the survey are assumed to be negative responses, the participation rate would fall to $16 \%$ (Poe, et al. 1997; Rose, et al. 1997).

- A market simulation study asked Public Service Company of Colorado customers who indicated a willingness to contribute to a voluntary renewables fund if they would like to receive a program registration card. Of the $75 \%$ that requested a program registration card, $10 \%$ actually returned the signed form indicating a true willingness to pay the cost of the program (Baugh, et al. 1995).

- Nearly 9\% of Wisconsin Public Service Company customers who were contacted both by telephone and then by mail actually registered to participate in the utility's green power program, while $4.7 \%$ of those that were contacted only by mail registered for the program (Byrnes, et al. 1999).

- A large sample of Madison Gas \& Electric (MG\&E) customers was the subject of a mailed field test involving the sale of wind power (Champ and Bishop 1998). As perhaps the most sophisticated of the field tests to date, and also the one that best approximates the types of products most typically offered by green power purveyors, this study contains telling results. Of those responding to the survey (the response rate averaged approximately $55 \%$ ), $47 \%$ agreed to pay a $\$ 2$ monthly cost, $35 \%$ a $\$ 4$ monthly cost, $23 \%$ an $\$ 8$ monthly cost, and $8 \%$ a $\$ 24$ monthly cost. ${ }^{12}$ Note that these responses were made to an actual offer. Concurrent responses to a hypothetical offer were $61 \%$ for a $\$ 2$ monthly cost, $58 \%$ for a $\$ 4$ monthly cost, $50 \%$ an $\$ 8$ monthly cost, and 31\% for a $\$ 24$ monthly cost. Response to the actual offers was therefore consistently lower than response to the hypothetical offers.

${ }^{11}$ To date, no market simulations have focused specifically on the non-residential sector.

${ }^{12}$ Note that this survey involved four different samples - one for each premium amount - and therefore the percentages do not add to $100 \%$. 
While the four field tests reach different conclusions on likely response, perhaps influenced by differences in the products offered and the different characteristics of the response populations, the Cornell and MG\&E studies indicate a possible response of $20 \%$ among residential households for modestly priced renewable products, while the other two studies suggest lower penetration rates. These results suggest that the more optimistic willingness-to-pay findings from opinion surveys should be tempered by results from field studies or market simulations involving actual consumer commitments. Nevertheless, significant numbers of customers may be willing and interested in buying green power.

\subsection{Green Power Market Experience}

Though the market simulation results presented above provide useful context for our analysis, it is also critical to understand early experience with actual product offers that exist outside of the researcher's laboratory. The actual market for green power is immature, characterized by low consumer awareness and understanding of renewable energy, information asymmetries, and varying levels of marketing. It is little wonder that actual results from this market differ substantially from the market research and simulation results presented above. Early experience with green power marketing, available from both regulated and restructured markets, must certainly be factored in when estimating market potential, and provides useful insight into the pace of market growth and factors hindering that growth. However, because of the nascent state of the green power market, these results provide only limited insights about the potential size of the market over the medium to long term.

In aggregate, considering all types of utility green pricing programs and all direct access markets (whether active or not), green power is today available to 40 million U.S. households, or nearly $40 \%$ of the nation's residents. Of these, more than 350,000 households, or approximately $1 \%$, have actually chosen to buy green power. However, these summary statistics mask considerable variation among different open access states and utility programs.

\section{Regulated Utility Markets}

Green power marketing began in the early- to mid-1990s with the advent of several utility green pricing programs. In these programs, utility ratepayers are given the opportunity to pay a premium tariff to their utility to help support the development of renewable electricity. Open electricity markets and retail competition are not necessary ingredients to this type of green power choice.

Green pricing programs are now offered in 29 states and in nearly every region of the United States with the exception of the Northeast, where the advent of retail competition has lessened utility interest in regulated green pricing programs.

For utility programs, market penetration frequently depends on program type. Utility programs are usually identified as:

- Contribution programs: Customers donate money to a fund for the future development of renewable resources.

- Capacity tariffs: Utilities charge a specific amount per unit of capacity, such as 100 watts, and customers decide how many units they want.

- Energy tariffs: Utilities charge either an extra cost per kWh or a fixed amount for a block of energy, such as $100 \mathrm{kWh}$, and customers decide how much they want to purchase.

Contribution programs and capacity tariffs, often targeted towards photovoltaics, serve useful and important market niches, but have generally not resulted in large additions of renewable energy capacity. 
Energy tariff programs have provided the vast majority of support for green power, and it is on these programs that we focus here.

As shown in Figure 2, the market penetration of energy tariff programs into the residential customer class ranges from just above zero to as much as $7.3 \%$, with a median penetration of $0.8 \%$. These programs earn average monthly revenue of from $\$ 1$ to $\$ 10$ per participant. Surprisingly, no apparent correlation has been found within this cost range between price and participation levels. Instead, participation seems to depend on a combination of utility motivation, level of promotional activity, marketing persistence, and, in some cases, demographics. Many utility green pricing programs tend to be constrained by customer awareness and weak utility marketing efforts, as well as by limited amounts of green power available for sale.

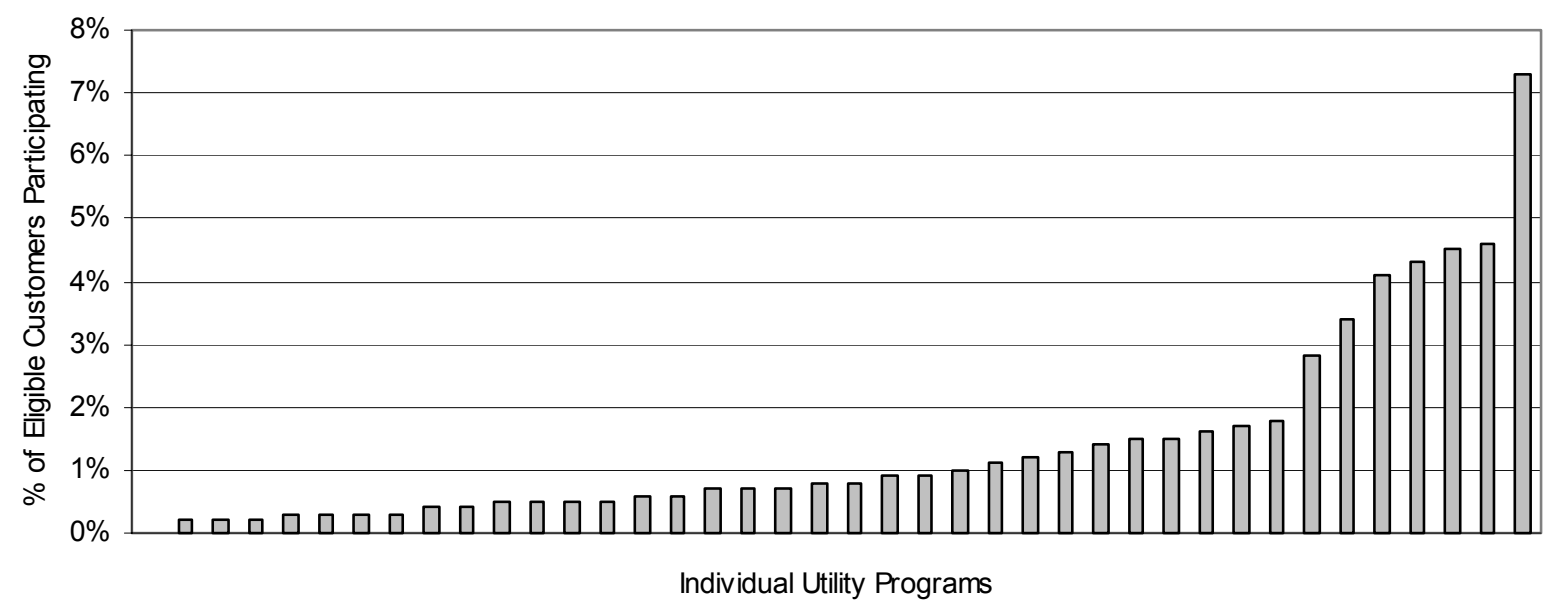

Figure 2. Residential Market Penetration for Utility Energy Tariff Programs

Based on utility experience to date, we conclude that residential market penetration of $1 \%$ can be attained within the first 2 years of product offering, with penetrations as high as $5 \%$ or more achievable with a focused, 2-year marketing effort. Because most utility products have only been available for 2 to 3 years, it is difficult to say whether a 5\% market penetration represents an upper limit for most utility programs or whether it is simply the highest penetration achieved so far. The field tests described previously suggest that market penetration could be higher still.

Other aspects of this utility experience that inform our assumptions for estimating the long-term potential for green power include the following:

- Product content - new renewables. Most of the utility green power products offered thus far consist of new renewable resources as opposed to already existing renewable resources.

- Product content - total renewables. Energy tariff products provide from $10 \%$ to $100 \%$ of a residential customer's total electricity needs. Programs that allow customers to choose how many units of renewable energy they want to buy account for the lower range of $10 \%$ to $20 \%$, but consumers often buy more than one unit. As a result, we estimate that, on average, renewable energy purchased through these programs generates $20 \%$ to $40 \%$ of an average residential participant's electricity use.

- Non-residential demand. On average, businesses and other non-residential customers account for about $25 \%$ of total green power sales in those utility programs that have made an effort to market to these customers.

- Total renewables supported. Utility programs are today responsible for supporting 110 megawatts (MW) of renewable capacity with another $170 \mathrm{MW}$ planned. 


\section{Restructured Markets}

More than 20 states have either opened their markets to retail competition - thereby allowing customers to select a new retail electricity provider - or have developed plans to move toward competition in the future. While the current electricity crisis in California and emerging problems in other states has slowed progress towards retail competition, customer choice of this nature holds the prospect of further encouraging the sale and purchase of green power products by new, independent green power retailers.

In those states that offer direct access today, the size and strength of the green power market depends to a large extent on the overall amount of customer switching taking place. Residential switching to new competitive suppliers in Rhode Island and Massachusetts, for example, has been nearly non-existent even though both states have been open to competition for 3 years. Consequently, there is little evidence of green power choice. On the other hand, California and Pennsylvania have seen modest switching and a relatively strong interest in green power, though increasing wholesale power costs have reduced competitive activity in Pennsylvania and severely curtailed such activity in California. Green power marketing in Connecticut, Maryland, New Jersey, Ohio, and Texas has just begun, with little data to report thus far.

The level of customer switching, in turn, is heavily influenced by the regulatory rules governing restructured markets. Some of the more important rules - discussed in further detail in Chapter 6 govern the level of default retail service pricing (relative to underlying wholesale market prices) and the treatment of incumbent utilities and their affiliates. For example, Rhode Island and Massachusetts have seen almost no residential switching because default retail service prices have generally been below wholesale prices since those markets opened in 1998, making it difficult for a competing marketer to both attract customers and earn a retail margin. And in New Jersey, the "wet signature" rule that was intended to protect consumers from "slamming" (i.e., being switched to a new supplier unknowingly) effectively outlawed enrollment over the Internet at the outset, thereby limiting power marketers that had developed their business strategies around this low-cost means of marketing and customer acquisition. Such rules, though often implemented with good intentions, can unwittingly delay retail competition in practice.

Green power market penetration in restructured markets has been very similar to the results of regulated green pricing programs. While the overall level of residential switching has been sluggish, green power products have generally captured a sizable segment of those customers who have switched. As of mid-tolate 2000, for example, approximately 670,000 residential customers, or $3.4 \%$ of all eligible direct access customers, had switched suppliers nationwide. More than one-third of those who had switched $(250,000$ or $1.2 \%$ of all eligible customers) were receiving green power (Wiser, et al. 2000). This $1.2 \%$ average response rate is similar to the median response of energy tariff-based green pricing programs. Experience in the two most active competitive green power markets is as follows:

- In California, about $1.7 \%$ of residential customers were being served by a competitive marketer at the end of 2000, and nearly all of these customers were purchasing green power, in part because of a state subsidy for renewable energy purchases. A substantial number of small commercial customers were being similarly served. With the dramatic run-up in wholesale power costs, however, many retail marketers have been forced to turn back customers to the default utility providers and retail competition has effectively ceased. As of April 2001, for example, residential customers being served by a competitive marketer had fallen to $0.9 \%$. When and how retail competition and green power choice will return to California is not yet known.

- In Pennsylvania, about $10 \%$ of residential customers had selected an alternative supplier by early 2001 because the default price has been high enough for consumers to save money by switching, and there have been a variety of retail suppliers and products in the market. Without any significant renewable energy subsidy, an estimated $15 \%$ to $20 \%$ of those who have switched $(1.5 \%$ to $2 \%$ of the 
total eligible to choose) have chosen green power (Swezey and Bird 2000; Wiser, et al. 2000). Increasing wholesale power prices, while not as dramatic or damaging as in California, have recently begun to slow competitive activity in the state.

Other aspects of restructured markets that affect our modeling assumptions include the following:

- Product content - new renewables. New renewables constitute a relatively small percentage of the overall content of green power products currently, with marketers often opting for lower cost preexisting resources. Nonetheless, some marketers attempt to differentiate their products by including new resources. In addition, the Green-e certification program ${ }^{13}$ carries a requirement for a minimum of 5\% new renewables, and this percentage will increase over time.

- Product content - total renewables. The fraction of total renewables in residential green power products has averaged approximately $50 \%$. In fact, Green-e product certification requires $50 \%$ renewables, but not all products are certified, and in some states the renewables content has often been less than $50 \%$.

- Non-residential demand. The Center for Resource Solutions reported that $38 \%$ of the demand for Green-e certified products in 1999 came from non-residential customers - small and large commercial, industrial, agricultural, and municipal. Nearly 28,000 non-residential customers purchased Green-e certified power nationwide in that year. ${ }^{14}$

- Total renewables supported. Renewable energy capacity supported by consumer demand for green power in restructured markets is difficult to estimate, but through late 2000, perhaps 280 average megawatts (aMW) ${ }^{15}$ may be claimed (Wiser, et al. 2000). The National Renewable Energy Laboratory, meanwhile, estimates that more than $130 \mathrm{MW}$ of $\boldsymbol{n e w}$ renewable generation had been supported by competitive marketers through June 2001 (Bird and Swezey, 2001).

\section{Summary}

Despite the high expectations raised by market research and even market simulations, the reality of both regulated and restructured markets is that green power market penetration is still modest at less than $2 \%$ overall. Many factors may influence this result, including lack of awareness, unfavorable market conditions, customer inertia, and lackluster promotional efforts. Because these are nascent markets, however, this early market experience may not be representative of the long-run market potential. Indeed, results from field studies requiring actual commitments to purchase green power suggest that market penetrations of $20 \%$ or more are achievable.

\footnotetext{
${ }^{13}$ Green-e is a renewable energy certification program established by the non-profit Center for Resource Solutions. The program certifies green power products in restructured markets that meet minimum resource and environmental standards.

${ }^{14}$ Center for Resource Solutions, "Commercial Customers Making Green Power Their Business.” Press Release, September 20, 2000.

${ }^{15}$ An average megawatt is a measure of capacity assuming that renewable generating facilities operate $100 \%$ of the time (i.e., have a 100\% capacity factor), and therefore yields a conservative estimate of the true capacity supported by the green market. Because renewable power plants have varying capacity factors, we have adopted the use of average megawatts as our convention for reporting capacity.
} 


\section{CHAPTER 3}

\section{Market Diffusion: Experience from Other Industries}

Forecasting future demand for green power based exclusively on market simulations and early results from regulated and restructured electricity markets is probably unwise. Instead, based on extensive experience with a myriad of other products, market penetration typically follows the standard " $S$ " curve of product diffusion. This diffusion curve is characterized by slow, initial market entry followed by rapid growth before tapering off at higher market penetration levels, as shown in Figure 3. Product diffusion is a process in which a product passes through life cycle stages (product development, growth, maturity, and decline) as the nature of the product or service use changes. The rate of product diffusion depends on many factors, including anticipated product cost reductions, consumer awareness and understanding, and removal of market barriers.

To examine the evidence for longer-term market penetration, we investigated the effect of consumer choice through case studies of several other industries. None of these industry case studies is a perfect analogy to green power, but they do provide a sense of what is possible over a longer period of time than the few years that green power has been offered to consumers.

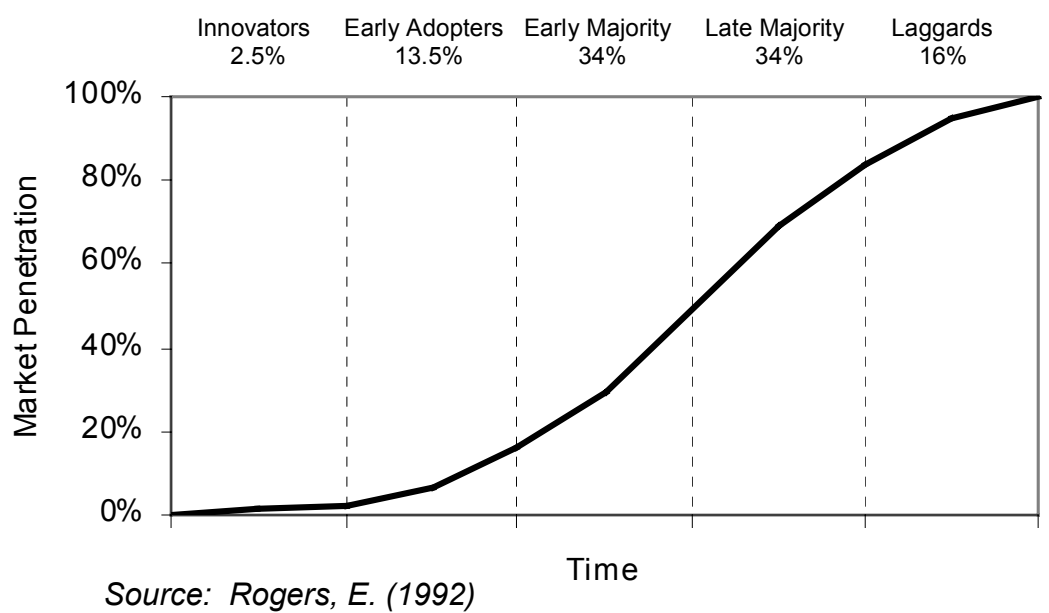

In this chapter, we first summarize case

Figure 3. The Product Diffusion Curve studies of customer switching in newly restructured markets, focusing on the long distance telecommunications and natural gas markets. By examining the rate and drivers of customer switching in these two markets, we hope to gain some insight into the likely nature and pace of customer switching in restructured electricity markets. We then highlight experience with the marketing of other green consumer products, services, and behaviors, including bottled water, organic foods, socially responsible investing, sustainable forestry products, charitable contributions to environmental organizations, recycling, and compact fluorescent light bulbs. Demand for many of these products, services, and behaviors has increased over the last 20 years, and an exploration of market trends can offer useful context for understanding the barriers to green power growth and the drivers for consumer demand. We conclude this chapter with a review of lessons learned from the case studies, and their implications for the green power market. We note to the reader that this chapter, while providing useful context, is by no means required reading for understanding later chapters of this report that describe our modeling assumptions and results. 


\subsection{Newly Restructured Markets}

\section{Telecommunications}

Though perhaps more analogous to the entire competitive electricity market than to the green power subset of that market, the switch from regulated to competitive long-distance telephone service following the 1984 breakup of AT\&T nevertheless provides perspective on the current state of and future prospects for nascent retail electricity markets. Such perspective is valuable because the growth of the competitive green power market will be influenced by the growth of the competitive electricity market as a whole.

While there are many different indicators of telecommunications market share (e.g., access minutes, terminating minutes, and revenues), the purest measure of customer switching is the number of lines presubscribed to each long-distance carrier. The Federal Communications Commission (FCC) first reported data on pre-subscribed lines in the fourth quarter of 1987 (3 years into the competitive market) and stopped reporting the data following the Telecommunications Act of 1996. An examination of various other indicators of market share, however, reveals a common trend among all of them — a steady erosion of AT\&T's dominance. The following graph shows three measures of AT\&T's market share, based on:

- the number of pre-subscribed lines for all customer classes,

- toll revenues (to illustrate the entire period), and

- residential access lines (for which data only exists from 1995 on).

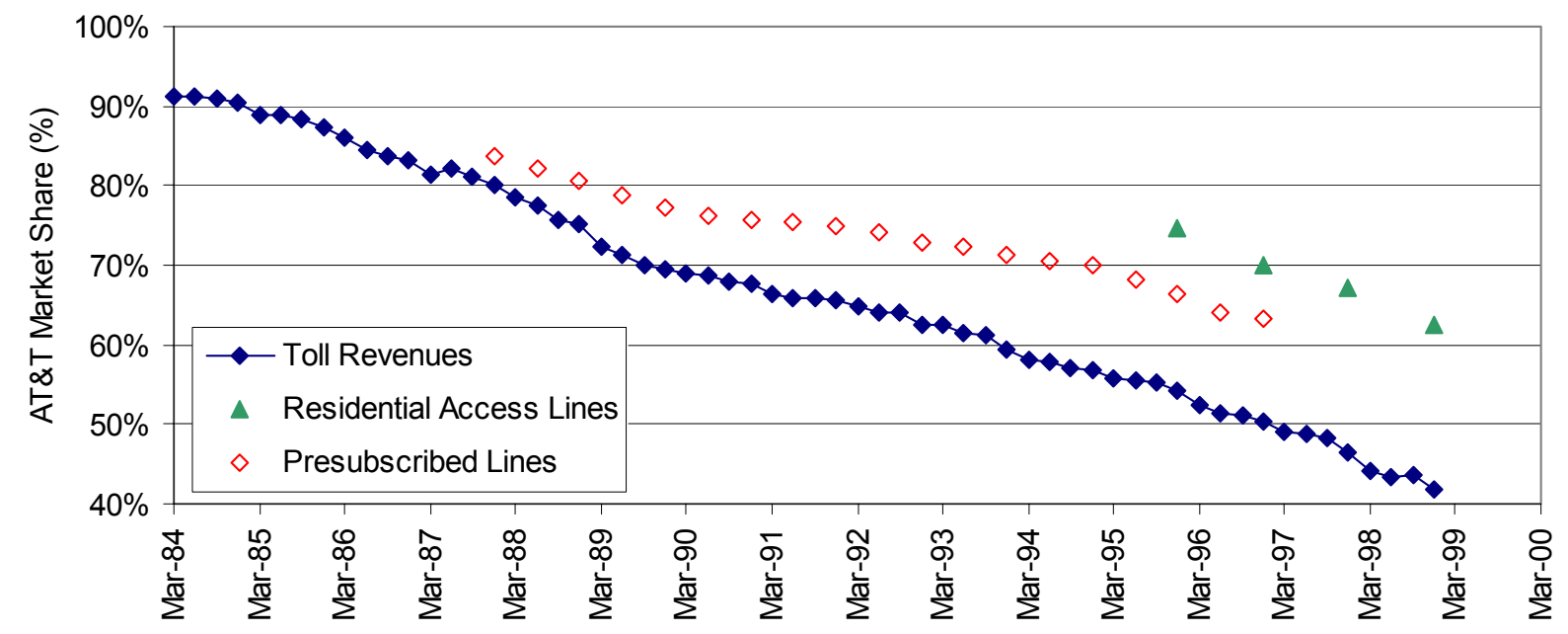

Source: Zolnierek, et al. (1999)

\section{Figure 4. Indicators of AT\&T Market Share}

A number of insights can be drawn from the data. Perhaps most importantly, it can clearly take some time for competitors to make inroads into a market historically dominated by a single monopoly seller; it has taken more than 15 years for competitors to capture roughly half of AT\&T's market share. Moreover, gains in competitor market share have not come in great leaps and bounds, but rather in more measured increases ranging between $2 \%$ and $4 \%$ annually. One might expect the competitive electricity market to follow a similar pattern of slow and steady growth.

In fact, there is some reason to believe that competitive electricity markets may grow even more slowly than the long distance market. The impetus for the breakup of AT\&T is commonly attributed to a burgeoning wave of technological innovation that AT\&T's historically tight grip on the market had long 
discouraged, as well as strong pent-up demand for the new services enabled by such innovation. Whether or not a similar situation exists in the electricity industry has been the subject of some debate (Spinner 1999), and recent events in California and other states further call into question the near-term viability and competitiveness of retail markets for electricity service.

Finally, AT\&T has lost a larger share of the commercial long distance market than it has of the residential market. This has also been and may continue to be the pattern in the electricity industry, where industrial and commercial customer switching has dwarfed residential switching to date.

\section{Natural Gas}

Arguably, the restructuring of the natural gas industry provides a closer analog to the electricity industry than does the opening of the long-distance telephone market. Natural gas industry restructuring, though in effect since the mid-1980s, has in many cases only recently made overtures to residential customers.

Given the recent introduction of retail competition in that sector and the various stages of restructuring in different states, only point estimates of customer switching are readily available, some of which are summarized in Table $1 .{ }^{16}$

Table 1. Estimates of Customer Switching

\begin{tabular}{|l|c|c|c|c|c|c|c|c|c|c|c|}
\hline & NJ & NY & NM & WV & OH & MA & MD & IL & WI & VA & IN \\
\hline Residential Switching & $3.0 \%$ & $1.8 \%$ & $0.0 \%$ & $0.0 \%$ & $33.3 \%$ & $20.5 \%$ & $21.7 \%$ & $9.1 \%$ & $7.5 \%$ & $52.5 \%$ & $2.3 \%$ \\
\hline$\%$ Eligible to Switch & $100 \%$ & $100 \%$ & $100 \%$ & $100 \%$ & $56 \%$ & $7 \%$ & $82 \%$ & $8 \%$ & $2 \%$ & $10 \%$ & $40 \%$ \\
\hline Commercial Switching & N/A & $12.3 \%$ & $0.3 \%$ & $5.1 \%$ & $38.0 \%$ & $17.0 \%$ & N/A & $12.8 \%$ & $4.9 \%$ & $20.0 \%$ & $8.5 \%$ \\
\hline$\%$ Eligible to Switch & N/A & $100 \%$ & $100 \%$ & $100 \%$ & $56 \%$ & N/A & $100 \%$ & $65 \%$ & $22 \%$ & $9 \%$ & $35 \%$ \\
\hline
\end{tabular}

Source: U.S. Energy Information Administration, http://www.eia.doe.gov/oil_gas/natural gas/restructure/restructure.html

Perhaps the single most important lesson that can be drawn from these data is that customer switching rates in newly competitive markets can be highly variable. Natural gas switching rates - both residential and commercial - clearly vary widely from state to state. Among residential customers alone, switching rates have ranged from zero to as high as $33 \%$.

A deeper understanding of the natural gas market also shows that regulatory rules and the potential abuse of market power are powerful influences on the degree of competition and on customer switching. In particular, since natural gas is largely an undifferentiated product (like electricity), the size of the potential cost savings to be gained from switching is generally considered to be the primary driver for this market (Bierman, et al. 1999). Regulatory rules and market power can considerably affect the scope of these savings (Schuler 1997).

In the four states that have mandated statewide open access (NJ, NM, NY, and WV), for example, the pace of change is often dictated by the incumbent local distribution companies (LDCs) and, as a result, vibrant markets have been slow to develop and barriers to competition remain. The principal barrier

${ }^{16}$ In addition to the states covered in the table, Georgia and Nebraska require that eligible customers choose their supplier (i.e., 100\% participation), and Montana does not report participation rates. The Pennsylvania PUC estimates that $30 \%$ of the 855,000 residential and small commercial customers that are eligible to switch in pilot programs have done so. In California, only 3\%-4\% of residential and small commercial gas customers have switched in the choice programs offered by three LDCs (U.S. Energy Information Administration, www.eia.doe.gov/oil_gas/natural_gas/restructure/ restructure.html). 
seems to be the ability of LDCs in some states to arrange their unbundled tariffs in ways that limit others from obtaining cost-effective transportation access to the LDCs' pipelines. ${ }^{17}$ West Virginia, meanwhile, exemplifies another barrier: customers wishing to switch gas suppliers must first install metering equipment or pay standby charges (U.S. Energy Information Administration, www.eia.doe.gov/oil_gas/natural_gas/restructure/state/wv.html).

\section{2 “Green” Product Markets}

While the telecommunications and natural gas industries provide broad perspective on customer switching trends in restructured markets, they tell us little about the emerging market segment of "green" customers that might opt to pay a premium for a green power product. The following cases therefore provide more specific data on markets that are shaped by some of the same customer motivations and barriers as the green power market.

\section{Bottled Water}

A growing number of Americans are choosing to drink water for its health benefits, but are also shunning tap water for reasons of taste or quality. Concern over tap water quality is no longer limited to toxins making their way into the public water supply; increasingly, chlorine and other chemical "purifiers" added to tap water are also being called into question. As a result, bottled water and home water filtration systems are gaining widespread popularity. Availability and convenience are also important drivers of the bottled water market: tap water (along with a container in which to carry it) is often not as readily available as bottled water.

Domestic non-sparkling water, which makes up more than $90 \%$ of the bottled water market in the United States, has been the fastest growing segment of the entire beverage industry over the past few years (BottledWaterWeb, www.bottledwaterweb.com). In 1997, for example, sales of bottled water grew by 9.5\%, compared to $2.5 \%$ for fruit beverages, $0.8 \%$ for beer, and $3.3 \%$ for soft drinks. Bottled water sales rose another $9.8 \%$ in 1998 and $12.1 \%$ in 1999 , bringing the annual sales of the domestic bottled water market to more than $\$ 5$ billion, according to Beverage Marketing Corp., a New York-based consulting firm. In February 2000, The Coca Cola Company (which entered the bottled water market in April 1999) projected that the bottled water market would surpass the $\$ 72$ billion soft drink market by 2010 (WaterBank, www.waterbank.com).

In terms of market penetration, bottled water consumption has grown from $1.8 \%$ of all beverage consumption in the United States (including tap water) in 1981 to 8.1\% in 1999 (BottledWaterWeb, www.bottledwaterweb.com; Beverage Marketing, www.beveragemarketing.com). The following graph depicts the steady market growth of bottled water.

${ }^{17}$ Since a competing marketer can only compete on the commodity price, and must pay to use the LDC's pipelines, an LDC can discourage competition by setting its unbundled gas commodity price artificially low (e.g., below the wholesale market), and making up the difference in the transportation tariff. Charges of such anticompetitive pricing have surfaced in New York, and may also be a factor in New Mexico (which has been fully open, with little activity, since the late 1980s). 


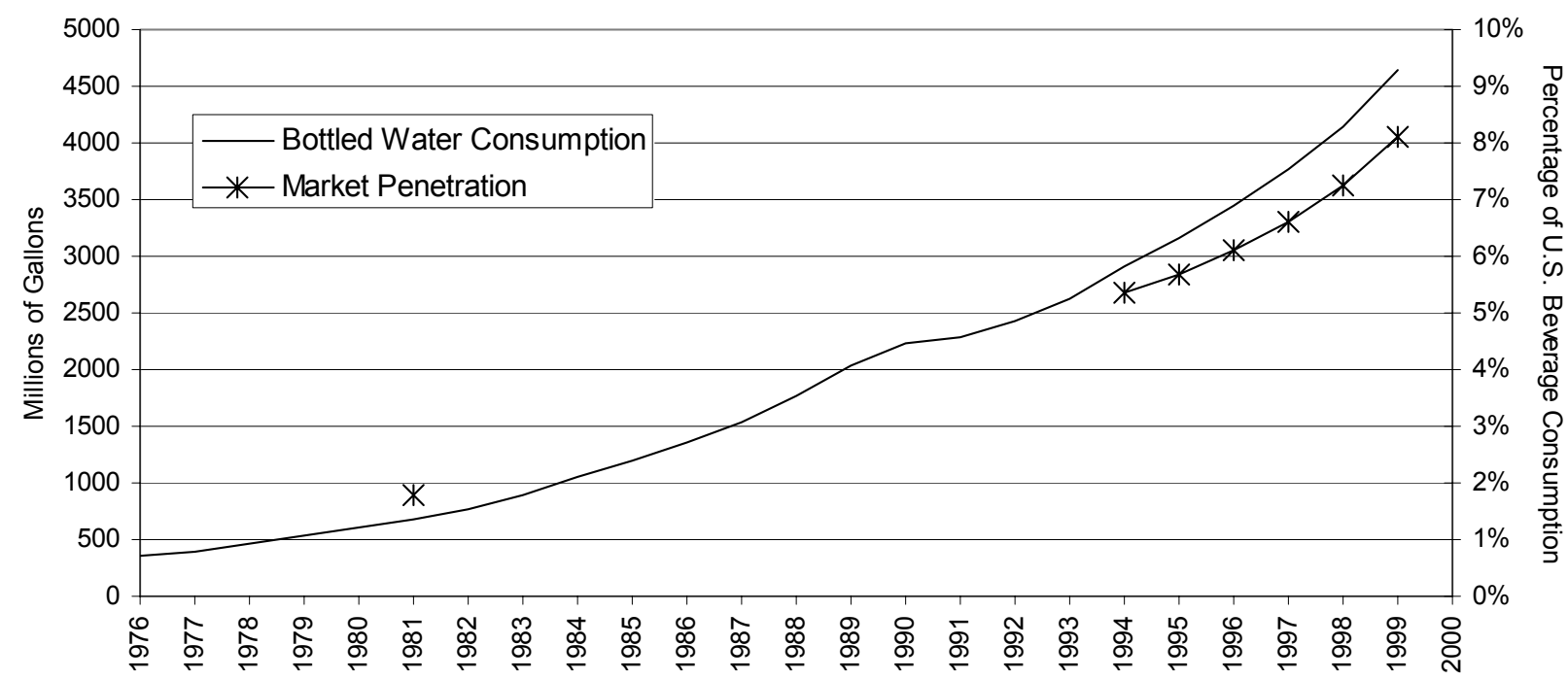

Source: International Bottled Water Association, www.bottledwater.org; Beverage Marketing, www.beveragemarketing.com

\section{Figure 5. Bottled Water in the United States}

These data confirm the insights raised earlier about the length of time needed between product introduction and market response; nearly 20 years passed before bottled water consumption increased from $2 \%$ to $8 \%$ penetration in the overall beverage market. The steady and sizable growth of this market over time also reflects increasing awareness of the health benefits of water consumption, as well as increasing concerns over tap water quality. Bottled water, however, fills this niche by offering (perceived) private health and convenience benefits to the consumer. This situation stands in sharp contrast to the green power market, where the environmental benefits are more public and less tangible in nature. Marketing a green power product may therefore present additional challenges and result in slower growth than the case of bottled water suggests.

\section{Organic Foods}

The market for organic food products is potentially more relevant to the green power market than is bottled water; organic foods provide not only private health benefits when consumed but also public environmental benefits when grown in accordance with the practices of sustainable organic agriculture. The degree of relevance is unclear, however, because market research indicates that most organic food purchasers do so primarily for the perceived health benefits of eating organically grown food (i.e., the private benefit) rather than to support the long-term environmental benefits associated with organic farming (i.e., the public benefit) (The Hartman Report 1996).

Despite these apparent differences, many of the early frustrations confronting green power marketers are paralleled in the market for organically grown foods. Just as a majority of consumers state a preference for renewable energy, so too are a majority of consumers concerned about pesticide use and its effects on their health and the environment. To date, however, both markets have had difficulty translating this apparent widespread support into actual market results. In 1999, for instance, organic food sales represented about $1.5 \%$ of all food sales in the United States - a penetration rate similar to that achieved by green power marketers.

But like the bottled water market, the market for organic foods has grown steadily over time from a small base (see Figure 6). Moreover, recent growth has been quite rapid, with annual growth rates exceeding $20 \%$ during the 1990 s. In response, the number of acres in organic production, though still only $0.2 \%$ of all farmland, nearly tripled between 1991 and 1997, while conventional farm acreage declined over this 
period (Greene 2000; Klonsky and Tourte 1998). Strong growth is expected to continue, with the total size of the market estimated to double from current levels to more than $\$ 13$ billion by 2003 (Organic Trade Association, www.ota.com).

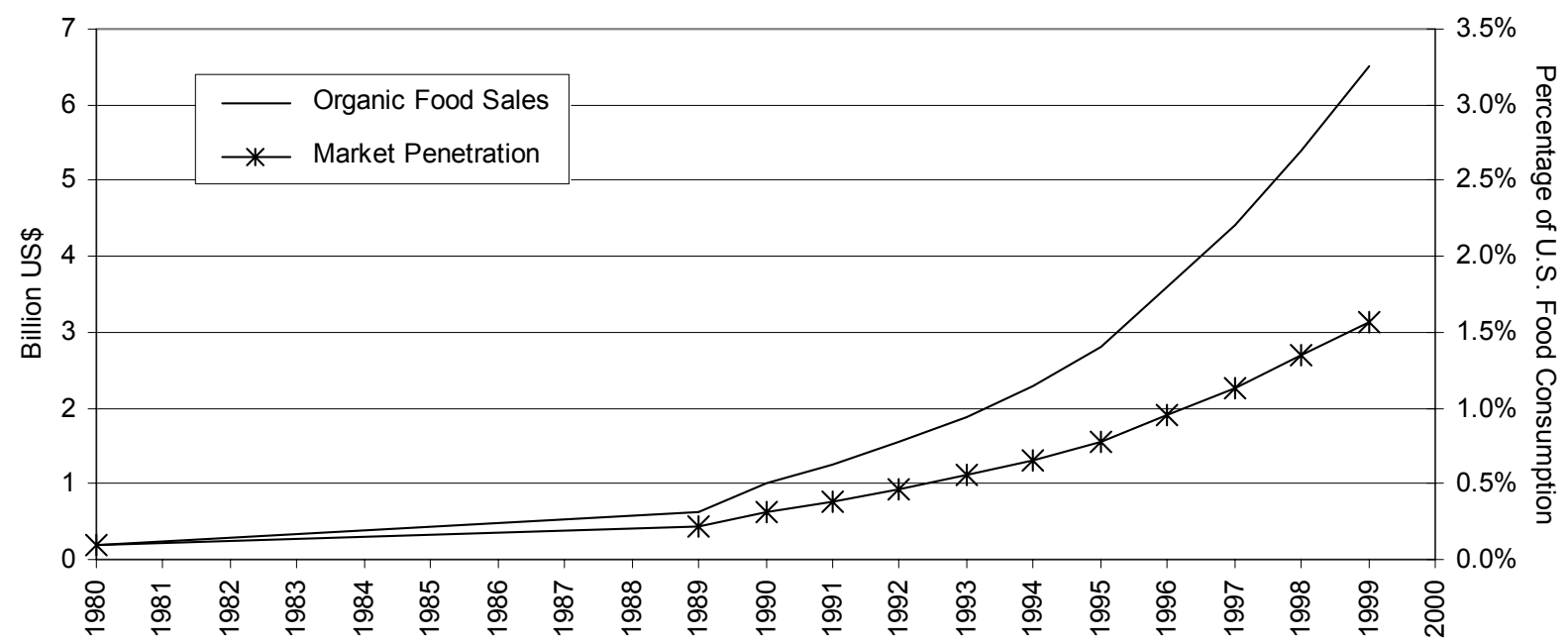

Source: Organic Trade Association and the USDA

\section{Figure 6. Organic Food Sales in the United States}

The trend in organic food sales is similar to that seen in both the long-distance and bottled water markets, and reinforces the lesson that markets take time to develop. This may be particularly true for the green power market, which, unlike organic foods and bottled water, offers far fewer direct private benefits to motivate consumers into action.

\section{Socially Responsible Investing}

Socially responsible investing (SRI) has exhibited similar growth to bottled water and organic food products, but may be more relevant to the green power market because SRI, relative to conventional investing, is presumably undertaken for social rather than private gain.

In the United States alone, more than $\$ 2$ trillion - more than $\$ 1$ out of every $\$ 8$ placed under professional investment management - is invested according to some form of social criteria (Social Investment Forum, www.socialinvest.org). The social causes targeted by these funds vary widely, from anti-tobacco to community development to pro-environment. ${ }^{18}$ There is also great disparity in the rigor of the social "screens" to which these funds are subjected. As a result, it is difficult to draw definitive conclusions about the overall composition or quality of the market, not unlike different "shades" of green power. Nonetheless, as shown in Figure 7, SRI, as a whole, has grown considerably over the last 15 years, with assets increasing an average of $30 \%$ annually. Of course, some portion of this impressive increase in both assets and market penetration is performance-related: most social screens tend to favor technology or "new economy" stocks, which outperformed the broader market during the $1990 \mathrm{~s}^{19}$

${ }^{18}$ According to the Social Investment Forum, the most common screens are tobacco $(96 \%$ of screened assets), gambling (86\%), alcohol (83\%), weapons (81\%), and the environment $(79 \%)$. Other screens include human rights (43\%), labor (38\%), birth control/abortion (23\%), and animal welfare (15\%).

${ }^{19}$ Moreover, this outperformance, which was highly touted by SRI enthusiasts, may have created another source of demand for SRI - those seeking higher returns (i.e., conventional investors with private motives). 


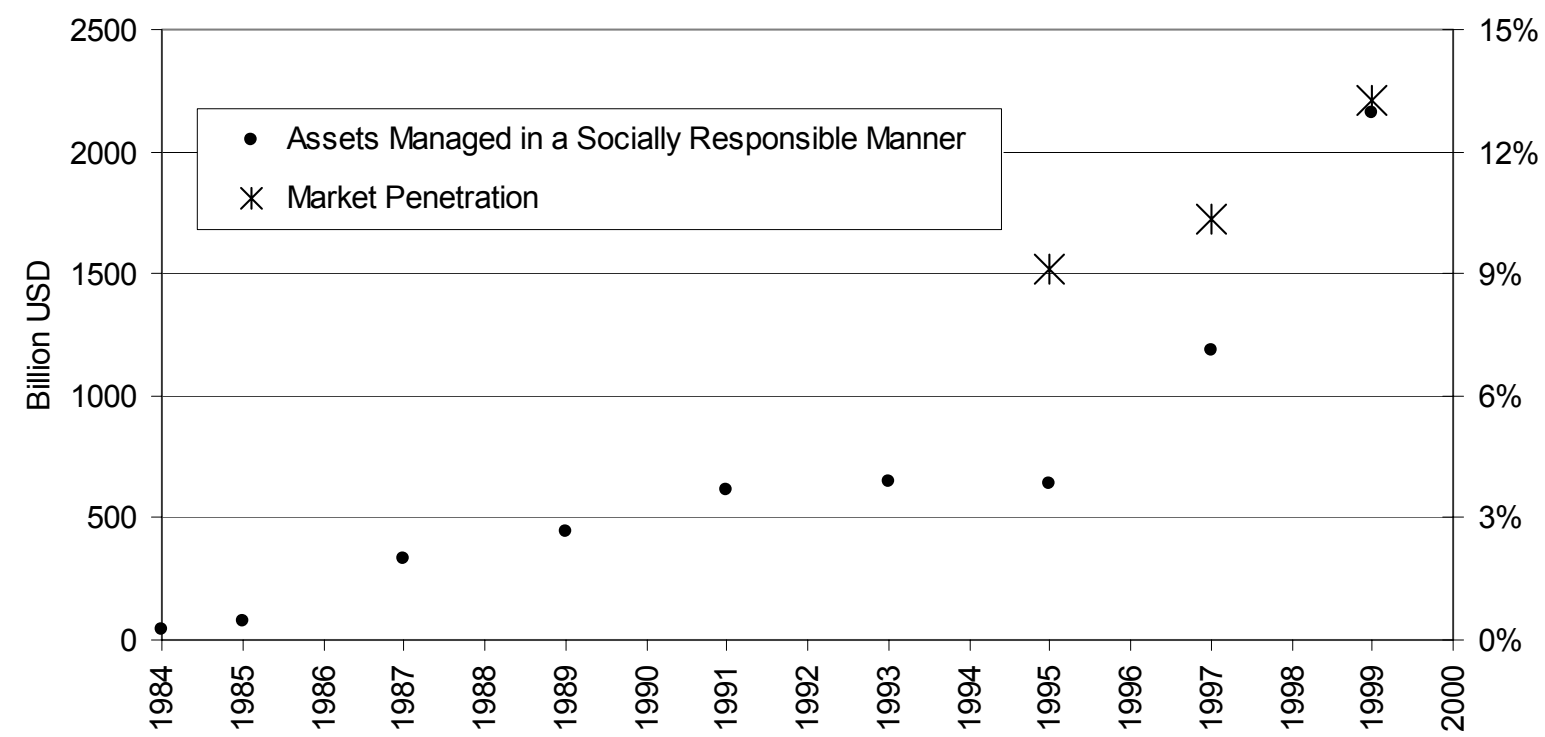

Source: Social Investment Forum (www.socialinvest.org) and Brill et al. 1999

\section{Figure 7. Assets Managed in A Socially Responsible Manner}

The popularity of SRI at 13\% market penetration, relative to that of the emerging green power market at less than $2 \%$ market penetration, in most cases, may be attributable to several factors. First, SRI has a long history compared to the few years that green power markets have existed, and encompasses many different social causes beyond clean energy. Second, people may be more willing to invest in socially responsible products and services than they are willing to pay extra for them. This theory is consistent with research that shows that people are often more willing to forego a monetary gain than they are to suffer an equally sized loss (or to pay an equally sized premium). ${ }^{20}$ Third, the rise in popularity of mutual funds during the 1990s — and the corresponding surge in the number of socially responsible mutual funds - may have greatly reduced the transaction costs associated with SRI. This final characteristic suggests that an enabling product structure that reduces transaction costs can facilitate market success.

\section{Sustainable Forestry}

The market for sustainable forest products is somewhat different from the other markets we have examined because it has been driven more by intermediaries than by end-use consumers per se, and retail demand has not yet caught up with supply. Instead, commercial producers and consumers from all stages of the forest products supply chain have banded together with environmental organizations into "buyers groups" such as the Certified Forest Products Council ${ }^{21}$ in the United States. These buyers groups are beginning to demand sustainably managed timber for four main reasons:

- to ensure their moral "right to operate" by working towards a sustainable supply of lumber without degrading the land,

${ }^{20}$ See, for example, Electric Power Research Institute, Green Power Guidelines: Assessing Residential Market Segments, TR-109192-V1, 1997. Whether SRI yields a lower return on investment than unrestricted investing has been a contentious subject.

${ }^{21}$ Business members include: The Home Depot, Habitat for Humanity, Gibson Guitar Company, World Wildlife Fund, Patagonia, Taunton Press, Wickes Lumber and many others. See The Certified Forest Products Council Web site (http://www.certifiedwood.org) for a complete list. 
- to improve market share and competitive advantage by tapping into latent consumer demand, as well as by offering wood that is often of a higher quality than that coming from unsustainably managed forests,

- to improve their reputation with consumers, employees, and local communities, and

- to manage risk, which can result in lower costs of capital and insurance (Crossley and Points 1998).

This unusual, intermediary-driven market structure results in the supply of certified wood far outstripping specific consumer demand for sustainably forested products, leaving the majority of certified timber to be sold as an undifferentiated product. ${ }^{22}$ As a result of this glut, most suppliers do not receive a premium for their certified products (Jenkins and Smith 1999).

Given a particularly complicated chain of custody and the lack of strong consumer demand, it is perhaps not surprising that there are very little publicly available data on certified wood products. ForestWorld (www.ForestWorld.com) states that market penetration of certified forest products has reached 5\% in parts of Western Europe and 1\% in the United States (representing approximately $\$ 500$ million worth of products in the United States). More often, however, data are reported by number of hectares of certified forest.

Forests cover about $28 \%$ of the earth's land area (4.1 billion hectares of forest), and two-thirds of all forests (2.8 billion hectares) are commercially timbered. As of May 2000, 17.8 million hectares, or just $0.6 \%$ of all commercial forestland, were certified under Forest Stewardship Council (FSC) guidelines. ${ }^{23}$ Even with rapid growth in the past 3 years (see Figure 8), the market for sustainable forestry products is clearly just getting off the ground. In fact, third-party certification based on environmental criteria has existed only since 1993, when the FSC was founded and began accrediting professional certification firms.

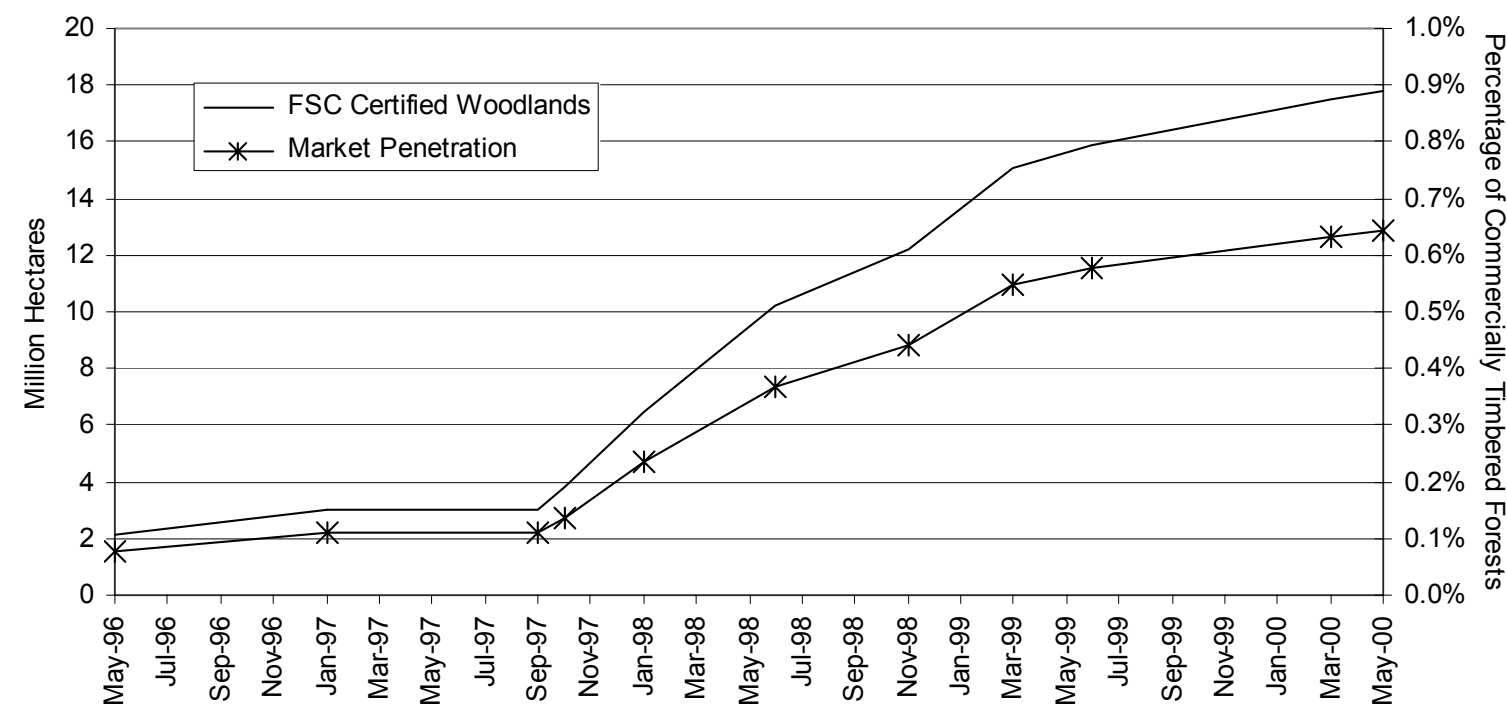

Source: Forest Stewardship Council; ForestWorld, www.forestworld.com; Jenkins and Smith 1999

Figure 8. FSC-Certified Woodlands (Worldwide)

\footnotetext{
${ }^{22}$ For example, Collins Pine — one of the leaders in sustainable forestry — markets less than $5 \%$ of their production as certified, even though at least 50\% qualifies (Jenkins and Smith 1999).

${ }^{23} \mathrm{FSC}$ is the most widely accepted forestry certification program.
} 
The market for sustainable forestry products is perhaps more like the green power market than any other market we have examined. Like green power, the benefits of sustainable forestry are primarily public in nature, and are largely invisible to the consumer. This creates a critical need for certification and verification mechanisms, which become complex in the face of complicated chains of custody facing each market. Both markets are also just beginning to grow.

Both markets have and will likely continue to benefit from the involvement of environmental groups. The World Wildlife Fund (WWF), for example, has taken the lead in organizing and working with buyers groups to expand markets for certified products and increase the amount of certified forestland. The WWF's "Forests for Life" campaign achieved its goal of having 10 million hectares FSC certified by the end of 1998, six months early, and subsequently extended its goal to 25 million hectares by the end of 2001. The World Bank and the WWF have also announced an alliance to ensure the certification of 200 million hectares by 2005 .

One potentially critical distinction between these two markets, however, is the perceived source of demand. To date, green power marketers have focused most heavily on the residential sector, pursuing commercial customers in a more ad hoc fashion. The sustainable forestry market, on the other hand, has been built around commercial "buyers groups" representing substantial purchasing power. It is too early to assess the relative merits of each approach, but one example suggests that the "buyers groups" model may serve as an important growth channel for the green power market: the World Resources Institute and Business for Social Responsibility announced in August 2000 that 11 of the nation's largest industrial electricity users would commit to buying green power from 1,000 MW of new capacity over the next 10 years.

\section{Charitable Contributions to Environmental Organizations}

In some ways, above-market payments for green power can be thought of as a charitable contribution. In this light, we turned to Giving USA, the annual summary of charitable contributions published by the American Association of Fundraising Counsel (AAFRC, www.aafrc.org), to see what could be learned from the trend in contributions to socially minded or environmental organizations. Figure 9 shows contributions received by environmental/wildlife and public/society benefit organizations, ${ }^{24}$ as well as the "market" penetration as a percentage of all charitable donations, dating back to $1968 .{ }^{25}$

${ }^{24}$ AAFRC defines environmental/wildlife organizations as those involved in environmental quality or protection, as well as animal-related activities (such as zoos, humane societies, and wildlife protection organizations). Public/society benefit organizations include those involved in civil rights or liberties, community improvement and development, philanthropy and volunteerism, science, social science, and public affairs.

${ }^{25}$ The environmental/wildlife category did not exist prior to 1987 , though some environmental organizations were included in the public/society benefit category. 


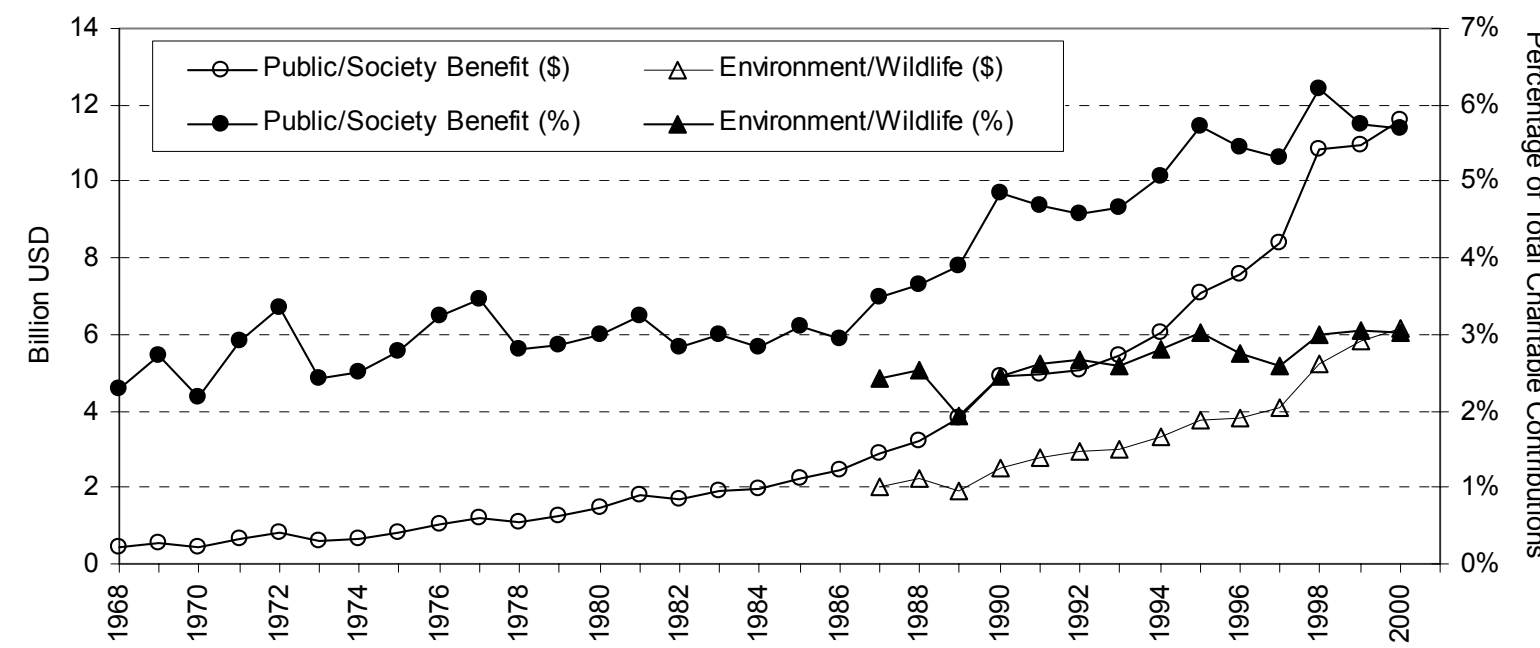

Source: American Association of Fundraising Counsel, www.aafrc.org

Figure 9. Contributions Received and Market Penetration by Type of Recipient Organization

Environmental/wildlife organizations received almost $\$ 6.2$ billion, or 3\% of total charitable contributions, in 2000. The public/society benefit category, which encompasses a broader array of organizations, fared about twice as well, receiving almost $\$ 11.6$ billion or $6 \%$ of all contributions in 2000 . Both categories have been gaining market share throughout the 1990s, presumably reflecting increasing concern for social well being and the environment. ${ }^{26}$

These data do not indicate what percentage of Americans are members of or contribute to such organizations, a potentially useful data point for our purposes. Other data show that, as a percentage of population, membership in large, nationwide environmental organizations varies from state to state, bounded at the high end by Vermont with $2 \%$ and at the low end by Mississippi with $0.25 \%$ (Mazur and Welch 1999). ${ }^{27}$ Another estimate placed membership in national environmental organizations at roughly $3 \%$ of the U.S. population in 1990 (Farhar 1993).

At $3 \%$ or less, the percentage of the American population directly involved with environmental organizations remains small and, without data showing trends in membership over time, it is difficult to draw additional insights. Perhaps the most interesting and concrete observation to be made based on these data is that among those who make charitable contributions, the environment seems to have gained favor over time.

\section{Recycling}

Recycling is perhaps the only market analog we have examined that demonstrates a close connection between general environmental attitudes and individual behavior, and shows that a majority of consumers are in some instances willing to recycle to help protect the environment. Of course, such behavior may not be entirely voluntary or reflect concern for the environment; bottle redemption programs and mandatory recycling in some areas create additional incentives. Nonetheless, it is clear that a large percentage of the American populace has embraced recycling. Several surveys from the early 1990s, for

\footnotetext{
${ }^{26}$ While the source of contributions to each individual category is unknown, individuals were accountable for $75 \%$ of all charitable contributions monitored by Giving USA in 2000.

${ }^{27}$ Organizations sampled include the Sierra Club, National Wildlife Federation, Greenpeace, Natural Resources Defense Council, Nature Conservancy, Rainforest Action Network, and World Wildlife Fund.
} 
example, indicate that $60 \%$ to $70 \%$ of the public recycles, up from about $50 \% 10$ years earlier (Farhar 1993).

One of the major factors in the success of recycling has no doubt been the proliferation of curbside recycling programs, which greatly reduce the transaction costs and increase the convenience of recycling. In 1996, for example, $51 \%$ of the U.S. population had access to curbside recycling programs. This insight further supports the importance of public policy in facilitating the development of green markets.

Other evidence on the growth and size of the recycling market comes from the percentage of municipal solid waste that has been recovered over time through recycling and composting, as shown in Figure 10. In 1996 more than $25 \%$ of municipal solid waste was recovered through recycling and composting, up from 10\% in 1980 (Franklin Associates, Ltd. 1998).

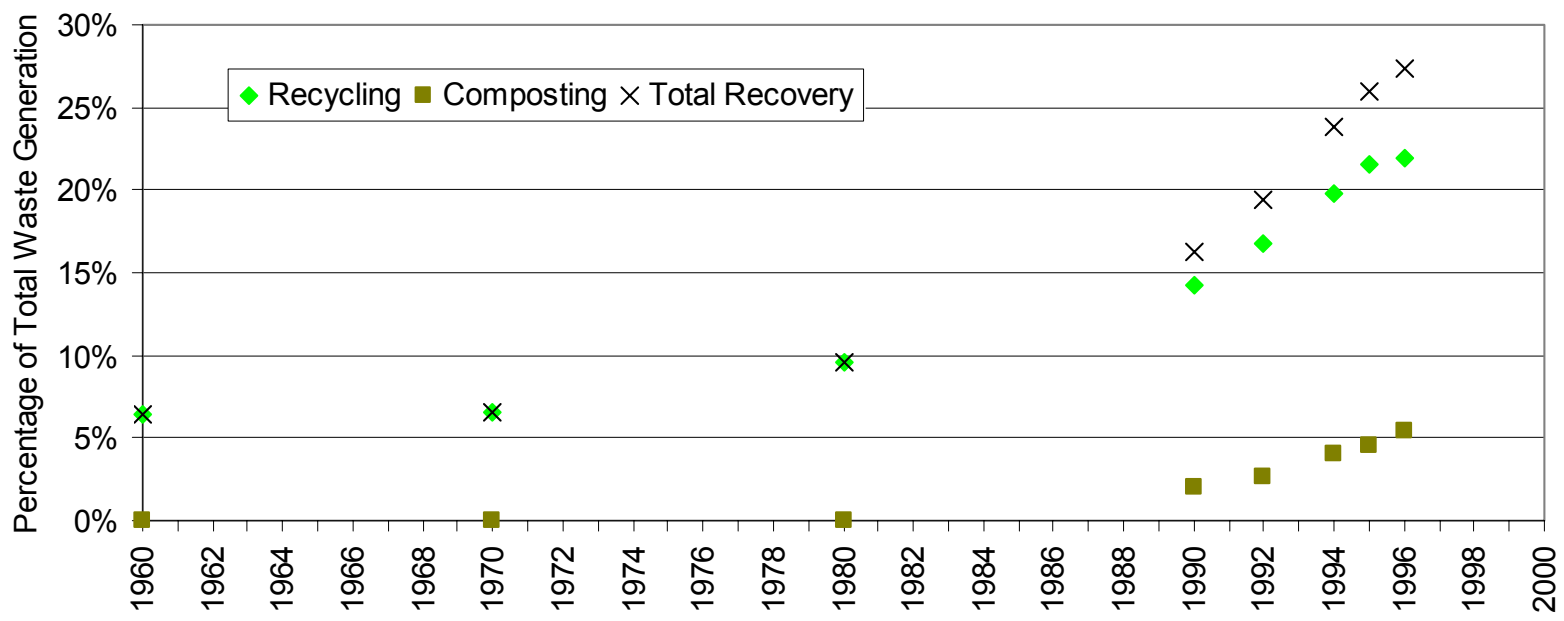

Source: Franklin Associates, Ltd. 1998

Figure 10. Recovery of Municipal Solid Waste

Like many of the other "green" markets explored in this chapter, recycling has caught on slowly over the years and posted impressive gains in the 1990s. As recycling behavior is largely consistent with indications of general environmental attitudes, the growth path reflected in the figure above may conceivably indicate a plausible high-growth scenario for green power (though, once again, policies and mandates have contributed to the success of recycling).

\section{Compact Fluorescent Light Bulbs}

Like green power, compact fluorescent light bulbs (CFLs) generate significant environmental benefits through the use of innovative technology. CFLs do have an important marketing advantage over green power, however, because they save consumers money over the long run by outpacing incandescent light bulbs in both energy efficiency and useful life.

Even with this economic incentive, consumers have been slow to adopt CFLs. The Energy Information Administration's 1993 Residential Energy Consumption Survey reported that 8.9\% of households use CFLs, though not very effectively-less than $1 \%$ of all lights used 15 minutes or more each day were CFLs. Another survey from the early 1990s found that among CFL-owning households, CFLs are used in fewer than two rooms on average (Weiner and Campbell 1992). More recently, the U.S. Department of Energy has estimated the national market penetration of CFLs to be 3\%, though this number may be 
increasing as regional energy crises have led to the sale or distribution of large numbers of CFLs, particularly in California. ${ }^{28}$

There are a number of factors potentially contributing to the slow adoption rate of CFLs over the past 15 years. Poor light quality in some early CFLs, for example, may have tarnished the reputation of CFLs in general. CFLs still tend to be bulkier than incandescent bulbs, and do not fit in all fixtures. Furthermore, until recently, no CFLs on the market could be used in fixtures controlled by dimmer switches.

Significantly, higher first costs than incandescent bulbs may discourage the purchase of CFLs, despite potential life-cycle savings. And, distribution channels may also play a role - CFLs are not readily available in most supermarkets and drug stores, where $39 \%$ of consumers reportedly buy their light bulbs (Voorsatz, et al. 1997). ${ }^{29}$ Similar barriers may face the introduction of green power.

The case of CFLs also illustrates the importance of customer education. Surveys suggest that a full $45 \%$ of consumers do not understand the unit "Watt" (a measure of energy consumption), perhaps confusing it with "lumens" (a measure of light output) - a misconception that could create bias against low-wattage CFLs. The average consumer may also not comprehend how a \$10 CFL can ultimately cost less than a $50 \notin$ incandescent bulb. Lighting salespeople are often similarly under-educated on the benefits of CFLs and so are unable to provide sound advice to their customers (Weiner and Campbell 1992).

\subsection{Implications}

As already noted, none of the preceding cases represent perfect analogs to the green power market. Likewise, the type and quality of data we were able to compile for each case is often less than ideal. Nonetheless, the cases do provide some insight about the maturation of restructured markets in general, and other green markets specifically.

Perhaps the most relevant implication for our 10-year forecast of green power penetration is that it often takes some time for markets to build. AT\&T did not lose half of its market share in just a few years; it happened gradually at a pace of a few percent each year over 15 years. Similarly, bottled water has reached $8 \%$ market penetration, socially responsible investing $13 \%$, and recycling $25 \%$, each over an extended time period often lasting 10 to 20 years from product launch to significant market penetration.

Furthermore, the general pattern of green market development has almost without exception been one of steady but restrained growth in the early years, followed by acceleration more recently. Though it is perhaps too early to conclude that green product markets, in general, are beginning to move out of the product development phase and into the growth phase of the product diffusion S-curve, recent market action at least hints at the beginnings of such a transition. This pattern implies that our forecast of green power penetration should start out low and grow steadily over a period of time that will most likely exceed our 10-year forecast horizon.

Finally, despite following similar growth paths, actual market penetration rates vary widely among the cases, and have been influenced by a number of factors:

- Regulation. Regulatory rules encouraged new entry into the long distance telephone market, for example, by regulating AT\&T more stringently than its competitors. Some incumbent natural gas

${ }^{28}$ Taking advantage of $\$ 3$ instant rebates from the state's investor-owned utilities, Californians purchased more than 120,000 CFLs in the last week of March 2001, and Pacific Gas and Electric expects to sell as many as 2 million CFLs this year.

${ }^{29}$ Conversely, CFLs are often most available in specialty lighting stores, where only $1 \%$ of consumers go to purchase light bulbs. 
utilities, on the other hand, have been allowed to effectively thwart retail choice through anticompetitive transportation pricing.

- Transaction costs. Socially responsible investing and recycling have each benefited from a reduction in transaction costs made possible by the rise of mutual funds and the spread of curbside recycling programs, respectively.

- Media attention and crisis. Bottled water and organic foods have each capitalized on growing consumer fear - often punctuated by widely publicized crisis events - of the deteriorating quality of conventional alternatives. Similarly, the California electricity crisis has focused attention on the need for energy conservation, boosting CFL sales.

- Education. Almost every market has faced at least some need to educate consumers, but perhaps nowhere is this need more pronounced than in the market for CFLs.

- Environmental partnerships. A partnership between environmental groups and the forest products industry has led the charge for sustainable forestry practices.

- Public policy. Recycling has achieved high participation rates, in part, because of community programs and redemption mandates, and market penetration of CFLs has benefited more recently from crisis-induced consumer purchase incentives.

Without a doubt, the growth of the green power market will also be influenced by most, if not all, of these variables. As discussed in Chapter 6, market rules and consumer education appear to be particularly important. Predicting the degree - or even the direction — of each variable's influence is of course extremely challenging. 


\section{Model Overview and Key Assumptions}

The primary aim of this study is to quantify the potential size and impact of the green power market in the United States during the next 10 years. To perform this analysis, we developed a model of national green power demand. Incorporating separate assumptions for restructured and regulated green power markets, the model allows us to simulate the potential impacts of green power demand on renewable energy supply and electricity-sector air pollutant emissions under various scenarios. Specifically, we develop two scenarios - high- and low-growth - to bound what we consider to be a range of plausible growth paths for the green power market. We also use several sensitivity runs to explore the impacts of model input assumptions on model output and to improve our understanding of the most important factors that will affect the pace and impact of green power demand. To account for recent events in electricity markets in California and the rest of the country, we pay particular attention to sensitivity cases in which the pace of electricity restructuring slows considerably.

\subsection{Basic Model Structure}

Figure 11 depicts the basic functions of our model of green power market growth. At the core of the model is a state-level forecast of residential electricity load through 2020, split into investor and publicly owned utilities ("IOU" and "Public"). To this load base, the model sequentially applies 20-year assumptions for the following variables:

- The Pace of Restructuring sets the date that a state opens its electricity market to competition.

- Access to Green Power is: (1) the percentage of regulated load that has access to a green pricing tariff, or (2) the percentage of load in restructured markets that has access to a competitive green power product.

- Residential Green Power Market Penetration is the percentage of load with access to green power that actually chooses to purchase green power. Non-residential green power demand is modeled as a percentage adder to the residential green power load. ${ }^{30}$

- Green Power Product Content is the percentage of existing renewables (renewable capacity built prior to the availability of green power choice), new renewables (renewable capacity built after the beginning of green power choice), and total renewables in a green power product.

- Current Average Emissions Profiles for each state come from the EPA's E-GRID2000 database (with data from 1998). Assuming that only new renewable generation provides incremental emissions reduction benefits, the model uses these emissions profiles to estimate the reduction in emissions attributable to green power markets.

Our assumptions, described in more detail later, differ by regulated and restructured markets, and in some cases also by IOU and public utilities. ${ }^{31}$ Though the model accepts assumptions and can produce forecasts

${ }^{30}$ This overly simplistic methodology was adopted as a modeling tool to circumvent limitations in the data at hand, and is not intended to imply a causal relationship between residential and non-residential demand for green power. That said, as the residential sector becomes increasingly educated about and begins to demand green power, it is plausible that there could be a spillover in demand to the non-residential sector, as businesses themselves become educated and respond to their customers' values (a persuasive case could also be made for a demand spillover in the opposite direction, from the non-residential to the residential sector).

${ }^{31}$ For example, assumptions about the pace of restructuring differ between IOU and public utility load, reflecting the assumption that public utilities - which are normally exempt from restructuring orders - will be slower to open their markets to competition. 
to 20 years, we report data only through 2010 , as any forecast beyond even a few years is fraught with uncertainty. Other specific features of the model are described in Text Box 1.

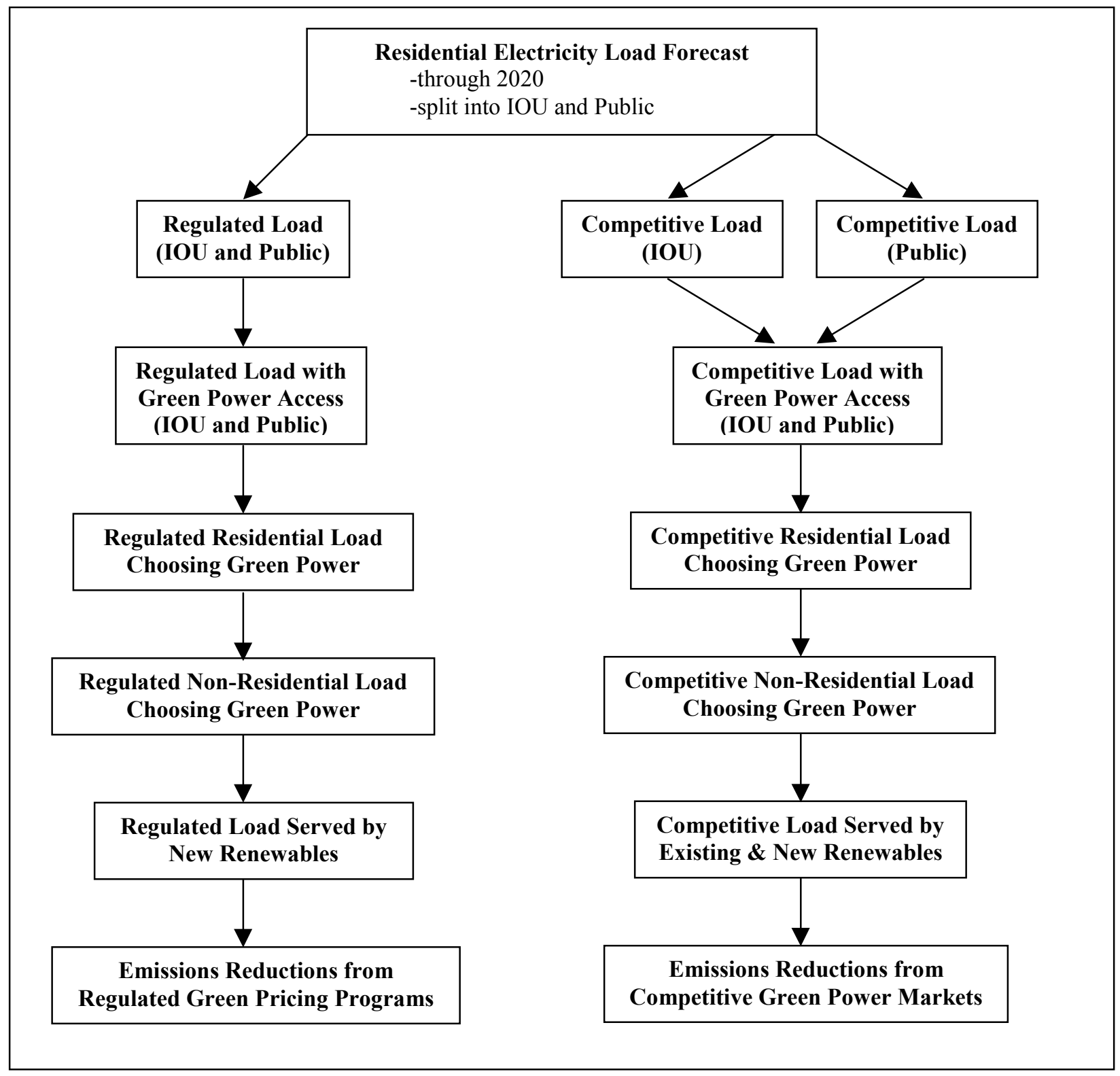

Figure 11. Flow Chart of Green Power Growth Model 


\section{LOAD BASE FORECAST}

The Energy Information Administration (EIA) does not forecast residential electricity loads by state, so we constructed our own state-level forecast through 2020, using other EIA data. Our forecast begins with actual 1998 residential electricity sales by state, split into investor- and publicly owned utilities. To this state-level base we apply regional growth rates from the EIA's Annual Energy Outlook 2000 forecast of residential electricity consumption by census region. Thus, the load of each state (and every IOU and public utility) within a region grows at the regional growth rate.

\section{TWENTY-YEAR ASSUMPTIONS}

Any projection of future green power demand should begin with conditions as they currently exist. Although our assumptions are for the most part national, meaning that they apply equally to each state, the year 2000 starting point for each state reflects year 2000 market conditions within that state with respect to green power. Accordingly, our national assumptions are applied to each state either "as is" in states with no current green power market or on an incremental basis in states that already have a green power track record. In other words, in those states where green power has made inroads and data on access to green power, market penetration, and product content are available (or can be accurately estimated), we use such data as the starting point for our forecasts. We then apply our assumptions by adding the change in assumptions from one year to the next to the starting value.

\section{TRANSITIONING FROM REGULATED TO COMPETITIVE MARKETS}

States that have set a firm restructuring date either legislatively or by other means are assumed to open their markets to competition on that date in the high case and 2 years after that in the low growth case. States that have not yet set a date to open their markets are subjectively assigned a restructuring timetable.

As a state opens to competition, competitive market assumptions take over from regulated market assumptions. Green power gains made in regulated markets, however, are not discarded. Our model assumes that those who had participated in regulated utility green pricing programs will, within a reasonably short period, choose a competitive green power provider, and that any renewable generation built to serve a regulated green pricing program will also serve green power products in a competitive market. Thus, the model preserves all gains made in regulated markets, essentially freezing them at the time of restructuring.

Finally, our 20-year assumptions for competitive markets are referenced to the inception date of open markets (e.g., "by the second year of open markets, we expect green power market penetration to reach $\mathrm{x} \%$ ") instead of the year 2000, and therefore our assumptions apply to different calendar years for different states, depending on when each state restructures its electricity markets. Regulated markets do not share this peculiarity, and so our assumptions for regulated markets do follow the calendar (e.g., "year 1" is 2001).

\section{OTHER SPECIFICS}

Various caps are employed throughout the model. One cap ensures that our assumptions do not increase beyond $100 \%$. Another ensures that our forecast of access to green power in regulated markets never falls below a state's year 2000 starting point (unless our assumptions decrease), and never grows above the national maximum forecast for regulated green pricing access over the entire forecast period.

The model is conservative in its treatment of access to green power in both competitive and regulated markets. Specifically, each year's new incremental load with access to green power reverts to year-1 assumptions about green power market penetration. For example, even if a competitive market has been open for 5 years, any new load gaining access to green power in year 5 will only achieve the green power market penetration rate assumption from year 1 . This mechanism essentially treats all incremental access to green power as if it were a new market starting from scratch. While such conservatism may be justified with respect to assumptions about green power market penetration, it is arguably less so with respect to product content assumptions. Thus, this mechanism was not employed for product content; any incremental load choosing green power in year 5 will receive year-5 product content.

\section{Text Box 1. Model Features}




\subsection{Scenario Analysis Approach}

Though all forecasts embody uncertainty, forecasting the future of an immature market such as green power proves particularly challenging. Consider the following:

- The nature and pace of electricity reform remains highly uncertain.

- The incentive for utilities to offer and market successful green pricing programs is variable and may change with time.

- Consumer understanding of energy issues in general, and renewable energy issues in particular, is low at present but may increase over time.

- Consumer willingness to act on environmental beliefs is not well known.

- The future cost differential between renewable electricity and traditional alternatives is unclear.

Given these considerable uncertainties, our analysis does not attempt to derive a single point estimate for future green power growth. Instead, we develop two scenarios - high- and low-growth - to bound what we consider to be a range of plausible growth paths for the green power market. There is no probability attached to either scenario or the range of possibilities that lie between. More extreme cases could be imagined. $^{32}$

As illustrated by the specific assumptions described in the next section, the high-growth scenario is intended to be aggressive, with sizable green power demand growth and steadily improving green power product content (e.g., the percentage of renewable energy contained in green power products increases). For such a growth pattern to develop, several general market characteristics might be required:

- restructuring proceeds with little delay,

- market rules in restructured markets are conducive to competition and customer switching is high,

- consumer understanding and acceptance of green power shows significant growth, and

- the premium spread between the cost of renewable and competing generation technologies continues to narrow, because of ongoing reductions in the cost of renewable energy technologies, the continued or enhanced availability of renewable energy tax credits or financial incentives, or increases in fuel (i.e., natural gas) costs for conventional generators.

The low-growth scenario, on the other hand, is intended to represent a far less aggressive case, with more limited growth in customer switching and lower quality product content (e.g., green power products contain less renewable energy). While even more conservative low-growth scenarios could be plausibly created, this case may be qualitatively characterized by a scenario in which:

- the introduction of restructured markets and utility green pricing programs is delayed,

- market rules in restructured markets are far less conducive to competitive suppliers and customer switching than under the high-growth scenario,

- consumer understanding and acceptance of green power grows only slowly, and

- the premium spread between the cost of renewable and competing generation technologies does not narrow appreciably.

${ }^{32}$ For example, on the low end, one could imagine a scenario where the fallout from California's electricity crisis completely halts the move toward restructuring in other states and greatly reduces access to green power (see our "restructuring meltdown" sensitivity scenario). On the high end, increasing recognition of the "non-green" value of renewable energy - e.g., its ability to function as a fuel price hedge - could become a strong driver of green power demand, above and beyond what we have modeled. 
In addition to the high- and low-growth scenarios, we constructed four other scenarios designed to test the sensitivity of our model to assumptions about product content, green power market penetration, and the fallout from California's electricity crisis (which could slow or even halt the pace of restructuring and limit consumer access to green power products). The specific assumptions behind our low- and highgrowth scenarios are described in more detail in the next section, while our sensitivity scenarios are more fully described in section 5.5.

\subsection{Model Assumptions}

The model requires assumptions for each of the variables defined in Section 4.1 under both the low- and high-growth scenarios, as well as the sensitivity scenarios. In developing these input assumptions, described in detail here, we began with what we already know about green power availability, customer response, and product content and how these variables have changed in the past. Table 2 summarizes the current state of these variables in both regulated and restructured green power markets.

Results from market simulations and field studies (showing 10\% to $20 \%$ residential market penetration) and our review of the case studies from other industries, meanwhile, influenced our longer-term assumptions. Nonetheless, we acknowledge that ultimately our assumptions are derived largely from our own professional judgments.

Table 3 summarizes the assumptions made in the low- and high-growth scenarios, while the text below provides additional detail on the nature of the assumptions and their source, first for regulated markets and then for restructured markets. Within each market type, and for each variable in the model, we first describe general market conditions in 2000 (i.e., the starting point), followed by the high-growth assumptions, and lastly the low-growth assumptions.

Table 2. Summary of Actual Market Experience To Date

\begin{tabular}{|c|c|c|}
\hline Variable & Market & Actual Market Experience To Date \\
\hline \multirow{3}{*}{$\begin{array}{c}\text { Pace of } \\
\text { Restructuring } \\
\text { (IOUs) }\end{array}$} & $\begin{array}{l}\text { States that } \\
\text { are already } \\
\text { open }\end{array}$ & $\sim 25 \%$ of nationwide residential load (13 states) \\
\hline & $\begin{array}{l}\text { States with } \\
\text { "firm" dates }\end{array}$ & $\sim 25 \%$ of nationwide residential load (8 states) \\
\hline & $\begin{array}{l}\text { States without } \\
\text { dates }\end{array}$ & $\sim 50 \%$ of nationwide residential load (29 states) \\
\hline $\begin{array}{c}\text { Pace of } \\
\text { Restructuring } \\
\text { (Public) }\end{array}$ & All states & $\begin{array}{l}\sim 0 \% \text { of nationwide residential load (to date, few publicly owned utilities have } \\
\text { opted to open their markets to competition) }\end{array}$ \\
\hline \multirow{2}{*}{$\begin{array}{l}\text { Access to } \\
\text { Green Power }\end{array}$} & Regulated & $\begin{array}{l}\text { IOU: } \sim 22 \% \text { of residential load } \\
\text { Public: } \sim 19 \% \text { of residential load }\end{array}$ \\
\hline & Restructured & $\begin{array}{l}\text { IOU: }>90 \% \text { of IOU load in has access to green power } \\
\text { Public: few public utilities are open to competition }\end{array}$ \\
\hline \multirow{2}{*}{$\begin{array}{c}\text { Green Power } \\
\text { Market } \\
\text { Penetration }\end{array}$} & Regulated & $\begin{array}{l}\text { Residential: }<1 \% \text { to } 7.4 \%(0.8 \% \text { median) of load with access to green power } \\
\text { Non-Residential: } 20 \% \text { of residential demand in many, but not all, markets }\end{array}$ \\
\hline & Restructured & $\begin{array}{l}\text { Residential: } 1.6 \% \text { (PA) to } 1.9 \% \text { (CA at height of market); CA is } \sim 1 \% \text { now } \\
\text { Non-Residential: } 20 \% \text { (PA) to } 100 \% \text { (CA at height of market) }\end{array}$ \\
\hline \multirow{2}{*}{$\begin{array}{c}\text { Green Power } \\
\text { Product } \\
\text { Content }\end{array}$} & Regulated & $\begin{array}{l}\% \text { existing renewables: } \sim 0 \% \text { of energy-based products on average } \\
\% \text { new renewables: } \sim 30 \% \text { of energy-based products on average }\end{array}$ \\
\hline & Restructured & $\begin{array}{l}\text { \% existing renewables: } 17.5 \%(\mathrm{PA}) \text { to } 95 \%(\mathrm{CA}) \text { of product } \\
\% \text { new renewables: } 2 \%(\mathrm{PA}) \text { to } 5 \%(\mathrm{CA}) \text { of product }\end{array}$ \\
\hline
\end{tabular}


Table 3. Summary of Model Assumptions (ranges are over 10 years, unless otherwise noted)*

\begin{tabular}{|c|c|c|c|}
\hline Variable & Market & Low-Growth Scenario & High-Growth Scenario \\
\hline \multirow{3}{*}{$\begin{array}{c}\text { Pace of } \\
\text { Restructuring } \\
\text { (IOUs) }\end{array}$} & $\begin{array}{c}\text { States that } \\
\text { are already } \\
\text { open }\end{array}$ & Remain open to competition & Remain open to competition \\
\hline & $\begin{array}{l}\text { States with } \\
\text { "firm" dates** }\end{array}$ & Retail choice delayed for 2 years & Retail choice occurs on schedule \\
\hline & $\begin{array}{l}\text { States without } \\
\text { dates** }\end{array}$ & $\begin{array}{l}\text { Fast states: } 25 \%(2004) \text { to } 100 \%(2008) \\
\text { Slow states: } 5 \%(2004) \text { to } 20 \%(2010)\end{array}$ & $\begin{array}{l}\text { Fast states: } 50 \%(2004) \text { to } 100 \%(2005) \\
\text { Slow states: } 20 \%(2004) \text { to } 100 \%(2008)\end{array}$ \\
\hline $\begin{array}{c}\text { Pace of } \\
\text { Restructuring } \\
\text { (Public) }\end{array}$ & All states & $\begin{array}{l}0.5 \% \text { (starting in } 3^{\text {rd }} \text { year after IOUs } \\
\text { open) to } 4 \% \text { in } 10^{\text {th }} \text { year }\end{array}$ & $\begin{array}{l}2.5 \% \text { (starting in } 3^{\text {rd }} \text { year after IOUs } \\
\text { open) to } 20 \% \text { in } 10^{\text {th }} \text { year }\end{array}$ \\
\hline \multirow{2}{*}{$\begin{array}{l}\text { Access to } \\
\text { Green Power }\end{array}$} & Regulated & $\begin{array}{l}\text { IOU: } 5 \% \text { to } 27.5 \% \text {, incremental } \\
\text { Public: } 5 \% \text { to } 27.5 \% \text {, incremental }\end{array}$ & $\begin{array}{l}\text { IOU: } 10 \% \text { to } 55 \% \text {, incremental } \\
\text { Public: } 10 \% \text { to } 55 \% \text {, incremental }\end{array}$ \\
\hline & Restructured & $\begin{array}{l}\text { IOU: constant } 100 \% \text { of open markets } \\
\text { Public: constant } 100 \% \text { of open markets }\end{array}$ & $\begin{array}{l}\text { IOU: constant } 100 \% \text { of open markets } \\
\text { Public: constant } 100 \% \text { of open markets }\end{array}$ \\
\hline \multirow{2}{*}{$\begin{array}{c}\text { Green Power } \\
\text { Market } \\
\text { Penetration }\end{array}$} & Regulated & $\begin{array}{l}\text { Residential: } 0.25 \% \text { to } 2.5 \% \\
\text { Non-Residential: constant } 10 \% \text { of Res }\end{array}$ & $\begin{array}{l}\text { Residential: } 0.75 \% \text { to } 7.50 \% \\
\text { Non-Residential: constant } 25 \% \text { of Res }\end{array}$ \\
\hline & Restructured & $\begin{array}{l}\text { Residential: } 0.25 \% \text { to } 2.5 \% \\
\text { Non-Residential: constant } 10 \% \text { of Res }\end{array}$ & $\begin{array}{l}\text { Residential: } 1 \% \text { to } 10 \% \\
\text { Non-Residential: constant } 25 \% \text { of Res }\end{array}$ \\
\hline \multirow{2}{*}{$\begin{array}{c}\text { Green Power } \\
\text { Product } \\
\text { Content }\end{array}$} & Regulated & $\begin{array}{l}\% \text { existing renewables: constant } 0 \% \\
\% \text { new renewables: constant } 20 \%\end{array}$ & $\begin{array}{l}\% \text { existing renewables: constant } 0 \% \\
\% \text { new: } 30 \% \text { to } 40 \% \text { over } 5 \text { years }\end{array}$ \\
\hline & Restructured & $\begin{array}{l}\% \text { existing renewables: constant } 20 \% \\
\% \text { new renewables: } 1 \% \text { to } 15 \%\end{array}$ & $\begin{array}{l}\% \text { existing renewables: constant } 30 \% \\
\% \text { new renewables: } 2 \% \text { to } 27.5 \%\end{array}$ \\
\hline
\end{tabular}

*The units for "Pace of Restructuring" are \% of residential electricity load, the units for "Access to Green Power" are \% of regulated or restructured load, the units for "Green Power Market Penetration" are \% of load with access to green power, and the units for "Green Power Product Content" are \% of load that has chosen green power.

**States with "firm" dates are those that have not yet restructured, but have passed restructuring legislation specifying a date for the inception of retail choice. All other states (i.e., "states without dates") are divided into two groups: those that are likely to restructure relatively quickly ("fast states" - includes only Indiana, Vermont, and Wisconsin), and those that are likely to proceed towards restructuring more cautiously, or perhaps not at all ("slow states" - includes all other states without restructuring legislation). We assume that 2004 is the earliest that states with no current plans to restructure (i.e., "states without dates") could realistically adopt a restructuring plan and begin to open their markets. Thus, in the low-growth scenario, for example, $25 \%$ of load in "fast states" and 5\% of load in "slow states" gains competitive access in 2004, incrementing to $100 \%$ and $25 \%$ over 4 and 10 years, respectively. Because of the extenuating circumstances caused by California's electricity crisis, we treat California differently from other states as follows: under the high-growth scenario, we freeze California's 2001 existing green power penetration rates through 2003, and classify California as a "fast state," resuming normal activities according to our national assumptions starting in 2004; under the low-growth scenario, we drop California's 2001 existing green power penetration rates to $0 \%$ in 2002 and 2003, and classify California as a "slow state," resuming normal activities according to our national assumptions starting in 2004.

For readers interested in a detailed description of our assumptions and their rationale under each scenario, we urge you to read on. Other readers may wish to forego the remainder of this chapter and proceed directly to the model results in Chapter 5.

\section{Regulated Markets}

Percent of Residential Load with Access to Green Pricing. Many utilities already offer green pricing programs. For public utilities, ${ }^{33}$ green power access ranges from $1 \%$ of the residential load in several states to $75 \%$ in Minnesota, with an average of about $19 \%$ of public utility residential load having access to a green pricing option. Among IOUs, meanwhile, green power access relative to statewide IOU residential load ranges from $9 \%$ in Texas to $100 \%$ in Utah, with about $22 \%$ access on average. Because green power access is broadly similar on average between IOUs and public utilities, we use one set of general, national assumptions for both. (Recall that for individual states, these national assumptions apply on an incremental basis, with the state's current experience with green power acting as the base).

\footnotetext{
${ }^{33}$ Public utilities include municipal utilities, public utility districts, and rural electric cooperatives.
} 
We assume that regulated green pricing programs will only exist in utility service territories not subject to retail competition. In these still-regulated service territories, for the high-growth scenario we assume that $10 \%$ of residential load will have incremental access to a green pricing option in 2001, and that this will increase by $5 \%$ each year until $60 \%$ of residential load has access to a green pricing option in 2011 (or $55 \%$ in 2010 , as shown in Table 2). For the low-growth scenario, we assume that $5 \%$ of residential load in the still-regulated service territories will have incremental access to a green pricing program in 2001, and that this will grow in increments of $2.5 \%$ annually until it plateaus at $30 \%$ in 2011 (or $27.5 \%$ in 2010 , as shown in Table 2).

These assumptions reflect a belief that utilities will continue to announce new green pricing programs. This might be because the utility sees competition coming and decides to gain some experience offering a differentiated product, tries to capture a share of the market before customers choose an alternative provider, or sees the positive public relations that other nearby utilities are receiving for offering a green power option. Or it could simply be the case that in the future, an increasing number of states will require regulated utilities to offer green pricing options. ${ }^{34}$

Regulated Residential Green Power Penetration Rates. As reported earlier, energy-tariff based green pricing options have achieved residential penetration rates from just above zero to as much as $7.3 \%$, with a median penetration of $0.8 \%$. Some of these programs have been operating for a short time only, while others have been offered for several years.

In the high-growth scenario, we assume that a newly introduced program will achieve a residential market penetration of $0.75 \%$ in year one and increment by $0.75 \%$ in each year thereafter until it plateaus at $7.5 \%$ in year 10 (or equivalently, an existing program will add $0.75 \%$ annually until it reaches $7.5 \%$ ). Accordingly, by year 10 of operation, on average, utility programs will achieve residential market penetration rates equivalent to the most successful program to date. A combination of increased marketing presence by utilities, enhanced customer education, and a reduction in the premium spread between the cost of renewable and competing generation technologies would likely be needed to reach this level in practice. To reflect a more modest growth scenario, in the low-growth case we assume that green pricing programs achieve $0.25 \%$ residential penetration in year 1 and increment by $0.25 \%$ in each year thereafter until they plateau at 5\% in year 20 - a much slower growth rate. Accordingly, through our 10-year forecast period, residential penetration rates of $2.5 \%$ are achieved in this scenario.

Regulated Non-Residential Green Power Penetration Rates. In programs where they have been targeted, non-residential customers (businesses, non-profit organizations and government institutions) have represented a significant share of green power sales. We estimate that in 2000 , sales to these nonresidential customers accounted for approximately $20 \%$ of residential green power sales in several (but not all) states where green pricing was available. We further expect that sales to non-residential customers will spread as utilities recognize the contribution that these customers can make to green power demand.

In our model, non-residential green power demand is represented as a percentage increment to residential green power demand. To reflect our expectations described previously, in the high-growth scenario we assume a flat $25 \%$ for non-residential sales as a percentage of residential green power sales. In the lowgrowth case, we assume a flat $10 \%$. States with programs that already exceed these assumptions, however, are assumed to remain at their year 2000 levels. While the reader might question our assumption that non-residential demand remains at a constant percentage of residential demand, without more experience in this market, we were unable to identify a compelling reason to make any other assumption. Also note that because our non-residential penetration assumption is constructed as a percentage of

${ }^{34}$ During 2001, four states (Iowa, Minnesota, Montana and Washington) enacted laws requiring utilities to offer green pricing. 
residential penetration, holding non-residential penetration constant over time equates to increasing amounts of non-residential load as long as residential penetration is increasing.

Regulated Total Renewable Content. The total renewable content variable represents the percent of total electricity sales to a residential customer that is derived from renewable sources. Logically, the renewable energy content in a green power product may vary based on the way regulated green pricing programs are designed.

- For programs offering blocks of capacity (solar electric programs) and contribution programs that for the most part support the development of solar projects, experience shows that only about $1 \%$ of the total electricity paid for by a participating residential customer is renewable.

- On the other hand, programs designed as energy tariffs may offer either $100 \%$ renewable energy or may offer blocks of renewable energy (most often 100 kilowatt-hours), with customers choosing how many blocks to buy. Experience shows that most customers buy more than one block, with the result that roughly $30 \%$ (on average) of the electricity purchased by a green pricing customer is generated from renewable sources.

- In states where combinations of these programs are offered, we estimate that the average percentage renewable content ranges from $2 \%$ to $15 \%$, depending on the types of programs offered and the size of the utilities involved.

There is a pronounced trend towards energy tariffs, however, and we expect this to drive up the percentage of renewable energy in the resource mix in the future. In the high-growth scenario, we therefore assume that $30 \%$ of electricity sold to residential green pricing customers will come from renewable sources in 2001-2002. This increases to $35 \%$ in 2003-2004, and $40 \%$ in 2005 , after which it remains constant. In the low-growth scenario, we assume that renewable energy content will be $20 \%$ of green pricing sales to participating residential customers, remaining flat throughout the projection period.

Regulated "New" Renewable Content. Existing renewable power plants may already be generating and selling their output into the electric grid. It may therefore be argued that building green power demand for these plants creates no new, incremental environmental improvement. ${ }^{35}$ The generation of renewable electricity from new facilities, however, will generally contribute incremental environmental benefits by displacing fossil fuel-fired power plants on the margin. Accordingly, the percent of "new" renewable electricity in a green power offer may be meaningful environmentally, where "new" is simply defined as a facility constructed for the purpose of serving consumer demand for green power.

Currently, nearly all regulated green pricing programs provide electricity from renewable power generators recently constructed for that purpose. As a result, we assume that all renewable energy supported by regulated green pricing programs is "new" over the entire forecast period for both the lowand high-growth scenarios. As will be shown shortly, this variable becomes more important in restructured markets where competitive green power products generally have much lower "new" renewable content.

Regulated "Existing" Renewable Content. With 100\% of the renewable power serving regulated green pricing programs coming from "new" renewable generators, the amount of "existing" renewable power in these products is assumed to be $0 \%$ under both scenarios.

${ }^{35}$ We note that this may not always be the case. An existing renewable generator may be available but not generating, or may be underutilized because of unfavorable economic and market conditions. If green power demand creates an incentive to start-up or increase output from such a plant, incremental environmental improvement could legitimately be claimed. 


\section{Restructured Markets}

Inception Date of Retail Competition. The inception date of retail competition dictates the time at which green power access in restructured markets may begin. For a number of states, restructuring legislation is available to help form our model assumptions; approximately 20 states have named a date for customer choice to begin (and a number of these states are already open), although in some cases the exact date is open to interpretation. In the high-growth scenario, then, we assume that states that have enacted restructuring legislation to open their retail markets do so on the date specified in the legislation (or any later revision thereof). In the low-growth scenario, on the other hand, we assume that restructuring is delayed, and we push these dates back by 2 years.

Since electricity restructuring legislation frequently applies only to the IOUs, we assume that only IOU load receives direct access on the indicated restructuring dates. So far at least, few public utilities in restructured states have chosen to open their territories to retail competition. As restructuring proceeds, however, public utilities may decide to compete for customers outside of their home territories and in turn allow competitors in. To allow for this possibility, our model gradually phases in retail competition for public utility load beginning in the third year of restructuring (i.e., the third year that IOU load in a particular state has access to open retail markets) as follows: in the high-growth scenario, $2.5 \%$ of public utility load opens to competition in the third year of restructuring, increasing to $20 \%$ by the tenth year; while in the low-growth scenario, $0.5 \%$ of public utility load opens to retail competition in the third year of restructuring, increasing to $4 \%$ by the tenth year. In other words, in both our high- and low-growth cases there will always be a sizable portion of public utility load that does not open to retail competition.

Several states have recently delayed their electricity restructuring deadlines, in part as a response to the California electricity crisis. Those delays that were finalized as of June 2001 are included in our assumptions for both the low- and high-growth scenarios. It could easily by argued, however, that fallout from the current crisis will impede retail choice even more than estimated in our low-growth assumptions. To accommodate this view, we designed sensitivity cases that involve dramatic reductions in restructuring activity (see Chapter 5).

While more than 20 states have enacted restructuring legislation and are therefore treated as described above, the remainder have not. For these markets, we assume that January 1, 2004 is the earliest date that customer choice for IOU load could conceivably begin. We further assign each of the nine census regions either "fast track" or "slow track" status, depending upon our assessment of how quickly states in those regions might open their retail markets to competition. Based on our assignment, 26 states are in slowtrack regions, and only three - Vermont, Indiana, and Wisconsin — are considered to be on a fast track to restructuring. Next we developed assumptions for the speed of assumed restructuring in the "fast track" and "slow track" regions, for both the high- and low-growth scenarios:

- In our high-growth scenario, $50 \%$ of the IOU load in "fast track" regions will open for competition in 2004 , increasing to $100 \%$ in 2005, and $20 \%$ of IOU load in "slow track" regions will open in 2004, increasing by $20 \%$ each year until all markets are open in 2008 . We note that this is clearly an aggressive electricity restructuring case and an argument could be made that such aggressive implementation of retail reform is now unlikely.

- In our low-growth scenario, $25 \%$ of the IOU load in "fast track" regions will open for competition in 2004 , increasing in $25 \%$ increments to $100 \%$ in 2007 , and $5 \%$ of IOU load in "slow track" regions will open in 2004 , increasing by $2.5 \%$ each year until reaching $20 \%$ in 2010 . In other words, in our low-growth scenario, $80 \%$ of the load in "slow track" regions, in which states do not already have plans to restructure their markets, will remain regulated during our forecast period.

Since the future of retail competition in California is highly uncertain, we treat California separately from other states. Specifically, in the high-growth scenario, we freeze the current (i.e., as of mid-2001) level of 
green power demand in California through 2003, and then increment national assumptions according to the "fast track" restructuring timetable. In the low-growth scenario, we retain the current level of demand for 2001, but drop it to zero in 2002 and 2003, and then start from scratch with national assumptions in 2004 according to the "slow-track" restructuring timetable.

As already discussed in Text Box 1, all inroads made by green power in regulated markets are preserved when switching to competitive markets. While it is possible that some markets could experience a loss of green power sales, we believe this would be only temporary; markets in which customers have become aware of and educated about green power through regulated green pricing programs will likely be attractive markets for competitive green power providers.

Percent of Residential Load with Access to a Competitive Green Power Product. In most states already open to competition, $100 \%$ of IOU load also has access to at least one green power product. We assume that this trend continues (and will apply to public utilities as they open), and freeze this variable at $100 \%$ for both the high- and low-growth scenarios.

Competitive Residential Green Power Penetration Rates. As of the end of 2000, the only two markets with appreciable green power penetration were California, which we estimate at $1.9 \%$ of residential load, and Pennsylvania, which we estimate at $1.6 \%$ of residential load. ${ }^{36}$ In all other states currently open to retail competition, there has been modest switching overall and growing, but still limited, green power choices. As of 2000, our model assumes that these other states have not yet seen customer switching to green power products.

On a going-forward basis, our high-growth scenario assumptions start at a $1 \%$ residential green power penetration rate in year 1 and increase in $1 \%$ increments until reaching $10 \%$ in the tenth year after a state opens its markets to retail competition. This assumption is more aggressive than our high-growth scenario assumption for residential penetration in regulated markets (7.5\% residential penetration by year 10$)$, reflecting a belief that open retail markets will be accompanied by more aggressive marketing than will exist in still-regulated markets. More broadly, however, this high-growth assumption is clearly an aggressive one when looked at from the perspective of current experience with green power marketing and when viewed in the context of the other industry case studies presented in Chapter 3. A combination of customer education, increased marketing exposure, and a reduction in the premium spread between the cost of renewable and competing generation technologies would likely be necessary to hit these aggressive targets.

To reflect a much a more modest pace of growth, our low-growth assumptions start at $0.25 \%$ residential green power penetration in year 1 and increase in $0.25 \%$ increments until reaching $2.5 \% 10$ years after a state opens its markets. This assumption is the same as that described earlier for regulated markets in the low-growth scenario.

Competitive Non-Residential Green Power Penetration Rates. In several existing markets, nonresidential sales of green power constitute a significant share of total green power sales. In California, as of late 2000, non-residential green power sales essentially equaled residential sales, while in Pennsylvania, non-residential sales are about $20 \%$ of residential.

As with the regulated markets, non-residential green power demand in competitive markets is represented as a percentage increment to residential green power demand. Consistent with our assumptions in regulated markets, we assume that non-residential green power sales hold steady at $25 \%$ of residential sales in the high-growth scenario, and at $10 \%$ of residential sales in the low-growth scenario.

\footnotetext{
${ }^{36}$ We note that, more recently, the green power market in California has become a casualty of the state's electricity crisis culminating in a September 2001 regulatory order that suspended direct access for all customers not already receiving power from an alternative provider.
} 
Competitive Total Renewable Content. Green power products may vary in quality. One measure of quality is the percentage of the product that is generated by renewable energy sources. In California, we estimate this percentage to be $100 \%$ in 2000 , again because of customer incentives that reward kilowatthour sales of eligible renewable energy. In Pennsylvania, where perhaps three quarters of residential green power customers have chosen a $1 \%$ renewable energy product, we estimate the average renewable content to be $19.5 \%$. We did not attempt to gauge the average renewable content of green products in other states because they have not yet penetrated the market to any significant extent. Going forward, we believe that the average percentage of renewable energy contained in green power products will be influenced by several factors, including Green-e certification criteria that require a minimum of $50 \%$ eligible renewables, increased availability and declining costs of renewable energy, and a desire by marketers to improve and differentiate their green power products.

To reflect these going-forward assumptions, our high-growth scenario assumes that the average renewable energy content will begin at $32 \%$ in year 1of restructuring, increase to $35 \%$ in year 2 , to $40 \%$ in year 3, and then increment by $2.5 \%$ in each successive year until it reaches an average of $60 \%$ in year 11 (or 57.5\% in year 10, as shown in Table 2). In our low-growth scenario, average renewable energy content starts at $21 \%$ in year 1 and increases linearly in increments of roughly $1.5 \%$ until reaching $35 \%$ in year 10 .

Competitive "New" Renewable Content. As noted earlier, a second measure of product quality is the percentage of the product that is generated from "new" renewable resources, where "new" is often defined by states or by green power certifiers as generation from facilities built after electricity restructuring commences. Unlike regulated green pricing programs, the new renewable energy content of competitive electricity offerings has often been modest - a fact that must be reflected in our model assumptions. In particular, experience shows the average new renewable content in California to be 5\% in 2000, while Pennsylvania works out to about $2 \%$ in the same year. We assume that other states start with a blank slate.

Despite modest beginnings, we expect competitive products to increasingly use new renewable energy sources over time as the green market matures. Our high-growth scenario assumes that newly competitive markets start at $2 \%$ in year 1 , increase to $5 \%$ in year $2,10 \%$ in year 3 , and then increment by $2.5 \%$ annually until they reach $30 \%$ in year 11 (or, as shown in Table 2, 27.5\% in year 10). While this path may require that the cost of building new renewable generation continues to fall, it is nevertheless slightly less ambitious than proposed Green-e standards for new renewable content. ${ }^{37}$ This reflects the fact that, on average, not all green power products will meet Green-e certification standards, and few will exceed them. Our low-growth scenario assumes that competitive green power products start with $1 \%$ new renewables and then grow linearly in increments of about $1.5 \%$ per year until reaching $15 \%$ in year 10 , a far less aggressive pace for improvements in product content.

Competitive "Existing" Renewable Content. Competitive existing renewable content is the percentage of the total green power product that is generated by renewable energy facilities already in operation at the time that restructuring occurred. The two components, new and existing renewables, sum to the assumed total renewable content. On average, Pennsylvania green power products contained roughly $17.5 \%$ existing renewables in 2000 , and California products contained roughly $95 \%$ existing renewables.

For all states, our high-growth scenario assumes that existing renewable content remains at $30 \%$ in each year of the projection, meaning that total renewable product content grows only as new renewables are added to the mix. Similarly, our low-growth scenario assumes a constant $20 \%$.

${ }^{37}$ Green-e standards contain a goal for $5 \%$ new renewable content in year 2 , growing by $5 \%$ per year until reaching $25 \%$ in year 6 . 


\section{Forecasting the Growth of Green Power Demand: Model Results}

In this chapter, we report the modeling results and in so doing help bound the possible impacts of green power demand over our 10-year forecast period. We begin in Section 5.1 by describing the aggregate impacts of the high- and low-growth scenarios on new and existing renewable energy capacity. The environmental improvements that could result from these impacts are highlighted in Section 5.2, and a breakdown of the results by region is provided in Section 5.3. Section 5.4 disaggregates the results from our two scenario runs by restructured and regulated markets. Finally, Section 5.5 presents several model runs that were developed to explore the sensitivities of the model to various input assumptions and to examine some of the most important factors that will affect the role and impact of green power demand on renewable energy supply. A particular emphasis is placed on analyzing the possible influence of a slowdown in the pace of electricity reform.

The reader should note that many of the results are presented in units of average megawatts (aMW). While model output comes in the form of megawatt-hours, we have translated that data into aMW to facilitate understanding of the data. An aMW is defined as a MW of capacity that operates continuously,

or has a capacity factor of $100 \%$. Because renewables tend to have different operating characteristics and thus capacity factors, the use of aMW allows us to represent the contribution from renewables in a generic fashion. As an example, 1,000 aMW is equivalent to 3,333 MW of nameplate wind power capacity operating at a $30 \%$ capacity factor or $1,250 \mathrm{MW}$ of nameplate geothermal capacity operating at an $80 \%$ capacity factor.

\subsection{Aggregate Impacts of Green Power Demand}

While recognizing that any market forecast beyond even a few years is subject to considerable uncertainty, given the assumptions presented in the previous chapter, our model projects that the amount of total renewable generation capacity supported by green power marketing could range from 905 aMW in our low-growth case to as much as 6,971 aMW in our high-growth scenario by 2010 (see Figure 12). This seven-fold difference reflects the high degree of uncertainty around the future development of green power markets. 


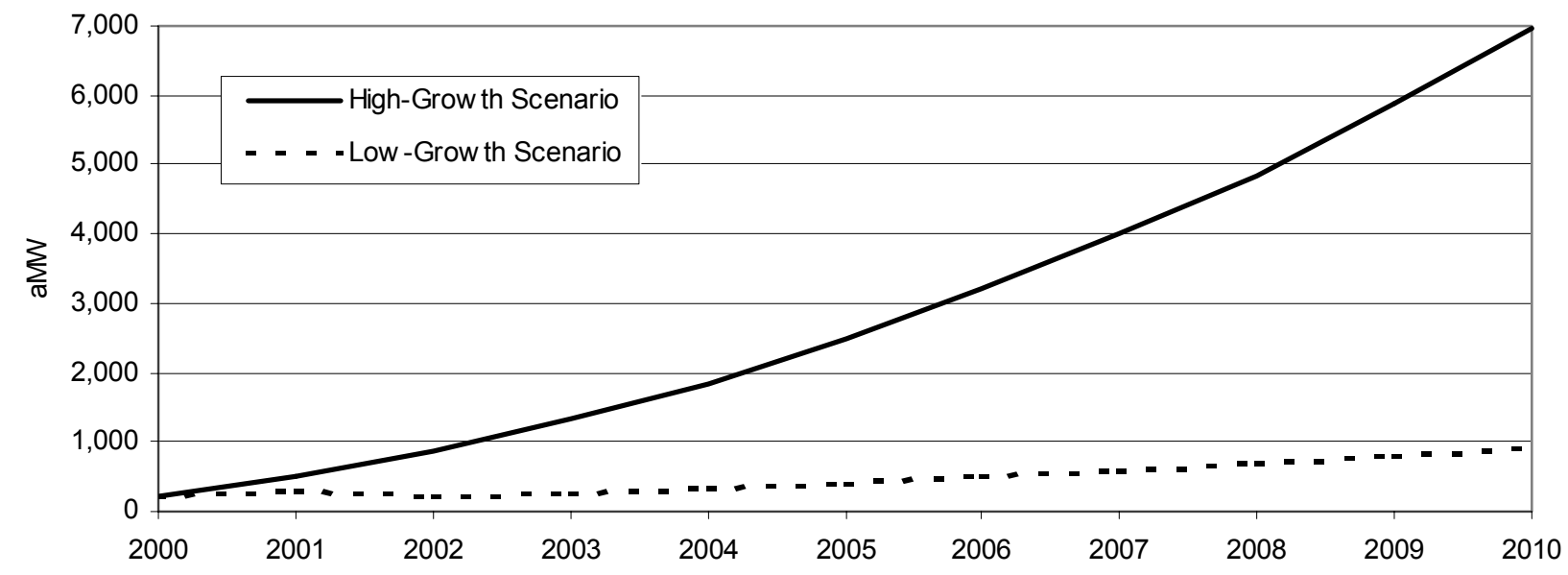

Figure 12. Total Renewables Capacity, High- and Low-Growth Scenarios (aMW)

The difference between our low- and high-growth scenarios is a direct result of several key model input assumptions:

- In regulated markets, consumer access to green power options in the low-growth case is half of what it is in the high-growth case.

- Residential market penetration varies by a factor of three or four (depending on whether the market is regulated or restructured) between the low- and high-growth scenarios.

- Non-residential demand as a percentage of residential demand varies by 2.5 times (10\% vs. $25 \%)$ between the low- and high-growth scenarios.

- The new renewable energy content of green power products varies by a factor of two between the low- and high-growth cases.

Of course, not all of this capacity represents new renewable energy development. Table 4 divides the total amount of renewable capacity supported by green power demand in 2010 into "existing" and "new" capacity. Broadly speaking, "existing" capacity is defined as renewable capacity that was operating prior to the inception of green power markets, but that is subsequently sold within a green power product. "New" renewable capacity is that which has come on line since the inception of these markets and that is sold as green power to end-use customers. Because new renewable generation provides clearer incremental environmental benefits, the distinction between new and existing renewable capacity is important.

Table 4. Estimates of Renewables Development to Serve Green Power Markets (2010)

\begin{tabular}{|l|c|c|}
\hline Renewable Capacity Type & Low-Growth (aMW) & High-Growth (aMW) \\
\hline Existing Capacity & 309 & 3,082 \\
\hline New Capacity & 596 & 3,890 \\
\hline Total Capacity & 905 & 6,971 \\
\hline
\end{tabular}

To put these numbers into perspective, there are approximately 9,100 aMW of existing non-hydro renewables capacity in the United States today. Under the low-growth scenario, only $3 \%$ of this existing capacity is used to supply competitive green power products by 2010 (309 aMW), while under our highgrowth scenario this utilization rate jumps to $34 \%$ (3,082 aMW). Meanwhile, the amount of new renewable generating capacity added to serve green power markets increases the total amount of nonhydro renewables capacity in the United States (i.e., 9,100 aMW) by about 7\% under our low-growth scenario (596 aMW), and by about $43 \%$ under our high-growth scenario $(3,890 \mathrm{aMW})$ by 2010 . In both 
the low- and high-growth scenarios, by 2010 green power demand supports more new renewable generating capacity than it does existing renewable capacity.

Qualitatively, the relative amounts of new and existing renewables supported by the market is a reflection of several assumptions:

- In regulated markets, green power demand is generally met with products made up of $100 \%$ new renewables.

- In restructured markets, the percentage of new renewables in green power products increases gradually (to $15 \%$ in the low-growth case and to $27.5 \%$ in the high-growth case) because of certification activities and a desire by green power marketers to improve their products by including increasing amounts of new resources.

- The new renewables that are developed for regulated green pricing programs are "captured" by restructured markets when those markets open to retail choice.

\subsection{Environmental Improvement}

Because green power demand should reduce the environmental footprint of the electric power industry through the displacement of fossil-fueled generation, we also forecast avoided air pollutant emissions under our low- and high-growth scenarios.

For each state, we calculated the annual emissions reductions of $\mathrm{NOx}, \mathrm{SO}_{2}$, and carbon using average fossil fuel emissions rates ${ }^{38}$ contained in the U.S. Environmental Protection Agency's E-GRID database for $1998 .{ }^{39}$ We assumed that only new renewable generation would create incremental environmental improvement through emissions avoidance, and therefore excluded any possible incremental benefits associated with the support of existing generation. Instead, we simply assumed that these existing sources would have continued to operate in the absence of a green power market. We further assumed that renewable energy generation emits no pollutants itself. ${ }^{40}$ Because several of these assumptions are intended to simplify our analysis - perhaps at the expense of accuracy - we offer our results below only as indicative of the possible impacts of green power demand on emissions reductions. We also note that, while we report emissions avoidance results for $\mathrm{SO}_{2}, \mathrm{NOx}$, and carbon, because of national "cap and trade" policies for $\mathrm{SO}_{2}$ and regional policies for $\mathrm{NOx}$, new renewable energy development may not directly reduce these emissions unless the resulting emissions allowances are retired.

With these caveats in mind, the results of our environmental analysis are displayed in Figures 13-15 for both the low- and high-growth scenarios. As shown, avoided emissions in 2010 range from roughly 10,000 to 70,000 metric tons for $\mathrm{NOx}, 20,000$ to 160,000 metric tons for $\mathrm{SO}_{2}$, and 1.2 million to 8.2 million metric tons of carbon equivalent for $\mathrm{CO}_{2}$. To put the carbon reduction estimates into perspective, by 2010 the United States would need to cut roughly 300 million metric tons of carbon from current (year 2000) emissions levels in order to reach its original commitment under the Kyoto Protocol; the carbon emissions reductions attained in our low- and high-growth scenarios represent $0.4 \%$ to $2.7 \%$ of this amount, respectively.

${ }^{38}$ We use average emissions instead of marginal emissions because of the lack of data on marginal emissions reductions, i.e., the emissions from the specific plants most likely to be displaced by green power generation.

${ }^{39}$ See www.epa.gov/airmarkets/egrid.

${ }^{40}$ This assumption is, of course, contestable. Generation from landfill gas may in fact be doubly beneficial (i.e., have a negative emissions profile) as it not only offsets emissions from fossil-fuel generation, but it may also reduce damaging methane emissions. The combustion of biomass, on the other hand, may result in net carbon emissions if the feedstock is not obtained in a sustainable manner. Net emissions of other pollutants are also possible. 


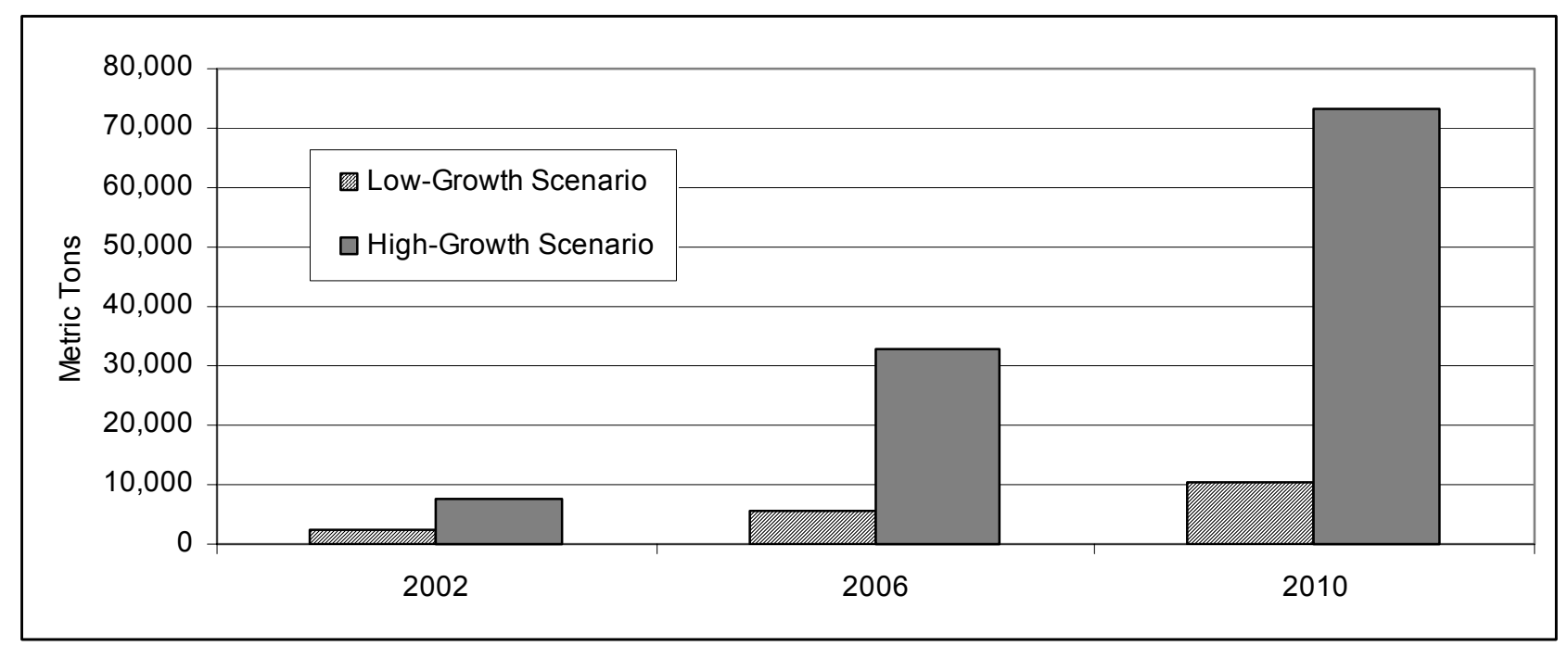

Figure 13. Annual NOx Emissions Avoided (metric tons)

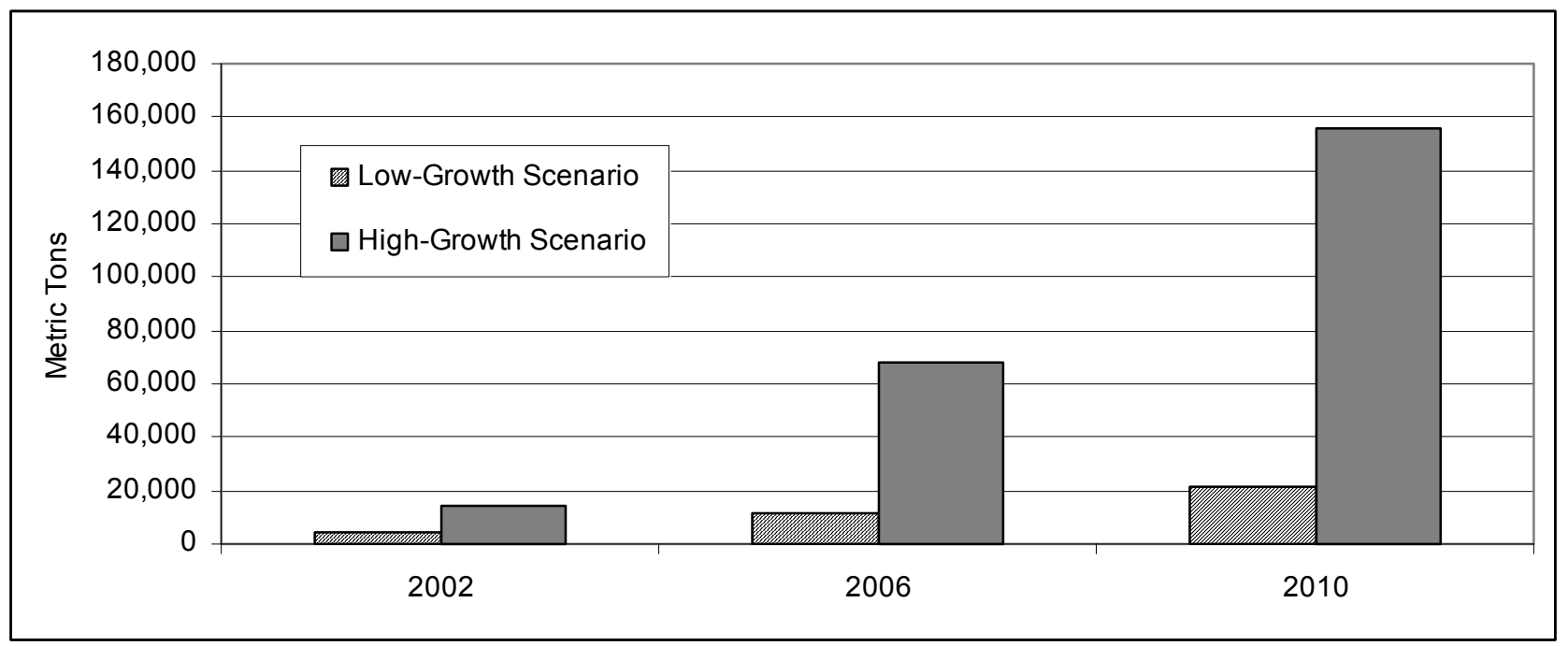

Figure 14. Annual $\mathrm{SO}_{2}$ Emissions Avoided (metric tons)

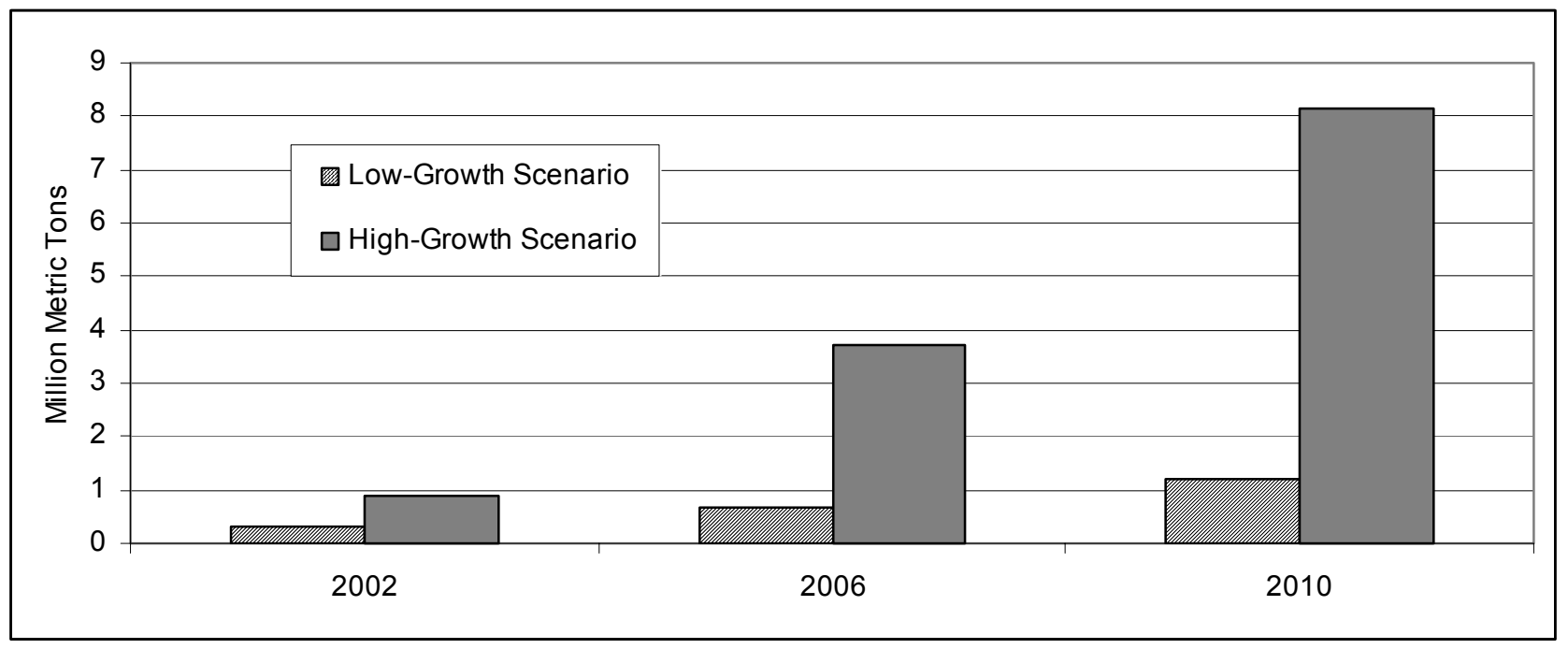

Figure 15. Annual Carbon Emissions Avoided (million metric tons carbon equivalent) 


\subsection{Regional Results}

Because green power demand and generation emissions profiles differ by region, here we disaggregate the model results by census region as defined in Text Box 2 .

New England: Connecticut, Maine, Massachusetts, New Hampshire, Rhode Island, Vermont

Middle Atlantic: New Jersey, New York, Pennsylvania

East North Central: Illinois, Indiana, Michigan, Ohio, Wisconsin

West North Central: Iowa, Kansas, Minnesota, Missouri, Nebraska, North Dakota, South Dakota

South Atlantic: Delaware, District of Columbia, Florida, Georgia, Maryland, North Carolina, South Carolina, Virginia, West Virginia

East South Central: Alabama, Kentucky, Mississippi, Tennessee

West South Central: Arkansas, Louisiana, Oklahoma, Texas

Mountain: Arizona, Colorado, Idaho, Montana, Nevada, New Mexico, Utah, Wyoming

Pacific: Alaska, California, Hawaii, Oregon, Washington

\section{Text Box 2. Regions of Analysis}

Figure 16 shows the regional breakout of total renewable energy capacity supported by green power demand for the high-growth scenario in 2010. The largest shares of renewables capacity occur in the South Atlantic (21\%), East North Central (17\%), and West South Central (15\%) regions, followed by the Middle Atlantic (13\%) and Pacific (11\%) regions. Although not shown, regional attribution of new renewables capacity follows a similar but not identical pattern, with the South Atlantic (20\%), East North Central (16\%), and West South Central (14\%) again the leading regions. Likewise, regional breakdowns of total and new renewable capacity under the low-growth scenario are quite similar to those shown here.

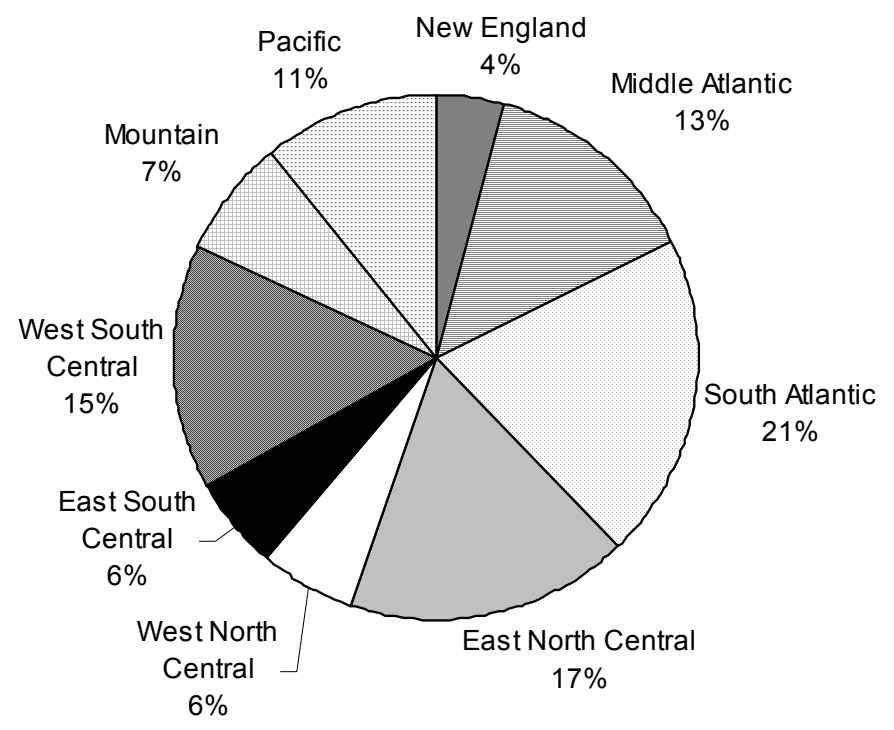

Figure 16. Regional Contribution to Total Renewable Capacity, High-Growth Scenario, 2010 


\subsection{Impacts of Restructured and Regulated Markets}

We were careful in our modeling approach to separate the green power market into two sub-markets: regulated green pricing programs and competitive green power products. Table 5 summarizes the results of our low- and high-growth scenarios in total aMW of renewables supported in 2010, broken down by these sub-markets.

Table 5. Estimates of Renewables Development to Serve Green Power Markets by Market Type (2010)

\begin{tabular}{|l|c|c|}
\hline Sub-Market Type & Low-Growth (aMW) & High-Growth (aMW) \\
\hline Restructured Markets & 543 & 5,945 \\
\hline Regulated Markets & 362 & 1,026 \\
\hline TOTAL & 905 & 6,971 \\
\hline
\end{tabular}

As shown, the impacts of green power demand on renewable energy supply is, by 2010, derived largely from restructured markets, especially in the high-growth scenario. Under the high-growth scenario, $85 \%$ of the renewables supported comes from restructured markets. Even in the low-growth scenario where access to competitive markets grows slowly, however, $60 \%$ of total renewables demand still comes from restructured markets.

This outcome results from two primary model input assumptions. First, in both the high- and low-growth scenarios, restructured markets are much larger than regulated markets - even now, for example, $24 \%$ of U. S. residential load is already in restructured markets. Moreover, green power demand gained initially through regulated markets is assumed to transfer to restructured markets as those markets open. Second, we have assumed that restructured markets are modestly more effective than regulated markets in achieving residential green power market penetration. In our high-growth case, for example, residential market penetration was assumed to reach $10 \%$ in restructured markets by the tenth year of competition (though not all restructured markets will reach year 10 by 2010) while market penetration in regulated markets was assumed to reach $7.5 \%$ in 2010 .

These effects can be further dissected into support for new and existing renewable energy generation over the 10-year forecast period. Figure 17, for example, shows that in the high-growth case, while regulated markets account for a greater amount of new renewable capacity development in the early years, restructured markets end up contributing more new capacity by the end of the forecast period. This outcome occurs because, by 2010 , more states are assumed to be restructured than not and, as previously regulated states restructure, the new renewables that had been developed in regulated markets are thereafter attributed to restructured markets. ${ }^{41}$ Furthermore, the amount of new renewable energy in competitive green power products is assumed to increase from its initial low base over this period. Note that, as shown in the figure, restructured markets provide all of the support for existing renewable projects - a result of our assumption that regulated utility products contain only new renewables content.

${ }^{41}$ The dip in the regulated line and the simultaneous jump in the restructured line from 2007 to 2008 is reflective of a re-attribution of new renewable capacity from regulated green pricing programs located in "slow track" states to competitive markets when slow track states fully open to competition in 2008. 


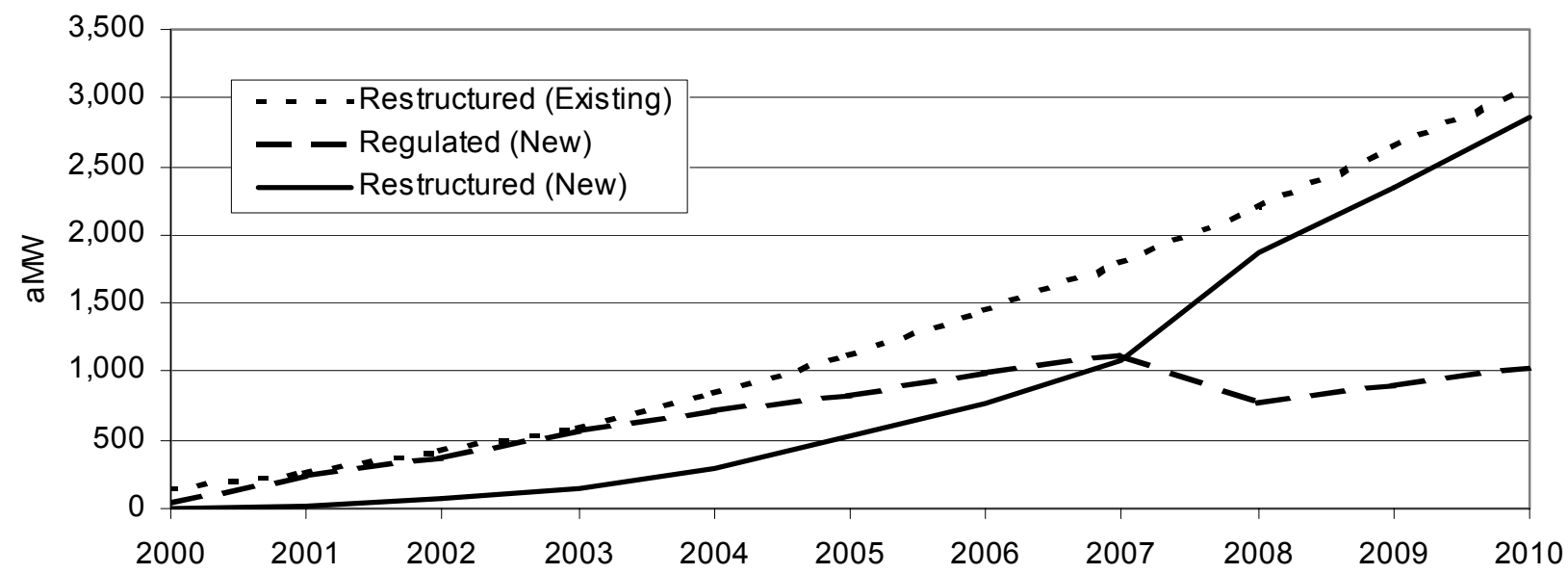

Figure 17. Renewables Capacity by Market Type, High-Growth Scenario (aMW)

Figure 18 shows the same information for the low-growth case. Regulated green power demand under this scenario provides the majority of support for new renewables throughout the 10 -year forecast period. This outcome results from the slower rate of electricity restructuring under this scenario, and the greater amount of new renewable content in regulated green pricing products (the dip in competitive market demand for existing renewables in 2002 reflects our low-growth assumption that California's current level of market penetration - served primarily by existing renewables - will fall to zero in 2002 because of the suspension of retail choice in the state).

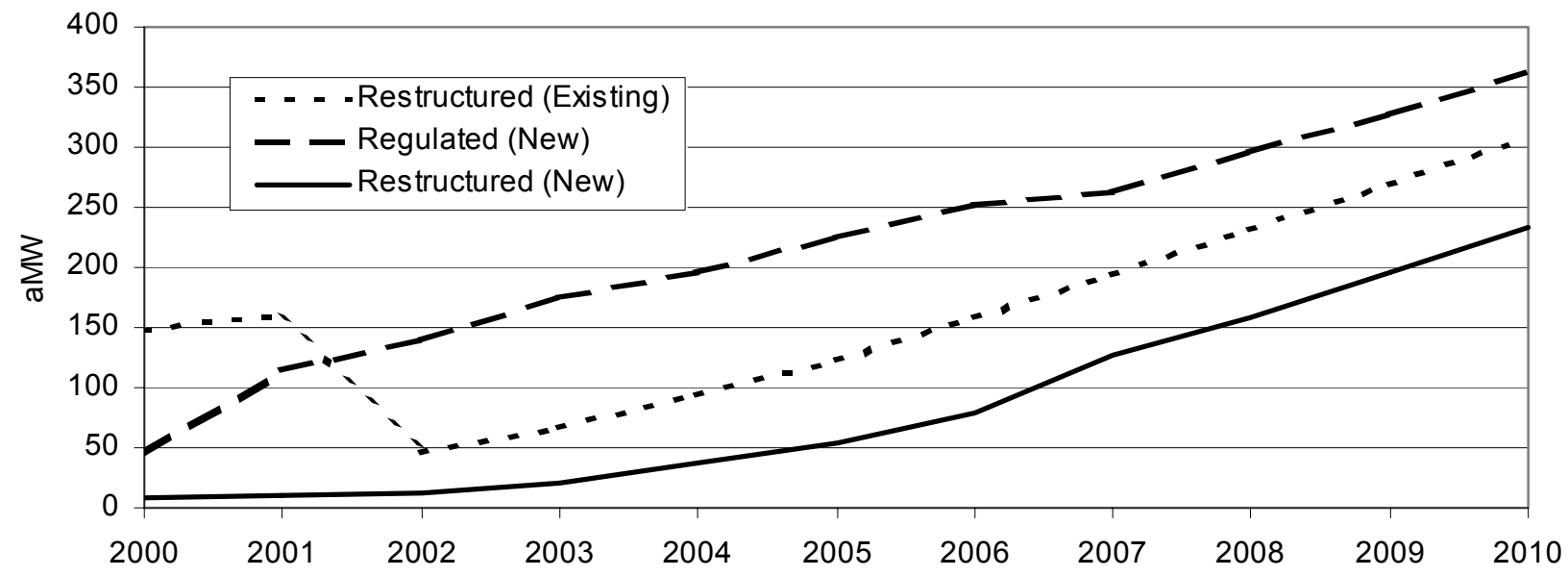

Figure 18. Renewables Capacity by Market Type, Low-Growth Scenario (aMW) 


\subsection{Model Sensitivities}

The wide difference shown between our low- and high-growth scenarios is illustrative of the high degree of uncertainty underlying the future growth and maturation of the green power market.

To better understand the factors that underlie this uncertainty and to explore the impacts of various model assumptions on model output, here we report the results of several sensitivity cases. In addition to serving a useful modeling purpose, these sensitivity results are helpful in identifying some of the important factors that will affect the role and impact of green power demand on renewable energy supply over time.

In particular, we explore the impacts of changes to the following assumptions:

- green power product content,

- green power penetration rates, and

- the pace of restructuring and green power access (as potentially affected by California's electricity crisis).

The results of each of these sensitivity cases are described in turn below. ${ }^{42}$

\section{Green Power Product Content}

To examine the sensitivity of our model to assumptions about product content (i.e., the percentage of existing, new, and total renewables in the average green power product), we simply substituted our lowgrowth product content assumptions into the high-growth model run, and vice versa. ${ }^{43}$ The heavy dashed line in Figure 19 represents the effect of substituting low-growth product content assumptions into the high-growth model run, while the light dashed line shows the effect of substituting high-growth product content assumptions into the low-growth model run. As shown, changes in product content assumptions have a significant impact on our forecast of total renewable energy capacity supported by green power demand.

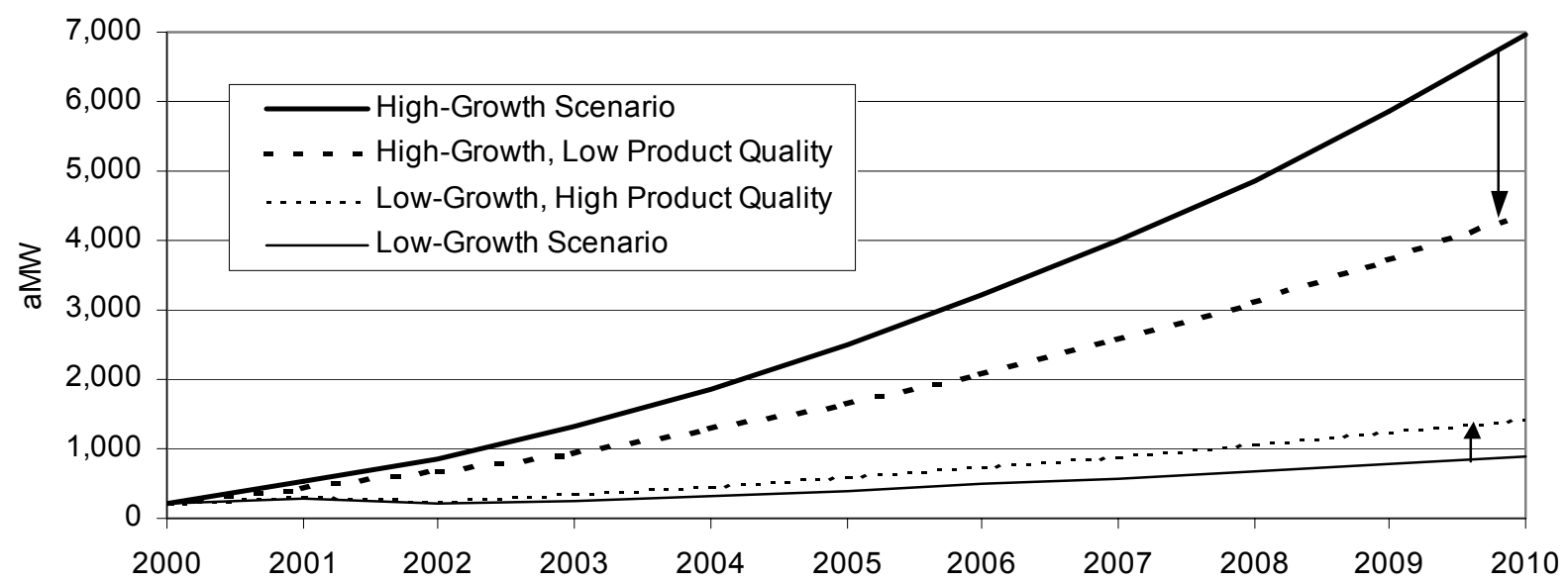

Figure 19. Sensitivity Case: Green Power Product Content (total capacity, aMW)

${ }^{42}$ Although we test the sensitivity of the model to each of these variables independently, we note that the variables are not necessarily independent. For example, it is plausible that improved product content could lead to higher market penetration rates.

${ }^{43}$ Recall that by 2010 , our low-growth scenario assumes $20 \%$ renewable content (all new) for regulated markets and 35\% renewable content (15\% new, 20\% existing) for restructured markets, while our high-growth scenario assumes $40 \%$ (all new) and 57.5\% (27.5\% new, 30\% existing) renewable content for these two markets, respectively. 


\section{Green Power Penetration Rates}

We tested sensitivity to green power penetration rates (both residential and non-residential in both regulated and restructured markets) in an identical fashion, ${ }^{44}$ and Figure 20 reports the results in the same format as above. As shown, substituting low-growth green power penetration rate assumptions into the high-growth model run results in a dramatic decrease $(-72 \%$, or $5,040 \mathrm{aMW})$ in total renewables capacity supported by the green market in 2010. Similarly, a scenario in which high-growth green power penetration rates appear in an otherwise low-growth model run results in a $261 \%$ increase (or 2,359 aMW) in total renewables capacity relative to the standard low-growth scenario. Clearly, changes in green power penetration rates have a substantial influence on our modeling results and explain a sizable portion of the difference between our low- and high-growth scenarios.

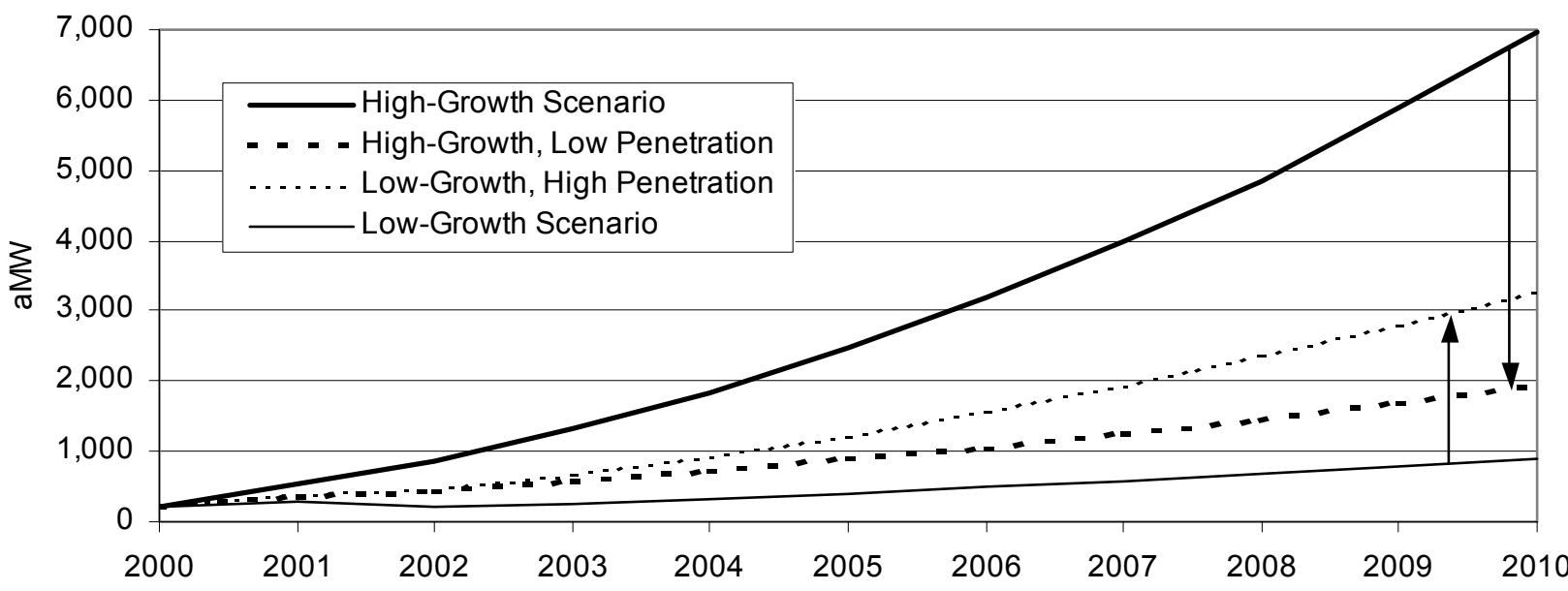

Figure 20. Sensitivity Case: Green Power Penetration Rates (total capacity, aMW)

\section{Restructuring Regrets}

As a result of the power crisis in California, a number of states are considering delaying or even reversing earlier electricity restructuring decisions. To examine the potential impact of California's electricity crisis on green power demand nationwide, we constructed a "restructuring regrets" scenario intended to represent a rethinking of the move towards retail competition. In this scenario, we assume (1) that any state that has not already opened for retail access will not do so during our 10-year forecast period, with the exception of Texas, which is assumed to open on schedule; and (2) that no publicly owned utility in a state that has already restructured will offer its customers retail access.

As shown in Figure 21, the impact of this scenario is surprisingly limited: "restructuring regrets" reduces total renewables capacity in 2010 by only $23 \%$ from the high-growth scenario, while almost imperceptibly impacting the low-growth scenario, which already contains a 2-year restructuring delay as well as an assumed slow growth in access to competitive markets. This limited sensitivity to changes in the pace of electricity reform is caused by a particular modeling feature: reducing access to competitive markets simply leaves more load eligible for regulated green pricing programs. Consequently, capacity from regulated markets increases under this scenario, while capacity from competitive markets declines

${ }^{44}$ Recall that by 2010 , our low-growth scenario assumes $2.5 \%$ residential market penetration for both regulated and restructured markets, while our high-growth scenario assumes 7.5\% market penetration for regulated markets and $10 \%$ for restructured markets. Also, we hold non-residential penetration constant at $10 \%$ of residential penetration in the low-growth scenario and $25 \%$ of residential penetration in the high-growth scenario for both regulated and restructured markets. 
as expected, with the net effect being a moderate decline in overall capacity compared to the high-growth scenario.

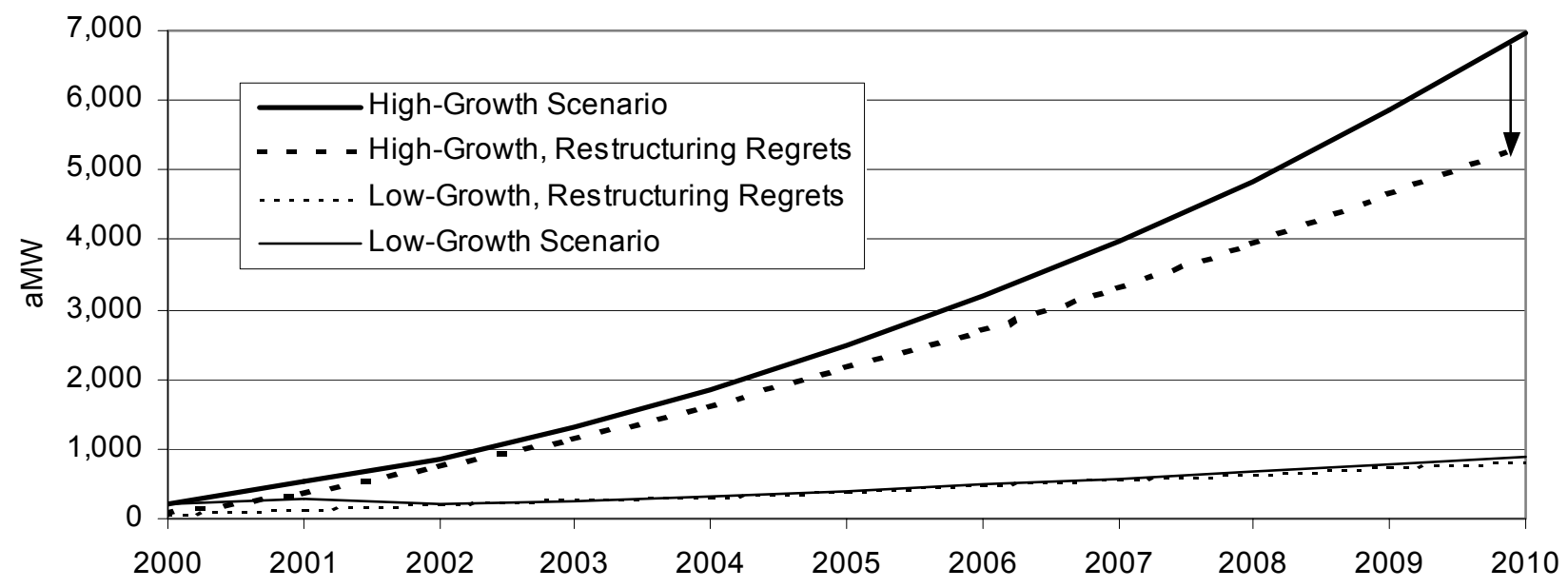

Figure 21. Sensitivity Case: Restructuring Regrets (total capacity, aMW)

Though not shown graphically here (but reflected later in Figure 24), this "restructuring regrets" scenario actually increases the amount of new renewable generation supported by green power demand. This is because load previously slated for retail choice is now given the opportunity to select a regulated green pricing product with a higher proportion of new renewable electricity than those products assumed to be offered in competitive markets.

\section{Restructuring Meltdown}

The foregoing "restructuring regrets" scenario presumes that all load denied access to competitive markets because of restructuring delays will gain access to regulated green pricing programs at a pace dictated by our low- and high-growth assumptions. Because this assumption is highly debatable, the "restructuring meltdown" scenario goes one step further and assumes that, in addition to the "restructuring regrets" assumptions described in the last section:

- retail access to green power products in states that have already restructured is cut in half (that is, the availability of green power products in states such as Pennsylvania is halved because those markets become unattractive, or even revert to a quasi- or un-restructured condition as has California); and

- growth in the availability of green pricing programs in regulated markets is also cut in half (e.g., incentives to develop regulated green pricing programs fade as the threat of electricity restructuring recedes).

As shown in Figure 22, the "restructuring meltdown" scenario has much more dire consequences than the "restructuring regrets" scenario. Total renewables capacity in 2010 declines by $50 \%$ from the high-growth scenario - more than twice the $23 \%$ decline seen in "restructuring regrets." Likewise, the effect on the low-growth scenario, while still moderate, is distinguishable. 


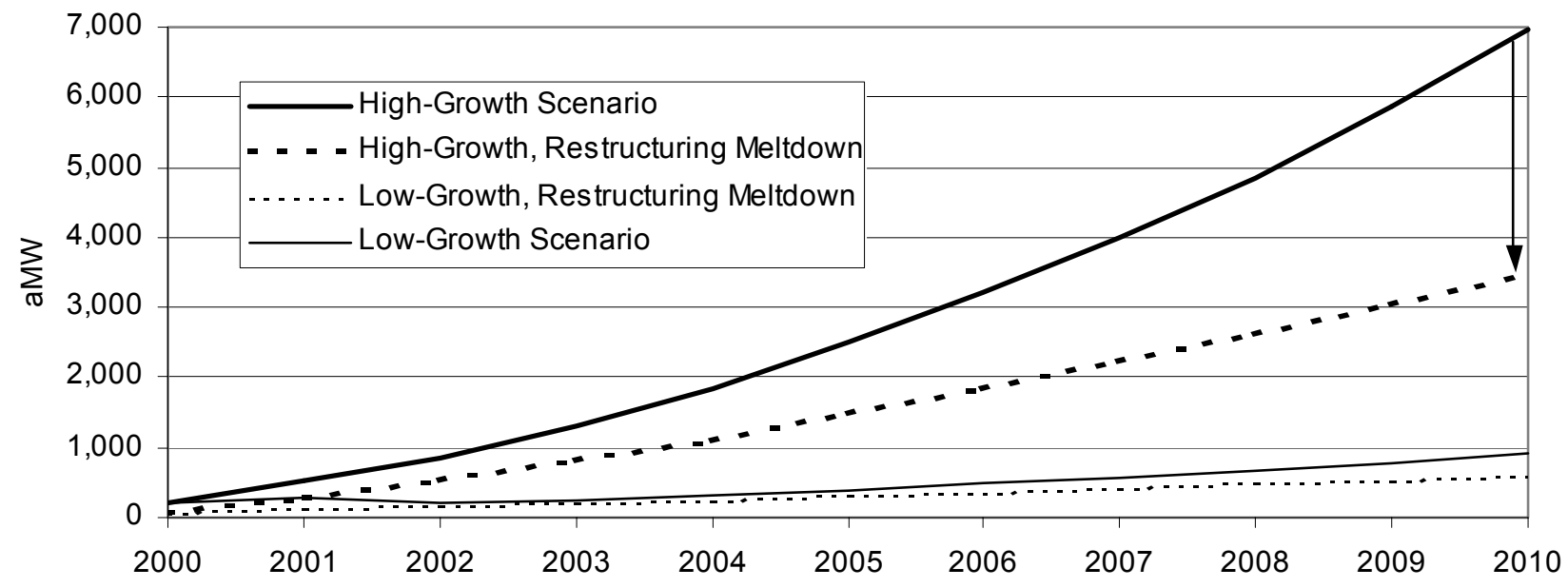

Figure 22. Sensitivity Case: Restructuring Meltdown (total capacity, aMW)

\section{Summary of Sensitivity Cases}

Figures 23 and 24 summarize the results of all four sensitivity cases in terms of total and new renewables capacity supported by green power demand in 2010, respectively. For comparison purposes, the dashed horizontal lines represent the capacity resulting from our low- and high-growth scenarios.

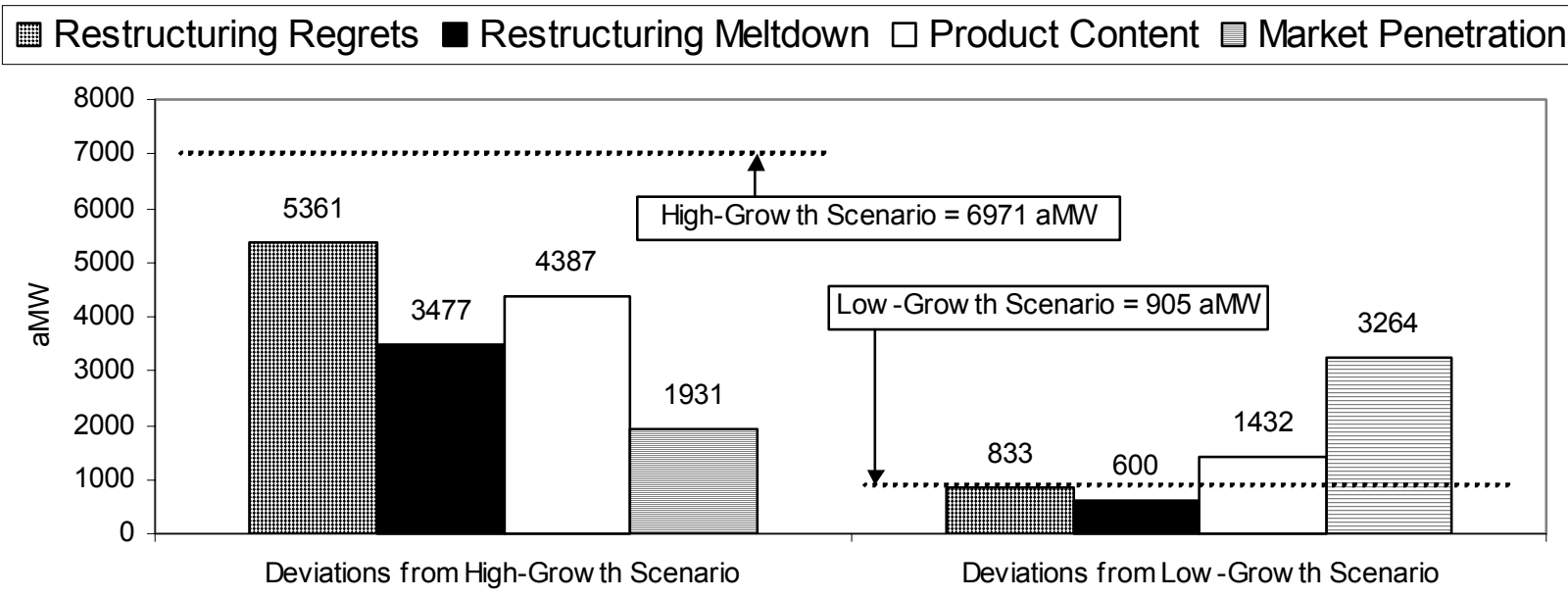

Figure 23. Total Renewables Capacity Resulting from Sensitivity Cases in 2010 (aMW) 


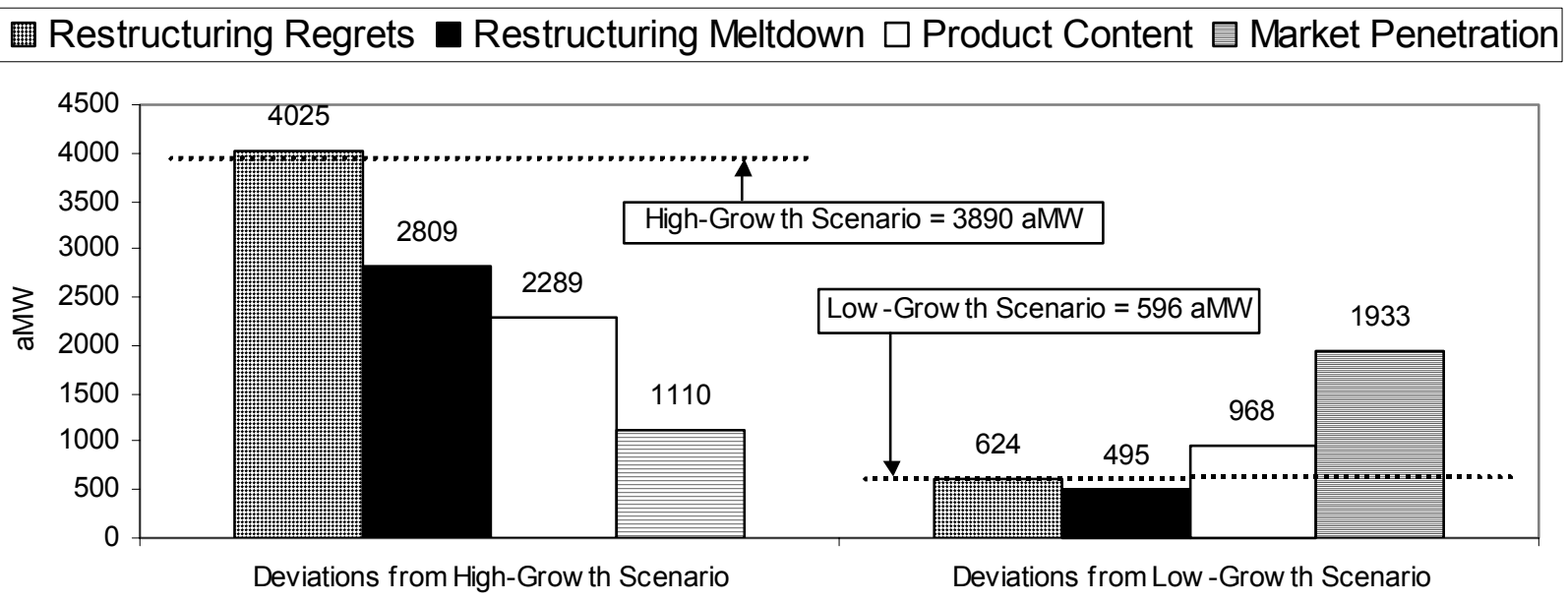

Figure 24. New Renewables Capacity Resulting from Sensitivity Cases in 2010 (aMW)

As illustrated here and described earlier, changes in our market penetration assumptions clearly have the largest impact on our modeling results for both total and new renewable capacity. Green power demand as forecast in our model is also quite sensitive to changes in product content assumptions. Interestingly, the model is least sensitive to changes in our assumptions about the pace of electricity reform, as demonstrated by the "restructuring regrets" scenario; this is particularly the case when one looks to the impacts of this scenario on new renewable generation. However, the "restructuring meltdown" scenario, which, in addition to halting the trend towards further restructuring, also cuts access to green power in half, results in a more severe impact, reducing our high-growth outcome by half. This result highlights one important aspect of possible delays or discontinuation of competitive retail choice: without continued development and marketing of regulated green pricing programs in the face of increased uncertainty about the pace of electricity reform, progress on bringing green power choices to consumers and expanding demand for renewable generation could be severely retarded. 


\section{Market Development Issues: A Qualitative Discussion of the Drivers for Green Power Growth}

The results from our high- and low-growth scenarios and sensitivity cases dramatically illustrate the pervasive uncertainties facing the green power market. The development path that the green power market follows will clearly depend on a host of factors.

The information gleaned from our case studies of other industries suggests that competition in newly deregulated markets will generally take some time to develop. And markets for green products, in particular, are often characterized by slow but steady growth, except where consumers have become especially concerned about the negative health or environmental aspects of conventional alternatives. These findings suggest that unless a compelling case is made for green power, it is likely that green power market development will mimic that of many other green products: slow and restrained growth with market penetration unlikely to exceed $5 \%$ or $10 \%$ of residential customers after a 10 -year period. At this level of penetration, support for renewable energy will not be negligible, but neither will green power demand spur substantial quantities of new renewable generation over the next 10 years.

It is also possible, however, that unique factors could come into play that would cause green power markets to grow more rapidly, perhaps meeting the targets obtained in our high-growth scenario. In this case, green power demand would stimulate a sizable and increasing amount of renewable generation over time. Below, we describe qualitatively a number of the factors that may be important determinants of the future growth pattern of green power markets. While this chapter discusses some issues not previously described in earlier chapters, it selectively draws upon the modeling results and case studies from other industries to highlight the importance of these issues.

\subsection{Access to Aggressive Green Marketing Programs}

Widespread access to aggressively marketed green power programs, whether in restructured or regulated markets, is an essential ingredient to achieving the targets suggested by our high-growth green power development scenario. Without green power access, customer response will be impossible. At present, perhaps the single-largest barrier to achieving such widespread access is uncertainty surrounding the pace and form of retail competition.

\section{The Pace of Electricity Reform}

More than 20 states have enacted legislation or adopted rulemakings to open retail power markets to competition, and 11 states are already open to retail choice. ${ }^{45}$ After an initial flurry of legislative activity, however, very few of the remaining states are today aggressively moving ahead with plans for retail competition. In fact, the well-publicized problems impacting the California power market have caused a number of states that have already passed legislation to reconsider their actions or otherwise delay implementation. Whether and how electricity markets will open to retail competition has, consequently, become highly uncertain, and future state actions to advance electricity restructuring any further may

${ }^{45}$ According to the U.S. Energy Information Administration, the 11 states are California, Connecticut, Maine, Maryland, Massachusetts, New Hampshire, New Jersey, New York, Ohio, Pennsylvania, and Rhode Island. See http://www.eia.doe.gov/cneaf/electricity/chg_str/regmap.html. 
await Congressional action. The impacts of these events on the future growth and maturation of the green power market could be severe.

\section{The Strength of Utility Programs}

Though our "restructuring regrets" scenario suggests that regulated green pricing programs could take up the slack should the pace of restructuring slow, the premise behind these results is questionable. Given that part of the impetus for regulated utilities to offer green pricing programs has been the threat of competition, the higher risk "restructuring meltdown" scenario provides an alternative view of this uncertain future, where regulated green pricing markets also shrink as restructuring fades. While four states - Iowa, Minnesota, Montana, and Washington - have recently enacted legislation requiring all utilities to offer green pricing programs, it is unclear whether sufficient incentives exist to stimulate the aggressive marketing that is necessary to encourage significant demand response. Consequently, green power market growth may be stunted by recent events unless successful utility programs were to multiply in the place of competitive product offers.

\section{Competitive Market Rules}

Early experience in restructured electricity markets suggests that, even where retail competition proceeds, the attractiveness of those markets to both competitive switching generally and to green power choice specifically will depend on a host of regulatory rules and policies established by state legislatures and regulatory commissions (Wiser 1999). Uncertainty in how these rules will be designed is reflected in our modeling assumptions about green power penetration rates - the single most important variable that drives green power capacity development. In particular, to achieve the results of the high-growth scenario, and perhaps even the low-growth scenario, market rules that encourage retail competition will be necessary.

Though increased wholesale power prices have recently had dramatic effects in California and more limited impacts in Pennsylvania, it is in these two states that the most vibrant retail markets have developed, but for markedly different reasons. In Pennsylvania, market rules were initially established to encourage retail market development and customer switching. A key factor in this development has been the establishment of a "shopping credit" or "price to compare" for retail customers that was set high enough to allow competitive suppliers to offer lower-priced product options. In the case of green power, this has allowed green power purveyors to match the default price or charge a lower premium. Pennsylvania's more recent experimentation with auctioning off large blocks of "default service" customers to competitive providers may further create limited green market opportunities. ${ }^{46}$

While no similar path was followed to encourage retail competition in California, the shear size of the retail market, along with more readily accessible renewable power sources and the availability of sizable incentives for renewable energy development and purchases, encouraged a number of marketers to sell green power. Largely because of a state-sponsored customer rebate, virtually all residential customers that switched suppliers, and many commercial customers, were receiving green power. More recently, however, market uncertainties caused by the state's precarious power situation has led many retail power marketers, including green power marketers, to exit the California market and return customers to their default utility providers from which they no longer receive green power.

In New England, meanwhile, where retail power markets have been open for more than 3 years in Massachusetts and Rhode Island, low-priced "default" service and the absence of incentives has limited the ability of alternative providers to offer competitively priced products. And in New Jersey, a "wet

${ }^{46}$ For example, Green Mountain Energy Company, a leading green power marketer, announced in early 2001 that it had been awarded 50,000 default service customers in PECO's service territory. 
signature" law, designed to protect consumers from being switched to a new supplier without proper consent, effectively delayed the development of a competitive retail market by prohibiting online enrollment over the Internet.

Clearly, the majority of the newly competitive retail markets are off to slow starts. Even in the most vigorous market, Pennsylvania, customer switching has only achieved $10 \%$ residential customer response. The degree to which this pattern is replicated in other states will significantly impact the development of green power markets.

\subsection{Consumer Education and Assurance Mechanisms}

\section{Consumer Education}

The industry case studies described earlier present a persuasive case that widespread customer education is needed on the merits of exercising green product choices. Absent such education, and a recognition by individual consumers that their actions are both necessary and make a difference, consumer response to green product offers will generally remain limited. We view such education as an absolutely essential endeavor if our high-growth green power scenario is to be achieved.

Electricity consumers are presently uninformed about how power is generated and the magnitude of the environmental impacts caused by that generation (Winneg, et al. 1998). And while many states have provided for some type of consumer education as a component of their restructuring programs, the educational messages do not usually address generation resource types and their relative environmental impacts, nor do they highlight green power as a customer option.

Nevertheless, the consumer education campaign run by the Pennsylvania Public Utilities Commission in particular has proven effective in promoting public awareness of customer choice. ${ }^{47}$ Once consumers understand that choice is available and that service reliability will not suffer by switching suppliers, they are frequently receptive to other messages, such as green power. However, if marketers must bear the entire burden of educating customers about the virtues of green power, market development will clearly be hindered. To reach the targets of our high-growth scenario, far more pervasive education and understanding of green power and its benefits will likely be necessary.

\section{Information Disclosure}

Related to consumer education is mandatory information disclosure of the environmental attributes of green power and other forms of generation. One of the basic principles of efficient market operation is that consumers have adequate information with which to make purchase decisions. In addition to consumer education, some states have adopted provisions for uniform information disclosure, usually in the form of product labels, to provide consumers with objective information on price and other important attributes of electricity products and services, such as fuel mix and air emissions. Information disclosure requirements also give green power marketers a mechanism with which to differentiate their products from both system power mixes and other green power products - based on their environmental attributes.

Although as many as 20 states now require electricity suppliers to provide their customers with periodic product disclosures or to include disclosure labels in their marketing literature, little information is available on the impact of these requirements on retail power purchase decisions. Nonetheless, to the

${ }^{47}$ Customer awareness of customer choice in Pennsylvania is greater than $90 \%$. See statistics from the Pennsylvania Electric Choice Program at http://www.electrichoice.com/public/index.html. 
extent that information disclosure requirements help build customer awareness of the relative environmental impacts of different electricity product choices, green power purchases should increase over the long term.

\section{Green Power Definitions and Certification}

Green power marketing will only result in increased development of renewable energy sources if the products being sold contain significant renewable energy content, and in particular new renewable energy content. As shown through our model sensitivity analysis, product content variables can have a sizable effect on the renewable energy supply engendered by green power demand. Experience also shows that product quality is of particular concern in restructured markets.

Although there is no common legal or formally adopted definition of green power, the term is most often used to indicate an electricity product differentiated by its superior environmental attributes and most green power products contain a high percentage of renewable energy content. To assist customers in identifying those products that meet minimum environmental standards, the Center for Resource Solutions manages the Green-e renewable electricity certification program in restructured markets, and a green pricing accreditation initiative for regulated markets. The existence of these and related rating and certification programs (e.g., Renew 2000 in the Northwest and the Power Scorecard from Pace University) may help shape the green power choices available to consumers and help consumers select products that meet certain minimum standards. As such, these programs may play an important role in building consumer-driven renewable energy markets.

\subsection{Renewable Energy Premiums}

Over the past year, sharp increases in natural gas and wholesale power prices nationwide, accompanied by ongoing cost reductions in renewable technologies, have reduced the cost premium for renewable power to its lowest level ever. In fact, in several recent instances throughout the West, wind power (aided by the $1.7 \mathrm{k} / \mathrm{kWh}$ federal production tax credit) has been deemed the cheapest source of new generation capacity. Even where renewables are not the cheapest resource, renewable technologies can play an important role as a price hedge against rising future fuel or wholesale power costs. Regulated utilities and competitive green power marketers can take advantage of this largely untapped value by offering fixedprice electricity service to their retail customers. The realization of such "non-green" values, along with even deeper reductions in renewable energy premiums (realized through some combination of lower renewable energy costs, higher wholesale prices for conventional generation, or the continuation or enhancement of renewable energy tax credits and financial incentives), may be necessary to ensure the availability of highly credible and reasonably priced green power products, and therefore to deliver the sizable customer demand necessary to achieve the high-growth scenario.

\subsection{Emerging Opportunities to Increase Green Power Sales}

Innovation in the types of green power products offered and the strategies used to reach out and attract customers are also likely to influence the pace of market development. Here we discuss three emerging opportunities to innovate in these areas: customer aggregation, large customer demand, and green certificate trading.

\section{Customer Aggregation}

Customer inertia is a key barrier in the development of robust retail electricity markets. As described in Holt and Bird (2001), one method of overcoming such inertia is to allow and encourage the development 
of "aggregators" that combine individual electricity buyers into larger customer buying pools that can then negotiate more favorable service terms from suppliers. Aggregation may also reduce transaction costs for the members of the buyers group. And from the electricity supplier's perspective, aggregation lowers marketing and customer acquisition costs, which can be a significant deterrent to green power market development. States have taken different positions on aggregation, with some states encouraging and others impeding the practice.

Aggregation may come in many forms, some of which hold more promise for green power than others. Nonetheless, to date only a handful of aggregations have included green power. ${ }^{48}$ However, customer or load aggregation is beginning to play an important role in the purchase of green power by consumer cooperatives, faith-based organizations, Internet power providers, universities, communities, and municipal, state, and federal governments. Effective aggregation mechanisms could help boost green power demand by making it easier for customers to access the product.

\section{Large Customer Demand}

In areas where they have been specifically targeted, large non-residential customers have comprised a significant portion of green power demand. Such customers are attractive for several reasons. First, they often purchase large amounts of green power, translating into more cost-effective marketing. Second, non-residential purchasers can be high-profile businesses or organizations that choose to publicize their switch to renewables, providing positive earned media exposure for the chosen marketer or green pricing program in particular, and for the green power market in general. Finally, marketers or utilities can sometimes secure a longer-term commitment from non-residential customers than they can in the residential sector, thereby reducing market risk. Working with the World Resources Institute and Business for Social Responsibility, some of the largest corporations in the United States are currently exploring ways to supply a portion of their electricity needs from green power. ${ }^{49}$

\section{Green Certificates}

A new and evolving mechanism for selling green power involves the separation of the environmental attributes of renewable energy generation from the physical electricity product. The introduction of tradable green certificates (or "green tags") allows the green power attribute to be sold or traded separately from the electricity commodity, thus obviating the need for a physical electrical contract path between sellers and buyers.

Because a green certificate system removes locational and physical contractual considerations, both suppliers and customers gain flexibility in the marketplace. Customers need not "switch" to an alternative electricity provider to purchase green power and customers of still-regulated utilities gain the ability to purchase green power where none may be offered by the host utility or where utility offerings are considered inferior to a green certificate product.

${ }^{48}$ For example, Green Mountain Energy Company was selected by the Northeast Ohio Public Energy Council (NOPEC), a buying group of nearly 100 Northeast Ohio communities formed under the state's electricity restructuring law, to supply power to more than 400,000 Ohio residents. In early 2001, Green Mountain Energy was also selected to serve 50,000 "default" customers in Pennsylvania. Though the product being sold in both instances contains only a limited amount of renewable electricity, aggregation of this form holds the promise of including additional renewables over time.

49 The Green Power Market Development Group — consisting of Alcoa, Cargill Dow, Delphi Automotive Systems, DuPont, General Motors, IBM, Interface, Johnson \& Johnson, Kinko’s, and Pitney Bowes - announced in August 2000 its intention to develop corporate markets for 1,000 MW of new renewable capacity by the year 2010 . 
Though significant consumer education and assurance mechanisms may be needed for this market to truly thrive, green power certificates offer the potential to expand the market for renewable energy by broadening the availability and scope of green power products to customers. Certificates may also result in lower green power prices by reducing transmission charges and increasing competition among green power providers. Only a handful of green certificate programs have been developed thus far in the United States, but all indications suggest an increase in their prominence over time.

\subsection{Relationship Between Green Power Markets and Public Policy}

Although green power marketing represents a market-based approach to increasing the deployment of renewable energy sources, the development of this market is often intertwined with policy initiatives or other supporting actions. We acknowledge, therefore, that the renewable energy targets achieved by our low- and high-growth scenarios for green power market development cannot be attributed solely to the existence of customer-driven green power demand. There are at least two ways in which the relationship between public policy measures and green markets will influence the rate and impact of green power market growth.

First, one of the key hurdles that green power products must overcome in the marketplace is that electricity from renewable energy sources is generally more expensive than the embedded cost of the existing power system mix. Even beyond the more mundane market and regulatory rules described earlier, public policy measures to directly and indirectly encourage renewable energy development may therefore be essential to the long-term growth of this market.

- Direct forms of support might include customer incentives to purchase renewable energy, education and marketing campaigns, grants to green power marketers and aggregators, and other related actions. Several states have already begun to initiate these types of activities, and experience in California shows that these programs can have a considerable influence on the pace of market development. California experience also cautions that these policies should be designed in ways that stimulate the creation of a sustainable market for green power sales (Bolinger, et al. 2001).

- Less direct forms of green power market support include programs aimed at lowering the cost of renewable energy generation, which benefits green power purveyors indirectly by lowering the cost of their wholesale power supply. Federal tax incentives, such as the production tax credit for wind and closed-loop biomass, and state system-benefits charge support appear to be particularly effective. Continuation of existing incentives and the creation of new programs may be necessary for our aggressive, high-growth scenario for green power development to materialize.

Second, customer-driven green power demand will only have a measurable impact on renewable energy supply if such demand is in addition to any supply-side obligations such as a renewables portfolio standard. Such supply policies should incorporate the principle of additionality by requiring that the obligation be met for every customer, not just those who are willing to purchase green power. 
Customer-driven green power markets have been simultaneously hailed and condemned as a way of supporting substantial amounts of renewable generation. Unfortunately, it is too early in the development of these markets to make robust conclusions regarding the strength of customer demand for renewable energy or the long-term effectiveness of green power marketing in supporting renewable energy development. Nonetheless, through the use of well-documented scenarios and sensitivity analysis, we have attempted to bound the possible impacts of green power demand through a 10-year forecast of market growth, and have discussed some of the factors that will influence the ultimate development path of green power markets. In developing these forecasts, we draw on green power market research, field studies, and early market experience, along with case studies from other related industries and markets. Though subject to limitations, our analysis finds that:

- The size of the green power market remains small today, but there is some evidence that sizable growth prospects do exist. As described in Chapter 2, roughly $40 \%$ of all U.S. households have access to either a regulated or competitive green power product, but so far, on average, only about $1 \%$ of those with access have actually chosen to support green power. This early experience is quite modest relative to results from field studies that show penetration rates of $10 \%$ to $20 \%$, and suggests that with improved product content, marketing, and consumer awareness, there is significant potential for future growth.

- Experience from other related industries shows that it takes time to build new markets, and that slow and steady growth in the early years is the norm. AT\&T lost half of its market share not in great leaps and bounds, but rather through gradual attrition of a few percent each year over 15 years. Similarly, bottled water, socially responsible investing, and recycling have all achieved significant market penetration over an extended time period often lasting 10 to 20 years from product launch. Furthermore, the relative degree of success among these and other markets we examined is influenced by a number of factors, including market or regulatory rules, transaction costs, response to a crisis, consumer awareness, and support from environmental organizations.

- The results from our low-growth scenario are modest by almost any standard, while our highgrowth scenario is far more robust, reflecting the high degree of uncertainty in the pace and ultimate potential for green power demand. Under our low-growth scenario, our model forecasts demand for 596 aMW of new renewable power by 2010, representing approximately 2,000 MW of wind and solar capacity or $750 \mathrm{MW}$ of geothermal and biomass capacity. Compared to the 16,500 MW of non-hydro renewable capacity on line today in the United States, ${ }^{50}$ this is a modest degree of development. The high-growth scenario represents a far more aggressive case, and leads to the support of 3,890 aMW of new renewable capacity, equivalent to roughly 13,000 MW of wind and solar or 5,000 MW of geothermal and biomass generation. These high-growth results engender optimism about the potential future impact of customer-driven demand for green power, and underscore the importance of continuing to pursue the development of green power markets. At the same time, however, a sizable wedge of more than 3,300 aMW of new renewables capacity divides the two scenarios, reflecting the high degree of uncertainty in the scope and future growth of green power and its impacts on the supply of renewable energy.

${ }^{50}$ U.S. Energy Information Administration, Renewable Energy Annual 2000, DOE/EIA-0603(2000), http://www.eia.doe.gov/cneaf/solar.renewables/page/rea_data/rea_sum.html 
- By far the most sensitive variable in our modeling analysis is the rate of green power market penetration. The sensitivity analysis presented in Section 5.5 reveals that much of the approximately 6,000 aMW difference between our low- and high-growth scenarios in 2010 can be explained by our assumptions about market penetration: substituting low-growth market penetration assumptions into our high-growth model run reduces total renewable capacity serving green power markets in 2010 by $72 \%$ (or 5,040 aMW). Similarly, using high-growth market penetration assumptions in our lowgrowth model run increases total renewables capacity in 2010 by $261 \%$. The model is less sensitive to green power product content, and is only moderately affected by variations in the pace of restructuring (as illustrated by the "restructuring regrets" scenario). This results from our modeling assumption that any household denied access to a competitive green power product is potentially eligible (subject to our regulated market assumptions) to be served by a regulated green pricing program. This is arguably a dubious assumption: without strong support and incentives for regulated green pricing programs in the face of increased uncertainty about the pace of electricity reform, it seems unlikely that regulated utilities would aggressively expand green pricing programs to markets previously slated for retail choice. In fact, the threat of competition has been a driving force in the creation of many utility green pricing programs; thus a rollback in restructuring could have ramifications that extend beyond restructured markets, also affecting the availability of utility green pricing programs. Our "restructuring meltdown" scenario demonstrates that such an outcome could hinder the growth of green power.

- Aggressive implementation is needed to prevent the low-growth scenario from becoming reality. Our high-growth scenario requires that restructuring proceed with little delay, that market rules in restructured markets are conducive to competition, that consumer awareness and acceptance of green power shows significant growth, and that the premium spread between the cost of renewable and competing generation technologies continues to narrow. Given modest results in green power markets to date and the potentially damaging effect of the electricity crisis in California and elsewhere, probably only the last of these four conditions is currently being met, and therefore a low-growth future appears more likely than a high-growth future. In order to reverse this trend and create significant demand-pull for renewables over the next 10 years, aggressive implementation of some of the factors mentioned in Chapter 6 will be needed. Specifically, all of the following are critical to the realization of a high-growth scenario: expanded access to high-quality green power products, market rules and public policies that are conducive to incremental customer-driven renewable energy development, effective consumer education programs coupled with information disclosure and product certification, aggregation of small customers and cultivation of large customer demand, and continued innovations in low-cost product delivery.

- Our modeling results highlight the fundamental limits of green power demand as the sole contributor to increasing the deployment of renewable energy resources. While the level of development projected under our high-growth scenario is certainly significant compared to historic growth patterns, it is modest compared to developable potential or to the possible impacts of other policy influences (e.g., global climate change policy or a national renewables portfolio standard). The limited potential for green power demand over our 10-year forecast period along with the great uncertainties inherent in our forecasts suggest that customer-driven markets for renewable energy are unlikely to adequately replace the need for more fundamental renewable energy policy measures if accelerated rates of renewable energy development are determined to be in the public interest. 


\section{Works Cited}

Baugh, K., B. Byrnes, C. Jones, and M. Rahimzadeh. 1995. "Green Pricing: Removing the Guesswork." Public Utilities Fortnightly, 133 (15), 26-28.

Bennett, P. 1998. "Consumer Choice in Natural Gas: A Hard Look at Savings.” Public Utilities Fortnightly, 136 (18), 32-43.

Bierman, S., P. Nelson and D. Stover. 1999. "PBR Plans: Market Power Unleashed? Rethinking Gas Supply Prudence After Retail Choice.” Public Utilities Fortnightly, 137 (6), 30-37.

Bird, L. and B. Swezey. 2001. "Estimates of Renewable Energy Developed to Serve Green Power Markets." Golden, CO: National Renewable Energy Laboratory. http://www.eren.doe.gov/greenpower/new_gp cap.shtml

Bolinger, M., R. Wiser, L. Milford, M. Stoddard, K. Porter. 2001. Clean Energy Funds: An Overview of State Support for Renewable Energy. LBNL-47705. Berkeley, California: Lawrence Berkeley National Laboratory.

Brill, H., J. Brill and C. Feigenbaum. 1999. Investing With Your Values: Making Money and Making a Difference. Princeton, NJ: Bloomberg Press.

Byrnes, B., C. Jones and S. Goodman. 1999. "Contingent Valuation and Real Economic Commitments: Evidence from Electric Utility Green Pricing Programmes.” Journal of Environmental Planning and Management, 42 (2), 149-166.

Champ, P. and R. Bishop. 1998. Wind-Power Program Participation: Developing Predictive Models. Madison, Wisconsin: Energy Center of Wisconsin.

Crossley, R. and J. Points. 1998. Investing in Tomorrow's Forests. World Wildlife Fund's Global Forestry and Finance Initiative. http://www.panda.org/forests4life/news/report.pdf

Farhar, B. 1993. Trends in Public Perceptions and Preferences on Energy and Environmental Policy. NREL/TP-461-4857. Golden, Colorado: National Renewable Energy Laboratory.

Farhar, B. 1996. Energy and the Environment: The Public View. REPP Issue Brief No. 3. College Park, Maryland: Renewable Energy Policy Project.

Farhar, B. 1999. Willingness to Pay for Electricity from Renewable Resources: A Review of Utility Market Research. Golden, Colorado: National Renewable Energy Laboratory.

Federal Communications Commission (FCC). 2000. Trends in Telephone Service. Washington, DC: Industry Analysis Division, Common Carrier Bureau.

Franklin Associates, Ltd. 1998. Characterization of Municipal Solid Waste in the United States: 1997 Update. Report No. EPA530-R-98-007. Prairie Village, KS: Environmental Protection Agency.

Greene, C. 2000. U.S. Organic Agriculture Gaining Ground. Agricultural Outlook. Economic Research Service/USDA. 
The Hartman Report. 1996. Food and the Environment: A Consumer's Perspective, Phase I. www.hartman-group.com/Food.html.

Holt, E. and L. Bird. 2001. Customer Aggregation: An Opportunity for Green Power? NREL/TP-62029408. Golden, Colorado: National Renewable Energy Laboratory.

Holt, E., R. Wiser, M. Fowlie, R. Mayer, S. Innis. 2001. Understanding Non-Residential Demand for Green Power. Washington, DC: National Wind Coordinating Committee.

Jenkins, M. and E. Smith. 1999. The Business of Sustainable Forestry: Strategies for an Industry in Transition. Covelo, CA: Island Press.

Johnson, K., M. Clouse, H. Tansey, R. Morgan. 2001. "The Role Of Environmental Information In Highlighting Electricity Choices." Proceedings of the 2001 ASES Annual Conference held in Washington, $D C$. Boulder, CO: American Solar Energy Society.

Kaplan, A. (editor). 2000. Giving USA 2000: The Annual Report on Philanthropy for the Year 1999. AAFRC Trust for Philanthropy.

Klonsky, K. and L. Tourte. 1998. "Organic Agricultural Production in the United States: Debates and Directions.” American Journal of Agricultural Economics, 80 (5), 1119-1124.

Mazur, A, and E. Welch. 1999. "The Geography of American Environmentalism.” Environmental Science \& Policy, 2, 389-396.

Piepmeier, J., D. Jermain and T. Egnor. 1993. "Breakup of the Bell Monopoly: Lessons for the Electric Utilities." The Electricity Journal, 6 (6), 45-51.

Poe, G., J.Clark and W. Schulze. 1997. Can Hypothetical Questions Predict Actual Participation in Public Programs? A Field Validity Test Using a Provision Point Mechanism. Working Paper Series in Environmental and Resource Economics. Ithaca, NY: Cornell University.

Rader, N. and W. Short. 1998. "Competitive Retail Markets: Tenuous Ground for Renewable Energy." The Electricity Journal, 11 (3), 72-80.

Rogers, E. 1992. Diffusion of Innovations. New York, NY: The Free Press.

Schuler, J. 1997. "Blue-Flame Blues: Gas Pilots Sputter at Burnertip.” Public Utilities Fortnightly. 135 (18), 22-26.

Spinner, H. 1999. "Ma Bell and Papa Edison: Close or Distant Relations?" The Electricity Journal, 12 (4), 37-45.

Swezey, B. and L. Bird. 2000. Green Power Marketing in the United States: A Status Report. NREL/TP620-28738. Golden, Colorado: National Renewable Energy Laboratory.

Voorsatz, D., L. Shown, J. Koomey, M. Moezzi, A. Denver and B. Atkinson. 1997. Lighting Market Sourcebook for the U.S. LBNL-39102. Berkeley, California: Lawrence Berkeley National Laboratory.

Weiner, J., and C Campbell. 1992. Perceptions of Compact Fluorescent Lamps in the Residential Market. Prepared by Macro Consulting for the Electric Power Research Institute. EPRI-TR100734. 
Wiser, R. 1999. The Role of Public Policy in Emerging Green Power Markets: An Analysis of Marketer Preferences. LBNL-44178. Berkeley, California: Lawrence Berkeley National Laboratory.

Wiser, R., M. Bolinger and E. Holt. 2000. "Customer Choice and Green Power Marketing: A Critical Review and Analysis of Experience to Date." Proceedings of the ACEEE 2000 summer Study on Energy Efficiency in Buildings. Washington, DC: American Council for an Energy-Efficient Economy.

Zolnierek, J., K. Rangos, and J. Eisner. 1999. Long Distance Market Shares Fourth Quarter 1998. Washington, D.C.: Industry Analysis Division, Common Carrier Bureau, Federal Communications Commission. 
Public reporting burden for this collection of information is estimated to average 1 hour per response, including the time for reviewing instructions, searching existing data sources,

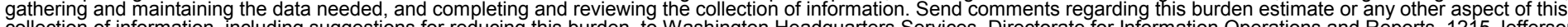

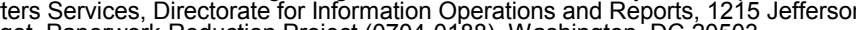
Davis Highway, Suite 1204, Arlington, VA 22202-4302, and to the Office of Management and Budget, Paperwork Reduction Project (0704-0188), Washington, DC 20503.
1. AGENCY USE ONLY (Leave blank)
2. REPORT DATE
October 31, 2001
3. REPORT TYPE AND DATES COVERED
Technical Report

4. TITLE AND SUBTITLE

Forecasting the Growth of Green Power Markets in the United States

5. FUNDING NUMBERS

6. AUTHOR(S)

Blair Swezey, Ed Holt, Ryan Wiser, and Mark Bolinger

7. PERFORMING ORGANIZATION NAME(S) AND ADDRESS(ES)

NREL, LBNL, Ed Holt and Associates

AS61.3010
9. SPONSORING/MONITORING AGENCY NAME(S) AND ADDRESS(ES)
National Renewable Energy Laboratory
1617 Cole Blvd.
Golden, CO 80401-3393

8. PERFORMING ORGANIZATION

REPORT NUMBER

LBNL-48611

NREL/TP-620-30101

10. SPONSORING/MONITORING AGENCY REPORT NUMBER

NREL/TP-620-30101

11. SUPPLEMENTARY NOTES

12a. DISTRIBUTION/AVAILABILITY STATEMENT

National Technical Information Service

12b. DISTRIBUTION CODE

U.S. Department of Commerce

5285 Port Royal Road

Springfield, VA 22161

13. ABSTRACT (Maximum 200 words)

In this report, we quantify the potential size and impact of the green power market in the United States, and identify features of the market that will most affect its ultimate growth trajectory. Our analysis does not cover the market for customer-sited distributed generation technologies, though it is arguably part of the green power market and there is a considerable amount of excitement surrounding its prospects. A discussion of some of the barriers to the growth of distributed power markets can be found in Alderfer, et al. (2000). We do this through a 10-year forecast of market development under both low- and high-growth scenarios. In addition, we present four scenarios structured to gauge the sensitivity of our low- and high-growth forecasts to assumptions about green power product content, market penetration, and the fallout from the recent California power crisis. We base all forecasts on a detailed model of national green power demand that we developed specifically for this purpose. Our analysis emphasizes the impacts of green power demand on renewable energy development and air pollutant emissions.

14. SUBJECT TERMS

Green power; NREL; LBNL; green pricing; green power market; deregulation; barriers; growth.

17. SECURITY CLASSIFICATION OF REPORT Unclassified
18. SECURITY CLASSIFICATION OF THIS PAGE Unclassified
19. SECURITY CLASSIFICATION OF ABSTRACT

Unclassified
15. NUMBER OF PAGES

16. PRICE CODE

UL

Standard Form 298 (Rev. 2-89) Prescribed by ANSI Std. Z39-18 